Jerusa Smid

\title{
Polimorfismos do gene da proteína príon celular em pacientes com doença de Alzheimer
}

Tese apresentada à Faculdade de Medicina da Universidade de São Paulo para a obtenção do Título de Doutor em Ciências

Programa de Neurologia

Orientador: Prof. Dr. Ricardo Nitrini

São Paulo

2011 
Jerusa Smid

\section{Polimorfismos do gene da proteína príon celular em pacientes com doença de Alzheimer}

Tese apresentada à Faculdade de Medicina da Universidade de São Paulo para a obtenção do Título de Doutor em Ciências

Programa de Neurologia

Orientador: Prof. Dr. Ricardo Nitrini

São Paulo

2011 
Dados Internacionais de Catalogação na Publicação (CIP)

Preparada pela Biblioteca da

Faculdade de Medicina da Universidade de São Paulo

Creprodução autorizada pelo autor

Smid, Jerusa

Polimorfismos do gene da proteína príon celular em pacientes com doença de Alzheimer / Jerusa Smid. -- São Paulo, 2011.

Tese(doutorado)--Faculdade de Medicina da Universidade de São Paulo. Programa de Neurologia.

Orientador: Ricardo Nitrini.

Descritores: 1.Gene da proteína priônica 2.Doença de Alzheimer 3.Polimorfismo genético 4.Desempenho cognitivo 5.Apolipoproteínas E

6.Cromatografia líquida de fase reversa

USP/FM/DBD-033/11 
Dedico

Aos meus pais, Francisco e Jeane, com a minha gratidão infinita por terem sempre acreditado em mim, de forma incondicional.

Ao Tarso, "é, você que é feito de azul", por quem e com quem me transformei em três.

À minha irmã, Janaína, pela participação nos momentos mais importantes da minha vida e disposição em sempre ajudar, com amor.

A Isabela, Leticia, Gabriela e Juliana, com carinho e desejo de que o exemplo deste trabalho possa trazer algum estímulo a vocês no futuro.

Aos pacientes e participantes do grupo controle, meu respeito e agradecimento pela disponibilidade e interesse em participar deste estudo. 


\section{AGRADECIMENTOS}

Ao Prof. Dr. Ricardo Nitrini, professor livre-docente do Departamento de Neurologia da Faculdade de Medicina da Universidade de São Paulo, coordenador do Curso de Pós-Graduação em Neurologia da Universidade de São Paulo, orientador desta tese, pelo exemplo de competência, perseverança, otimismo e ética, e pela possibilidade em compartilhar de seus ensinamentos, com grande admiração.

Ao Prof. Dr. Paulo Caramelli, professor adjunto do Departamento de Clínica Médica da Faculdade de Medicina da Universidade Federal de Minas Gerais, pela confiança desde o primeiro momento e pelo incentivo à carreira de neurologista.

À Dra. Vilma Regina Martins, coordenadora do Grupo de Biologia Celular e Molecular do Centro Internacional de Pesquisa e Ensino do Hospital A. C. Camargo, pela imensa contribuição para a realização deste estudo e inestimável participação no exame de qualificação desta tese.

À Dra. Michele Christine Landemberger, pesquisadora Junior do Grupo de Biologia Celular e Molecular do Centro Internacional de Pesquisa e Ensino do Hospital A. C. Camargo, pela ajuda e paciência inesgotáveis durante a realização deste estudo. 
À Dra. Valéria Santoro Bahia, neurologista do Ambulatório de Neurologia Cognitiva e do Comportamento do Hospital das Clínicas da Faculdade de Medicina da Universidade de São Paulo, pelo apoio e pronta disponibilidade em ajudar com os dados que contribuíram para a realização deste estudo e pela importante participação no exame de qualificação desta tese.

Ao Dr. Fernando Kok, professor livre-docente do Departamento de Neurologia da Faculdade de Medicina da Universidade de São Paulo, pela valiosa contribuição no exame de qualificação desta tese.

À Dra. Márcia Radanovic, docente do Departamento de Neurologia da Faculdade de Medicina da Universidade de São Paulo, pela importante contribuição no exame de qualificação desta tese.

À Dra. Márcia Rúbia Rodrigues Gonçalves, assistente do Setor de Emergência do Hospital das Clínicas da Faculdade de Medicina da Universidade, pela ajuda incondicional em todas as horas.

À Dra. Cláudia Sellitto Porto, neuropsicóloga do Grupo de Neurologia Cognitiva e do Comportamento do Hospital das Clínicas da Faculdade de Medicina da Universidade de São Paulo, e à Dra. Mirna Lie Hosogi Senaha, fonoaudióloga do Grupo de Neurologia Cognitiva e do Comportamento do Hospital das Clínicas da Faculdade de Medicina da Universidade de São Paulo, pelo estímulo durante a elaboração desta tese. 
Aos amigos do Grupo de Neurologia Cognitiva e do Comportamento do Hospital das Clínicas da Faculdade de Medicina da Universidade de São Paulo, pelo companheirismo. 
"O valor em praticar com rigor, por algum tempo, uma ciência rigorosa não está propriamente em seus resultados: pois eles sempre serão uma gota ínfima, ante o mar das coisas dignas de saber. Mas isso produz um aumento de energia, de capacidade dedutiva, de tenacidade; aprende-se a alcançar um fim de modo pertinente. Neste sentido é valioso, em vista de tudo o que se fará depois, ter sido um homem de ciência."

(Nietzsche, In: Humano, demasiado humano) 


\section{SUMÁRIO}

Lista de Abreviaturas e Siglas

Lista de Símbolos

Lista de Figuras

Lista de Tabelas

Resumo

Summary

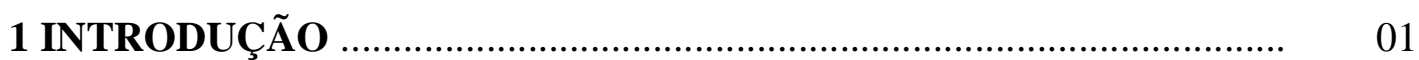

1.1 Doença de Alzheimer ............................................................................ 02

1.2 Proteína príon celular, príons e doenças priônicas ..................................... 04

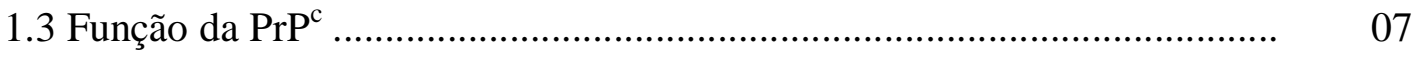

1.4 Doenças neurológicas e PRNP .......................................................... 10

1.4.1 Doenças priônicas ........................................................................ $\quad 10$

1.4.2 Outras doenças neurológicas ................................................................. 12

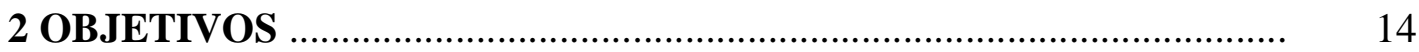

3 CASUÍSTICA E MÉTODOS ............................................................ 16

3.1 Casuística …............................................................................. 17

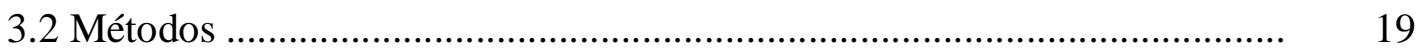

3.2.1 Técnicas laboratoriais ........................................................................... 19

3.2.1.1 Extração de DNA de leucócitos ........................................................... 19

3.2.1.2 Análise do gene PRNP ................................................................. 20

3.2.2 Extratificação por genótipo da apoE ................................................... 26

3.2.3 Análise estatística ............................................................................... 26

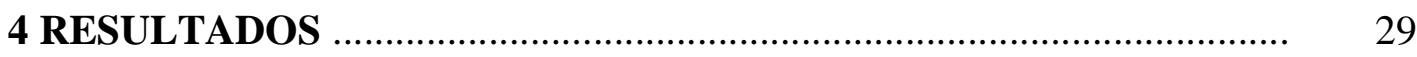

4.1 Variantes alélicas do PRNP .................................................................... $\quad 30$ 
4.2 Análise do códon 129 entre os diferentes subgrupos da amostra

4.3 Desempenho nos testes cognitivos e genótipo do códon 129.

4.3.1 Comparação entre as medidas de tendência central dos testes cognitivos no grupo DA

4.3.2 Comparação entre as medidas de tendência central dos testes cognitivos no grupo controle

4.3.3 Análise bivariada e regressão logística dos grupos DA e controle em relação ao desempenho nos testes cognitivos

4.4 Extratificação do polimorfismo do códon 129 do PRNP em relação ao alelo $\varepsilon 4$ do gene da apoE

5 DISCUSSÃO

5.1 Polimorfismos do códon 117, 171 e da região de 5 octapeptídeos repetidos

5.2 Polimorfismo do códon 129

5.3 Mutação do códon 180

6 CONCLUSÕES

APÊNDICE - Banco de dados 


\section{LISTA DE ABREVIATURAS E SIGLAS}

$\begin{array}{ll}\text { A } & \text { alanina } \\ \text { apoE } & \text { apolipoproteína E } \\ \text { APP } & \text { afasia progressiva primária } \\ \text { CCL } & \text { comprometimento cognitivo leve } \\ \text { CEREDIC } & \text { Centro de Referência em Distúrbios Cognitivos } \\ \text { D } & \text { ácido aspártico } \\ \text { DA } & \text { doença de Alzheimer } \\ \text { DAPS } & \text { doença de Alzheimer Pré-Senil } \\ \text { DAS } & \text { doença de Alzheimer Senil } \\ \text { DCJ } & \text { doença de Creutzfeldt-Jakob } \\ \text { DHPLC } & \text { cromatografia líquida de fase reversa desnaturante } \\ \text { DP } & \text { desvio padrão } \\ \text { E } & \text { ácido glutâmico } \\ \text { eDCJ } & \text { Doença de Creutzfeldt-Jakob esporádica } \\ \text { ENF } & \text { emaranhados neurofibrilares } \\ \text { ERK1/2 } & \text { quinases reguladoras de sinal extracelular 1 e 2 } \\ \text { F } & \text { fenilalanina } \\ \text { FV } & \text { fluência verbal } \\ \text { G } & \text { glicina } \\ \text { gDCJ } & \text { DCJ genética } \\ \text { GNCC } & \text { Grupo de Neurologia Cognitiva e do Comportamento } \\ \text { GSS } & \text { Gerstmann-Sträussler-Scheinker } \\ \text { H } & \text { histidina } \\ \text { HC- } & \text { Hospital das Clínicas da Faculdade de Medicina da Universidade de } \\ \text { FMUSP } & \text { São Paulo } \\ \text { I } & \text { isoleucina } \\ \text { ICtervalo de confiança }\end{array}$




\begin{tabular}{|c|c|}
\hline IF & insônia fatal \\
\hline IFF & insônia fatal familiar \\
\hline K & lisina \\
\hline $\mathrm{L}$ & leucina \\
\hline M & metionina \\
\hline M129M & metionina em homozigose \\
\hline M129V & metionina em heterozigose com valina \\
\hline MEEM & miniexame do estado mental \\
\hline máx & máximo \\
\hline mín & mínimo \\
\hline $\mathrm{M} / \mathrm{M}$ & metionina-metionina \\
\hline $\mathrm{M} / \mathrm{V}$ & metionina-valina \\
\hline $\mathrm{n}$ & quantidade de pacientes \\
\hline $\mathrm{N}$ & aspargina \\
\hline $\mathrm{N} / \mathrm{N}$ & aspargina em homozigose \\
\hline OR & odds ratio \\
\hline $\mathrm{OR}_{\mathrm{br}}$ & odds ratio bruto \\
\hline $\mathrm{OR}_{\mathrm{aj}}$ & odds ratio ajustado \\
\hline$p$ & valor-p \\
\hline $\mathrm{P}$ & prolina \\
\hline PKA & proteína quinase $\mathrm{A}$ \\
\hline PPA & proteína precursora do amilóide \\
\hline Prnp & gene da proteína priônica, camundongo \\
\hline PRNP & gene da proteína priônica, humano \\
\hline $\operatorname{PrP}$ & proteína príon \\
\hline $\operatorname{PrP}^{\mathrm{c}}$ & proteína príon celular \\
\hline $\operatorname{PrP}^{\mathrm{sc}}$ & PrP scrapie \\
\hline PS & placas senis \\
\hline Q & glutamina \\
\hline stop & códon de parada \\
\hline $\mathrm{R}$ & argirina \\
\hline S & serina \\
\hline
\end{tabular}




$\begin{array}{ll}\text { SDS } & \text { dodecil sulfato de sódio } \\ \text { SNC } & \text { sistema nervoso central } \\ \text { SR } & \text { sem registro } \\ \text { STI1 } & \text { proteína indutora de estresse 1 } \\ \text { T } & \text { treonina } \\ \text { V } & \text { valina } \\ \text { V129V } & \text { valina em homozigose } \\ \text { V180I } & \text { mutação no códon 180 } \\ \text { vDCJ } & \text { nova variante de DCJ } \\ \text { V/V } & \text { valina-valina } \\ \text { Y } & \text { tirosina }\end{array}$




\section{LISTA DE SÍMBOLOS}

$\begin{array}{ll}{ }^{0} \mathrm{C} & \text { grau centígrado } \\ \mathrm{g} & \text { força centrífuga } \\ \mathrm{mL} & \text { mililitro } \\ \mathrm{mM} & \text { milimol } \\ \mu \mathrm{g} & \text { micrograma } \\ \mu \mathrm{L} & \text { microlitro } \\ \mu \mathrm{M} & \text { micromol } \\ \mathrm{nm} & \text { nanometro } \\ \mathrm{pmol} & \text { picomol } \\ \mathrm{U} & \text { unidade internacional de atividade enzimática } \\ > & \text { maior } \\ < & \text { menor } \\ \geq & \text { maior ou igual } \\ \leq & \text { menor ou igual } \\ \% & \text { porcento }\end{array}$




\section{LISTA DE FIGURAS E QUADROS}

Figura 1 Auguste D (1850-1906) ........................................................... 02

Figura 2 Alois Alzheimer (1864-1915) ..................................................... 02

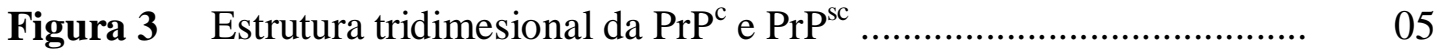

Figura 4 Mutações e polimorfismos do PRNP. ....................................... 11

Figura 5 Perfil de saída dos cromatogramas das principais variantes alélicas pesquisadas - primeira metade do $P R N P$

Figura 6 Perfil de saída dos cromatogramas das principais variantes alélicas pesquisadas - segunda metade do PRNP.

Figura 7 Eletroesferograma específico da região do códon 180 gene da paciente ID 211: (A) V180I - mutado; (B) V180V 


\section{LISTA DE TABELAS}

Tabela 1 Características clínicas e demográficas dos grupos DA e controle

Tabela 2 Variantes alélicas do $P R N P$ nos pacientes com DA e controles ......

Tabela 3 Análise dos genótipos do códon 129 e dos alelos M e V em diferentes subgrupos da amostra

Tabela 4 Análise dos genótipos do códon 129 em homozigose e heterozigose em diferentes subgrupos da amostra

Tabela 5 Equilíbrio de Hardy-Weinberg dos diferentes genótipos do códon 129 nos subgrupos da amostra

Tabela 6 Desempenho nos testes cognitivos e aspectos demográficos do grupo com DA segundo genótipo do códon 129

Tabela 7 Desempenho nos testes cognitivos e aspectos demográficos do grupo controle segundo genótipo do códon 129

Tabela 8 Estatística descritiva dos testes cognitivos dos grupos DA e controle

Tabela 9 Pacientes com DA e desempenho no teste do MEEM

Tabela 10 Análise de regressão logística para fatores associados ao melhor desempenho cognitivo no MEEM em indivíduos com DA

Tabela 11 Pacientes com DA e desempenho no teste de FV

Tabela 12 Controles e desempenho no teste do MEEM

Tabela 13 Controles e desempenho no teste de FV

Tabela 14 Extratificação dos genótipos do códon 129 em pacientes com DA e controles em relação ao genótipo da apoE

Tabela 15 Genótipo da apoE nos pacientes com DA e controles

Tabela 16 Distribuição dos genótipos do códon 129 na população brasileira e neste estudo 
Tabela 17 Resultado dos estudos caso-controle sobre associação do genótipo do códon 129 do PRNP em pacientes com DA esporádica (modificado de Poleggi et al., 2008) 


\section{RESUMO}

Smid J. Polimorfismos do gene da proteína príon celular em pacientes com doença de Alzheimer [tese] São Paulo. Faculdade de Medicina, Universidade de São Paulo; 2011.

INTRODUÇÃO: Os polimorfismos do gene da proteína priônica $(P R N P)$ podem estar associados a doenças neurológicas não priônicas. Estudos em pacientes com doença de Alzheimer (DA) apontam para possível associação entre os polimorfismos do códon 129 do PRNP e DA. Essa associação não foi estudada na população brasileira. Neste estudo, descrevemos a associação entre os diferentes polimorfismos do PRNP e DA. MÉTODOS: Foi estudada amostra composta por 100 pacientes com DA, acompanhados no Ambulatório de Neurologia Cognitiva e do Comportamento e no Centro de Referência em Distúrbios Cognitivos do Hospital das Clínicas da Faculdade de Medicina da Universidade de São Paulo, pareados para grupo controle com 111 indivíduos, em relação à frequência dos diferentes polimorfismos do $P R N P$ e o desempenho cognitivo. Os polimorfismos do PRNP foram estudados pelo método de cromotografia líquida de fase reversa desnaturante (DHPLC). Foi realizada extratificação da amostra pelo genótipo da apolipoproteína $\mathrm{E}$ (apoE). RESULTADOS: A frequência dos polimorfismos do códon 129 foi: 45,5\% M/M, $42,4 \% \mathrm{M} / \mathrm{V}$ e $12,2 \% \mathrm{~V} / \mathrm{V}$ nos pacientes com DA; e $39,6 \% \mathrm{M} / \mathrm{M}, 50,5 \% \mathrm{M} / \mathrm{V}$ e $9,9 \%$ V/V nos indivíduos controles $(p=0,503)$. O códon 117 apresentou variante alélica silenciosa em 5\% dos pacientes com DA e 3\% dos controles $(p=0,780)$. A deleção de um ocatapeptídeo repetido ocorreu em 5\% dos pacientes com DA e 4\% dos controles $(p=0,738)$. Todos os pacientes com DA e os controles eram N171N. Uma paciente do grupo com DA apresentou a mutação V180I. A análise bivariada e regressão 
logística não mostraram associação entre os diferentes polimorfismos do códon 129 e o desempenho cognitivo nos pacientes com DA, assim como nos indivíduos cognitivamente normais. A extratificação segundo genótipo da apoE não revelou diferença em relação aos polimorfismos do códon 129 do $P R N P$ entre os grupos DA e controles. CONCLUSÕES: Não houve diferença de frequência dos diferentes polimorfismos do códon 129 do PRNP entre os pacientes com DA e idosos cognitivamente normais, bem como em relação aos demais códons polimórficos do gene. Não houve diferença em relação ao desempenho cognitivo nos pacientes com DA e nos controles segundo o polimorfismo do códon 129 do PRNP. Um paciente apresentou mutação do códon 180 (V180I), e recebeu o diagnóstico de doença de Creutzfeldt-Jakob genética.

Descritores: gene da proteína priônica, doença de Alzheimer, polimorfismo genético, desempenho cognitivo, apolipoproteína E, cromotografia líquida de fase reversa. 


\begin{abstract}
Smid J. Prion protein gene polymorphism in Alzheimer's disease [thesis] São Paulo: "Faculdade de Medicina, Universidade de São Paulo"; 2011.
\end{abstract}

INTRODUCTION: The polymorphism in the prion protein gene $(P R N P)$ may influence non prion neurological diseases. Some reports associate Alzheimer's disease (AD) and the polymorphic codon 129 of the PRNP. This association has not been studied in Brazilian population. In this study we aimed to describe the association between the polymorphisms of codon 129 of the PRNP and AD. METHODS: One hundred $\mathrm{AD}$ patients were evaluated in the Cognitive and Behavioral Neurology Unit and Cognitive Disorders Reference Center of the Hospital das Clínicas of the University of São Paulo School of Medicine, matched for 111 controls, regarding to the PRNP polymorphism and cognitive measures. The PRNP polymorphisms were analyzed using denaturing high-performance liquid chromatography (DHPLC). Analyzes stratifying by apoE genotype was performed. RESULTS: The distribution of the codon 129 polymorphisms were: $45.5 \% \mathrm{M} / \mathrm{M}$, 42.4\% $\mathrm{M} / \mathrm{V}$ and $12.2 \% \mathrm{~V} / \mathrm{V}$ in $\mathrm{AD}$ patients; $39.6 \% \mathrm{M} / \mathrm{M}, 50.5 \% \mathrm{M} / \mathrm{V}$ and $9.9 \% \mathrm{~V} / \mathrm{V}$ in the control group ( $p=0.503)$. The 117 codon analysis revealed silent allelic variant in $5 \%$ of $\mathrm{AD}$ patients and $3 \%$ of controls $(p=0.780)$. The octarepeat deletion occurred in $5 \%$ of $\mathrm{AD}$ and $4 \%$ of controls $(p=0.738)$. All $\mathrm{AD}$ patients and controls were N171N. One AD patient had a point mutation at codon 180 (V180I). Logistic regression failed to confirm any association between $\mathrm{AD}$ cognitive performance and the codon 129 of PRNP, as well as in the control group. There was no association between the codon 129 genotypes and genotypes and $\mathrm{AD}$ according to the apoE 
stratification. CONCLUSIONS: There were no differences in the frequency of the codon 129 polymorphism between AD. control group, according to the codon 129 polymorphisms. A point mutation at the codon 180 (V180I) was diagnosed in one patient.

Descriptors: prion protein gene, Alzheimer's disease, polymorphism, cognitive performance, apolipoproteins E, high-performance liquid chromatography. 
1 INTRODUÇÃO 


\section{INTRODUÇÃO}

\subsection{Doença de Alzheimer}

A doença de Alzheimer (DA) foi descrita por Alois Alzheimer em 1906, após exame clínico e patológico de Auguste D., mulher cuja doença iniciou-se aos 51 anos de idade e caracterizava-se por quadro de declínio cognitivo progressivo, alucinações, delírios e prejuízo nas atividades cotidianas (Maurer et al., 1997) (Figuras 1 e 2).

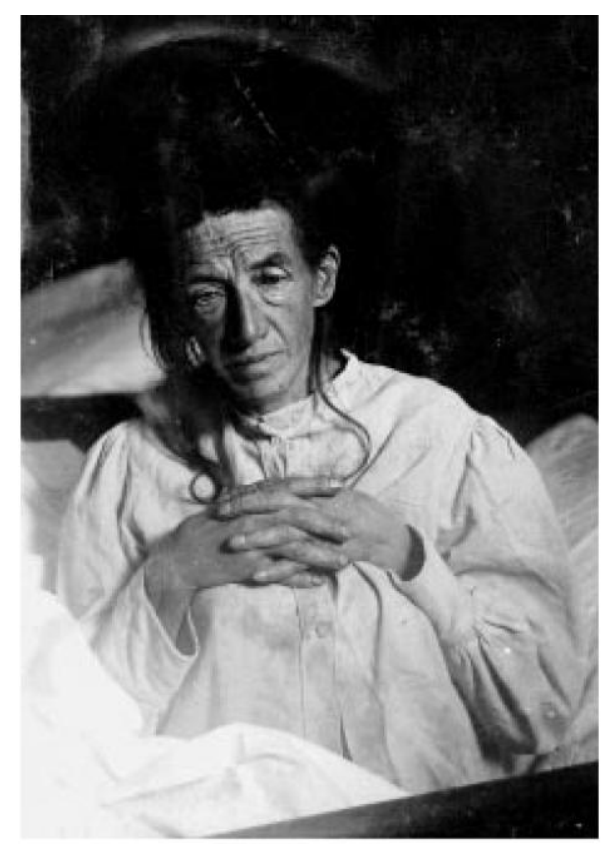

Figura 1. Auguste D (1850-1906) Fonte: Maurer et al. (1997)

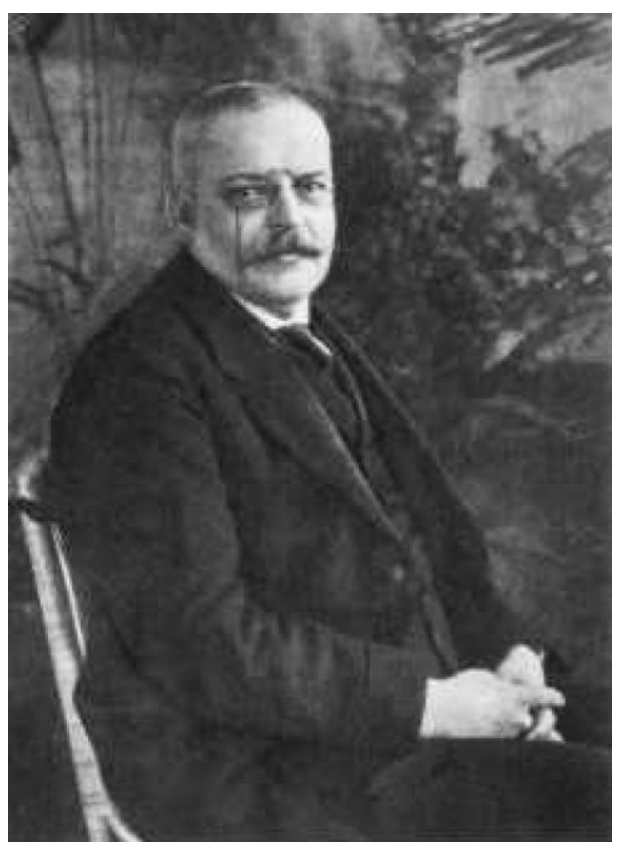

Figura 2. Alois Alzheimer (1864-1915) Fonte: Small e Cappai (2006) 
A DA era considerada, inicialmente, uma forma de demência pré-senil (com início antes dos 65 anos de idade). A partir da década de 70, a demência senil e a DA foram finalmente consideradas uma única doença, uma vez que apresentavam as mesmas alterações anatomopatológicas (Katzman, 1976).

A partir dos 65 anos, a prevalência de demência dobra a cada cinco anos, e a DA é a principal causa de demência (Evans et al., 1989; Hofman et al., 1991; Lobo et al., 2000; Suh e Shah, 2001; Herrera et al., 2002; Kalaria et al., 2008).

Na maior parte dos casos a DA ocorre de forma esporádica e menos de $1 \%$ dos casos são determinados geneticamente. Os casos genéticos estão associados a herança autossômica dominante, por mutação nos genes da proteína precursora do amilóide (PPA), da pré-senilina 1 e da pré-senilina 2 (Goate et al., 1991; Levy-Lahad e Bird, 1996; Campion et al., 1999; Mayeux, 2008).

Os principais fatores de risco associados a DA são: idade, trauma cranioencefálico, história familiar, sexo feminino e a presença do alelo $\varepsilon 4$ da apolipoproteína E (apoE) (Jorm e Jolley, 1998; Saunders et al., 1993; Levy-Lahad e Bird, 1996; Fleminger et al., 2003; Burns e Iliffe, 2009). O alelo $\varepsilon 4$ da apoE é o principal fator de risco genético para a DA, embora estudos genômicos recentes apontem para papel relevante dos genes $C L U, P I C A L M$ e $C R I$ nos casos de DA senil (Corneveaux et al., 2010; Seshadri et al., 2010).

Trata-se de doença neurodegenerativa de instalação insidiosa e curso lentamente progressivo, caracterizada por deterioração cognitiva, sintomas comportamentais e psiquiátricos e prejuízo no desempenho das atividades cotidianas (Mesulam, 1985; Burns e Iliffe, 2009).

As alterações anatomopatológicas típicas da doença são as placas senis (PS) e 
os emaranhados neurofibrilares (ENF), além de perda da densidade sináptica. As PS formam-se a partir do acúmulo extracelular da proteína ß-amilóide enquanto os ENF são intracelulares e constituídos principalmente por proteína tau hiperfosforilada (Braak e Braak, 1997; Querfurth e LaFerla, 2010).

\subsection{Proteína príon celular, príons e doenças priônicas}

A descoberta dos príons e da proteína príon celular $\left(\operatorname{PrP}^{c}\right)$ foi resultado de extensa pesquisa em doença do sistema nervoso central (SNC) de ovelhas e cabras, denominada scrapie. O scrapie, a doença de Creutzfeldt-Jakob e o Kuru apresentavam características clínicas e patológicas semelhantes. Esta observação levou à hipótese de que essas doenças pertenciam ao mesmo grupo nosológico antes mesmo da descoberta do agente patológico (Hadlow, 1959; Prusiner, 1982).

O termo príon (acrônimo de "proteinaceous infectious particle") foi proposto, em 1982, por Prusiner para substituir a terminologia utilizada de vírus lento ou vírus não convencional, uma vez que as características fisicoquímicas do agente infeccioso do scrapie eram semelhantes àquelas das proteínas e indicavam ausência de ácidos nucléicos (Prusiner, 1982).

A primeira isoforma da proteína príon $(\mathrm{PrP})$ foi identificada em cérebros de hamsters infectados pelo scrapie e denominada $\operatorname{PrP}^{27-30}$ com base no seu peso molecular. Esta isoforma não era encontrada em animais controles. A determinação da sequência de aminoácidos desta proteína permitiu a clonagem do gene PrP. A observação de que os níveis de RNA mensageiro para PrP eram semelhantes nos 
tecidos infectados e nos não infectados levaram à pesquisa de isoforma da proteína em animais não infectados, com propriedades fisicoquímicas diferentes da $\operatorname{PrP}^{27-30}$. Essa isoforma foi denominada proteína príon celular $\left(\operatorname{PrP}^{c}\right)$. A $\operatorname{PrP}^{27-30}$ é um fragmento da isoforma patogênica, denominada $\operatorname{PrP}$ scrapie $\left(\operatorname{PrP}^{\mathrm{sc}}\right)$, após clivagem de sua região aminoterminal (Prusiner, 1991; Prusiner, 1998).

O conhecimento acumulado com pesquisas sucessivas demonstrou que os príons são desprovidos de ácidos nucléicos e compostos exclusivamente pela $\mathrm{PrP}^{\mathrm{sc}}$, que é resistente à ação de proteases e difere da $\operatorname{PrP}^{c}$ em sua estrutura tridimensional. $\mathrm{A} \operatorname{PrP}^{\mathrm{c}}$ é rica em $\alpha$-hélices e possui pouca estrutura $\beta$-pregueada. $\mathrm{A} \operatorname{PrP}^{\mathrm{sc}}$, por sua vez, é rica em estrutura $\beta$-pregueada e possui pouca $\alpha$-hélice (Prusiner, 1998; Prusiner, 2001) (Figura 3).

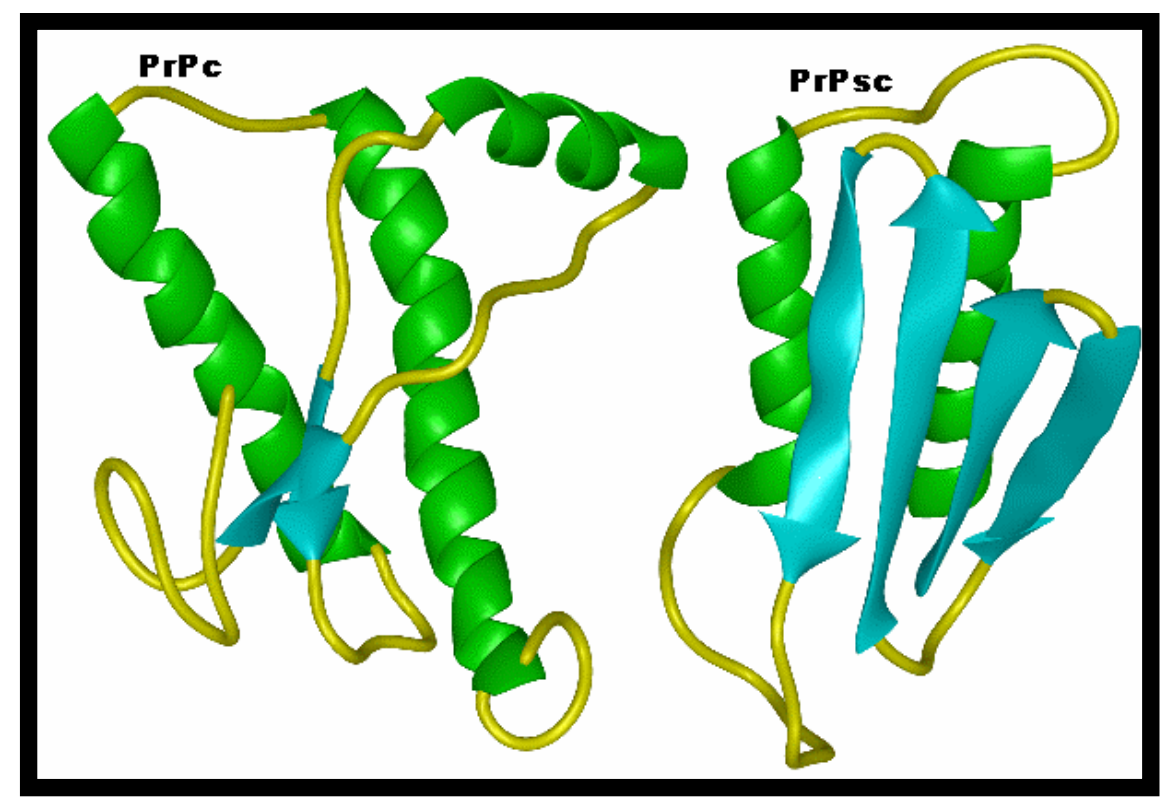

Figura 3. Estrutura tridimesional da $\operatorname{Pr}^{\mathrm{c}}$ e $\operatorname{Pr}^{\mathrm{sc}}\left(\operatorname{PrP}^{\mathrm{c}}\right.$ : proteína príon celular; $\operatorname{Pr}^{\mathrm{sc}}$ : proteína príon scrapie) Fonte: http://www.stanford.edu 
O gene que codifica a $\operatorname{PrP}^{\mathrm{c}}$ em humanos, denominado PRNP, encontra-se no cromossomo 20 e possui três éxons, sendo que apenas o terceiro éxon codifica a proteína, que é constituída por 253 aminoácidos (Prusiner, 1998).

$\mathrm{A} \mathrm{PrP}^{\mathrm{c}}$ é expressa em neurônios e glias em situações normais. $\mathrm{O}$ fato de haver conservação na sua sequência de aminoácidos entre as diferentes espécies sugere que esta proteína apresente função celular importante (Prusiner, 1991; Prusiner, 1998).

A teoria conhecida com "prion only hypothesis" especula que a doença priônica ocorre por conversão da $\operatorname{PrP}^{\mathrm{c}}$ em sua isoforma patogência, $\operatorname{PrP}^{\mathrm{sc}}$, que é capaz de atuar como um molde conformacional e promover novas conversões (Prusiner, 1998).

As doenças priônicas são classificadas em esporádicas, genéticas e adquiridas. As doenças priônicas humanas são: doença de Creutzfeldt-Jakob (DCJ), doença de Gerstmann-Sträussler-Scheinker (GSS), Insônia Fatal (IF) e Kuru (Prusiner, 1998). A forma esporádica corresponde a maioria dos casos de DCJ, enquanto a forma genética, caracterizada por padrão autossômico dominante de herança, corresponde a cerca de $15 \%$ dos casos de DCJ e a maioria dos casos de IF e todos os casos de GSS (Hsiao e Prusiner, 1990; Collins et al., 2004). As formas infecciosas da doença estão associadas à prática de canibalismo (Kuru) ou a ingestão de carne bovina contaminada (nova variante da DCJ), procedimentos neurocirúrgicos e uso de hormônio de crescimento humano derivado de glândulas pituitárias humanas contaminadas com príons (Collins et al., 2004).

Acredita-se que as doenças priônicas são causadas por ganho de função da $\operatorname{PrP}^{\mathrm{c}}$, que adquire novas características, em particular a neurotoxicidade, ao se converter em $\operatorname{PrP}^{\mathrm{sc}}$ (Collins et al., 2004). Entretanto, vários grupos já admitem a 
possibilidade de que algumas doenças possam estar relacionadas à perda de função de $\operatorname{PrP}^{\mathrm{c}}$ (Aguzzi e Weissmann, 1997; Samaia e Brentani, 1998 Chiarini et al., 2002; Linden et al., 2008; Martins et al., 2010).

\subsection{Funções da $\operatorname{PrP}^{c}$}

As funções da $\operatorname{PrP}^{c}$ ainda não estão completamente elucidadas, embora diversas linhas de pesquisa apontem para diferentes papéis da $\operatorname{PrP}^{\mathrm{c}}$ em situações normais e patológicas (Linden et al., 2008; Martins et al., 2010).

Weissman e colaboradores, em 1992, produziram o primeiro camundongo nocaute para o gene Prnp. Foram realizadas avaliações de desenvolvimento anatômico, imunológicas e de aprendizado, cujos resultados não mostraram diferença entre os animais normais e os animais $\operatorname{Prnp}^{0 / 0}$ (Büeler et al., 1992). Alterações circadianas foram, posteriormente, descritas em camundongos $\operatorname{Prnp}^{0 / 0}$, além de bloqueio da inibição rápida do receptor GABA-A e alteração no potencial de longa duração, e aumento da sensibilidade a crises epilépticas (Tobler et al., 1996; Collinge et al., 1994; Walz et al., 1999). Os camundongos nocautes também apresentam alterações em neurotransmissão e plasticidade sináptica, memória hipocampal espacial e resposta imune (Martins et al., 2010). O excesso de $\operatorname{PrP}^{\mathrm{c}}$ também foi associado a doença neurológica caracterizada por tremor e paresia em modelos experimentais (Chiesa et al., 2008).

Algumas das funções atribuídas a $\operatorname{PrP}^{\mathrm{c}}$ são: (Martins et al., 2001; Wechselberger et al., 2002; Linden et al., 2008; Martins et al., 2010; Gunther e 
Strittmatter, 2010).

a) $\operatorname{PrP}^{\mathrm{c}}$ como proteína ligadora do cobre: a $\mathrm{PrP}^{\mathrm{c}}$ liga-se ao cobre, e esta ligação contribui para sua conformação espacial (Viles et al., 1999). O cobre é um metal envolvido na atividade catalítica de várias enzimas relacionadas com processos neurobiológicos, e seu metabolismo inadequado está relacionado à formação de radicais livres e ao estresse oxidativo. A atividade da principal enzima antioxidante celular, denominada superóxido dismutase, é modulada pela $\operatorname{PrP}^{\mathrm{c}}$. A atividade antioxidante da $\operatorname{PrP}^{c}$ pode estar relacionada à atividade sináptica anormal (Brown et al., 1999; Wong et al., 2000; Brown, 2001; Wong et al., 2001).

b) $\operatorname{PrP}^{c}$ e a diferenciação e sobrevivência neuronal: a laminina é uma das proteínas que interage com a $\operatorname{PrP}^{\mathrm{c}}$ no $\mathrm{SNC}$. A laminina tem função de mediar a diferenciação neuronal e está associada a formação e extensão de neuritos, migração neuronal, regeneração neuronal e axonal, e prevenção de morte neuronal após injeção de ácido caínico (Luckenbill-Edds, 1997; Chen e Strickland, 1997; Graner et al., 2000). A PrP ${ }^{c}$ também está envolvida na proteção da apoptose neuronal (Solforosi et al., 2004; Choi et al., 2007).

c) $\operatorname{PrP}^{c}$ e excitabilidade neuronal: a ablação do Prnp aumenta a excitabilidade neuronal hipocampal in vitro e in vivo por promover: a) alteração no funcionamento de corrente de potássio mediada por cálcio; b) inibição hipocampal anormal mediada por GABA-A; c) reorganização de fibras musgosas hipocampais; d) aumento de estresse oxidativo em hipocampo e neocórtex; e e) mudanças em ectonucleotidases no hipocampo e neocórtex (Colling et al., 1996; Collinge et al., 1994; Colling et al., 1997; Wong et al., 2001; Klamt et al., 2001; Pereira et al., 2001; Walz et al., 2002). Camundongos sem Prnp também apresentam aumento da sensibilidade a crises 
epilépticas in vivo (Walz et al., 1999).

d) $\operatorname{PrP}^{\mathrm{c}}$ e transdução de sinal: a $\operatorname{PrP}^{\mathrm{c}}$ está envolvida na transdução de sinais celulares (Mouillet-Richard et al., 2000). Experimentos mostram que a $\operatorname{PrP}^{\mathrm{c}}$ é capaz de induzir, através de sua ligação com a proteína indutora de estresse 1 (STI1), uma resposta neuroprotetora e de neuritogênese por meio da ativação das vias dependentes de AMPc-proteína quinase A (PKA) e das quinases reguladoras de sinal extracelular 1 e 2 (ERK1/2), respectivamente (Zanata et al., 2002; Chiarini et al., 2002; Lopes et al., 2005).

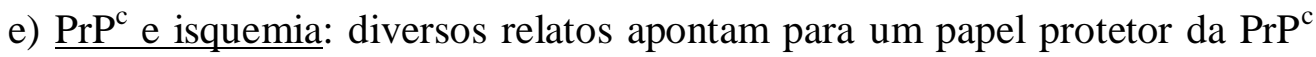
contra a lesão isquêmica, especialmente na área de penumbra isquêmica (McLennan et al., 2004; Shyu et al., 2005; Weise et al., 2006).

f) $\operatorname{PrP}^{\mathrm{c}}$ e proteína $\beta$-amilóide: dados recentes sugerem que a $\operatorname{PrP}^{\mathrm{c}}$ atua como receptor para oligômeros de $\beta$-amilóide. Os oligômeros de $\beta$-amilóide são compostos com ação sinaptotóxica e podem ser os principais agentes na disfunção e na degeneração neuronal na DA. Esta interação $\operatorname{PrP}^{\mathrm{c}}-\beta$-amilóide parece mediar a inibição da potenciação de longo prazo hipocampal e a disfunção cognitiva relacionados aos A $\beta$-oligômeros (Laurén et al., 2009; Nygaard e Strittmatter, 2009; Gimbel et al., 2010; Gunther e Strittmatter, 2010; Chen et al., 2010), embora essa opinião não seja unânime (Balducci et al., 2010; Calella et al., 2010; Kessels et al., 2010). Também existe evidência de que a $\operatorname{PrP}^{c}$ regula a atividade da enzima $\beta$ secretase, que atua na clivagem da proteína precursora do amilóide favorecendo a formação da proteína $\beta$-amilóide (Parkin et al., 2007). 


\subsection{Doenças neurológicas e PRNP}

\subsubsection{Doenças priônicas}

Mais de 50 mutações patogênicas do $P R N P$ estão relacionadas com as formas genéticas das doenças priônicas: DCJ genética (gDCJ), insônia fatal familiar (IFF) e GSS (Figura 4). A mutação mais comum da gDCJ é a E200K, relatada em diversos países, inclusive no Brasil (Smid et al., 2007). A GSS está, mais comumente, associada à mutação P102L, também relatada em nosso meio (Smid et al., 2009). A IFF está associada à mutação D178N-129M (Doh-ura et al., 1989; Kovács et al.; 2005; Lee e Goldfarb, 2008). O fenótipo da mutação D178N é determinado pelo polimorfismo do códon 129 do alelo mutado. O fenótipo IF está relacionado ao polimorfismo metionina do códon 129 do alelo mutado, e o fenótipo DCJ, ao polimorfismo valina (Goldfarb et al., 1992).

Alguns polimorfismos do $P R N P$ ocorrem em frequência variada na população normal, principalmente os polimorfismos dos códons 117, 129, 171, 219 e a deleção de um octapeptídeo repetido. À exceção do códon 117, os demais polimorfismos estão associados à alteração na sequência de aminoácidos (Kong et al., 2004; Meade, 2006). Os diferentes polimorfismos do códon 219 são encontrados em populações asiáticas (Shibuya et al., 1998; Jeong et al., 2004) (Figura 4). 


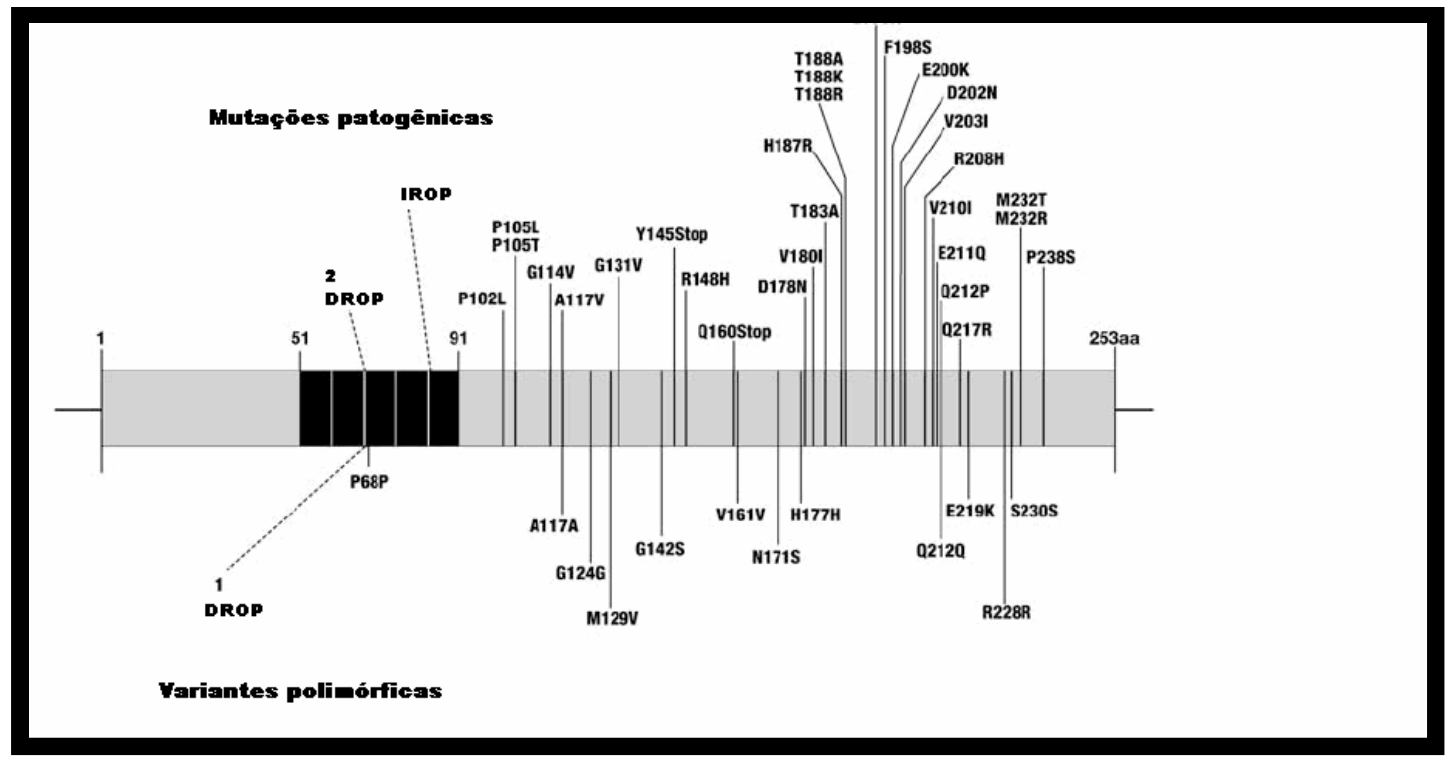

Figura 4. Mutações e polimorfismos do PRNP. (DROP: deleção de repetição de octapeptídeo; IROP: inserção de repetição de octapeptídeo) (Adaptado de Meade, 2006)

O códon 129 pode apresentar metionina em homozigose (M129M), metionina em heterozigose com valina (M129V) ou valina em homozigose (V129V). O códon 129 tem efeito modificador no fenótipo e interfere na suscetibilidade a todas as doenças priônicas. A homozigose para metionina é fator de risco bem estabelecido para DCJ esporádica (eDCJ), e a heterozigose é fator protetor em algumas populações. Todos os indivíduos que desenvolveram a nova variante de DCJ (vDCJ), doença priônica adquirida por ingestão de carne bovina contaminada por príon, apresentavam homozigose para metionina $(\mathrm{M} 129 \mathrm{M})$. O relato recente de diagnóstico clínico de vDCJ sem confirmação anatomopatológica em paciente M129V colocou em dúvida se a vDCJ ocorre somente em indivíduos M129M ou se, por outro lado, a vDCJ em pacientes M129V e V129V ocorreria depois de maior tempo de incubação da doença (Palmer et al., 1991; Windl et al. 1996; Alperovitch et al., 1999; Glatzel et al., 2005; Wadsworth et al., 2004; Meade, 2006; Kaski et al., 2009). Estudos com camundongos transgênicos para $\operatorname{PrP}^{\mathrm{c}}$ humana mostraram que os camundongos 
M129V e V129V apresentam doença priônica de fenótipo distinto ao da vDCJ, e que são mais susceptíveis à infecção transmitida por humanos com vDCJ do que à infecção transmitida por carne bovina contaminada (Wadsworth et al., 2004; Asante et al., 2006).

\subsubsection{Outras doenças neurológicas}

O polimorfismo do códon 129 tem sido estudado no contexto de diversas doenças neurológicas, principalmente doenças neurodegenerativas e epilepsia.

Estudo com 39 pacientes com afasia progressiva primária (APP) mostrou que os pacientes apresentam maior frequência do genótipo M129V quando comparados aos controles, "odds-ratio" de 8,47 (IC=3,42-21,0) (Li et al., 2005).

A homozigose para metionina em pacientes com doença de Wilson (degeneração hepatolenticular) está relacionada a maior gravidade dos sintomas neurológicos nos pacientes idosos, além início mais tardio da doença (Grubenbecher et al., 2006, Merle et al., 2006).

Estudos em pacientes com esclerose múltipla não mostraram associação com os diferentes polimorfismos do códon 129 (Stüve et al., 2009; Choi et al., 2010).

Pacientes com doença de Parkinson idiopática não apresentam diferença na proporção dos polimorfismos do códon 129 em relação ao grupo controle. No entanto, o grupo de pacientes com fenótipo tremulante apresentava menos M129M do que o grupo com doença rígido-acinética (Scholz et al., 2006; Gossrau et al., 2006).

O polimorfismo do códon 129 parece influenciar o desempenho cognitivo em indivíduos normais e com DA. Em indivíduos jovens, a homozigose para valina 
esteve associada a pior desempenho em teste de memória de longo prazo (Papassotiropoulos et al., 2005). A homozigose no códon 129, principalmente para metionina, representa fator de risco para DA em algumas populações (Berr et al., 1998; Del Bo et al., 2006; Poleggi et al. 2008). A maioria dos dados, no entanto, não mostra associação entre DA e os genótipos do códon 129. Os dados do único estudo com confirmação anatomopatológica também descartam associação entre DA e o códon 129 do PRNP (Poleggi et al., 2008). Estudo com pacientes com comprometimento cognitivo leve (CCL), estágio clínico que antecede o quadro demencial, não mostrou associação com os diferentes polimorfismos do códon 129 (Choi et al., 2010). 
2 OBJETIVOS 


\section{OBJETIVOS}

Os objetivos deste estudo foram:

1) Identificar a frequência dos polimorfismos do $P R N P$ em pacientes com DA de amostra de população brasileira.

2) Identificar eventual presença de mutações do PRNP em pacientes com DA.

3) Comparar o desempenho cognitivo dos pacientes com DA em relação aos polimorfismos do códon 129 do $P R N P$.

4) Comparar o desempenho cognitivo dos idosos cognitivamente normais em relação aos polimorfismos do códon 129 do $P R N P$.

5) Comparar a frequência dos polimorfismos do códon 129 do PRNP em relação ao genótipo do gene da apoE em pacientes com DA e idosos cognitivamente normais. 
3 CASUÍSTICA E MÉTODOS 


\section{CASUÍSTICA E MÉTODOS}

\subsection{Casuística}

Cem pacientes com DA avaliados no ambulatório do Grupo de Neurologia Cognitiva e do Comportamento (GNCC), no Centro de Referência em Distúrbios Cognitivos (CEREDIC) do Hospital das Clínicas da Faculdade de Medicina da Universidade de São Paulo (HC-FMUSP) e que haviam sido avaliados em estudo anterior de nosso grupo (Bahia et al., 2008) foram inicialmente incluídos neste estudo. A paciente ID 211 foi excluída da amostra geral após análise do PRNP por apresentar mutação no códon 180 deste gene, caracterizando diagnóstico de doença de Creutzfeltd-Jakob genética. Dessa forma, o grupo de pacientes com DA totalizou 99 indivíduos.

Os critérios diagnósticos utilizados para a inclusão dos doentes foram os critérios para demência do DSM-IV (American Psychiatric Association, 1994) e os critérios do NINCDS/ADRDA para DA provável (McKhann et al., 1984).

Cento e onze indivíduos cognitivamente normais foram incluídos no grupo controle. Estes indivíduos eram, na maioria, cônjuges ou acompanhantes não relacionados dos pacientes sem evidência de doença neurológica, psiquiátrica ou doença sistêmica descompensada. Para o grupo controle, indivíduos avaliados no estudo anteriormente citado (Bahia et al., 2008) também foram incluídos.

Os indivíduos controles foram submetidos à avaliação cognitiva com os testes do miniexame do estado mental (MEEM) e o teste de fluência verbal (FV) 
semântica. Foram adotadas as seguintes notas de corte no MEEM para os indivíduos do grupo controle: 18 para analfabetos, 24 para indivíduos de escolaridade de 1 a 7 anos, e 26 para indivíduos com escolaridade mínima de 8 anos (Nitrini et al., 1994; Bertolucci et al., 1994; Brucki et al., 1997). A nota de corte adotada para o teste de fluência verbal foi 9 para indivíduos analfabetos e 12 para as demais escolaridades.

Os dados clínicos e demográficos dos pacientes e controles estão resumidos na Tabela 1.

Tabela 1. Características clínicas e demográficas dos grupos DA e controle.

\begin{tabular}{|c|c|c|c|}
\hline & DA & Controles & $p$ \\
\hline $\mathbf{n}$ & 99 & 111 & \\
\hline Mulheres & $66(66,7 \%)$ & $76(68,5 \%)$ & 0,781 \\
\hline $\begin{array}{l}\text { Média etária ao início da } \\
\text { doença em anos (DP) }\end{array}$ & $72,2(9,1)$ & & \\
\hline $\begin{array}{l}\text { Média etária à coleta do sangue } \\
\text { em anos (DP) }\end{array}$ & & $71,4(8,2)$ & \\
\hline $\begin{array}{l}\text { Mediana da idade em anos } \\
\text { (intervalo) }\end{array}$ & $74(50-90)$ & $71(53-90)$ & $0,236^{*}$ \\
\hline $\begin{array}{l}\text { Tempo médio de duração da } \\
\text { doença em meses (DP) }\end{array}$ & $30,5(20,1)^{+}$ & & \\
\hline Idade (anos) & & & 0,536 \\
\hline$<65$ & $21(21,2)$ & $28(25,2)$ & \\
\hline 65 a 74 & $35(35,4)$ & $43(38,7)$ & \\
\hline$\geq 75$ & $43(43,4)$ & $40(36,1)$ & \\
\hline $\begin{array}{l}\text { Escolaridade } \\
\qquad \begin{array}{r}\text { Mediana (intervalo) } \\
\text { Média (DP) }\end{array}\end{array}$ & $\begin{array}{c}4,0(0-17)^{+} \\
6,3(5,2)^{+}\end{array}$ & $\begin{array}{l}6,5(0-16)^{\xi} \\
7,1(4,1)^{\xi}\end{array}$ & $0,060 *$ \\
\hline
\end{tabular}


O projeto deste estudo obteve a aprovação da Comissão de Ética para Análise de Projetos de Pesquisa da Faculdade de Medicina da Universidade de São Paulo, número 075/7, em 18 de abril de 2007. Este estudo foi realizado sem subsídio ou bolsa de estudo.

A anuência para a realização do estudo por parte dos doentes e dos indivíduos que integraram o grupo controle (ou de seus responsáveis legais no caso de pacientes com demência grave) foi obtida mediante a assinatura do Termo de Consentimento Livre e Esclarecido.

\subsection{Métodos}

\subsubsection{Técnicas laboratoriais}

A análise laboratorial descrita a seguir foi realizada no Instituto Ludwig de Pesquisa para o Câncer, em São Paulo, SP.

As alíquotas de DNA dos participantes do estudo "Polimorfismos da região promotora e codificadora do gene APOE e do gene LRP na doença de Alzheimer em indivíduos brasileiros" estavam armazenadas no LIM 45 da FMUSP.

\subsubsection{Extração de DNA de leucócitos}

O DNA genômico dos participantes do estudo foi extraído a partir de $3 \mathrm{ml}$ de sangue periférico usando o Kit Wizard Genomic DNA Purification da Promega, catálogo A1120.

Seguindo o protocolo do fabricante, as amostras de sangue foram 
homogeneizadas por 15 minutos e adicionadas a $9 \mathrm{~mL}$ de solução de lise seguido de incubação à temperatura ambiente por 15 minutos. As amostras foram então centrifugadas por 10 minutos a $1700 x g$, o sobrenadante descartado e o precipitado homogeneizado vigorosamente. A seguir foram adicionados $3 \mathrm{~mL}$ de solução de lise nuclear e $30 \mu \mathrm{L}$ de RNAse (estoque a $20 \mathrm{mg} / \mathrm{mL}$ ) seguidos de incubação a $37^{\circ} \mathrm{C}$ por 30 minutos. A amostra foi então resfriada a $4^{\circ} \mathrm{C}$, e $2 \mathrm{~mL}$ de solução de precipitação de proteínas contendo SDS foi adicionada e misturada vigorosamente. O material foi novamente centrifugado, o sobrenadante transferido para um novo tubo contendo $3 \mathrm{~mL}$ de isopropanol e misturado lentamente até a precipitação do DNA. A amostra foi centrifugada e o precipitado lavado com $3 \mathrm{~mL}$ de etanol a $70 \%$ seguido de nova centrifugação por 5 minutos. O sobrenadante foi descartado, o precipitado de DNA foi então seco por 30 minutos a $50^{\circ} \mathrm{C}$ e ressuspenso em $100 \mu \mathrm{L}$ de Tampão de Eluição (10mM de Tris e $1 \mathrm{mM}$ de EDTA).

Após a extração, o DNA foi quantificado pela absorbância, em comprimento de onda de 260nm, e sua pureza foi quantificada pela relação entre as absorbâncias 260/280. Esta foi sempre maior do que 1.8. O DNA submetido a eletroforese em gel de agarose a $0,8 \%$ para verificação de sua integridade e pureza. $\mathrm{O}$ material foi aliquotado e armazenado a $-20^{\circ} \mathrm{C}$.

\subsubsection{Análise do gene PRNP}

A) Reação de amplificação por PCR

Baseados na sequência de PRNP depositada no GenBank sob o número $\mathrm{AY}=008282$ e para facilitar na identificação dos polimorfismos, a região codificadora (fase aberta de leitura) do gene PRNP foi dividida em duas porções que 
se sobrepõem: 1) Fragmento 1: corresponde a 423 pb, com início no nucleotídeo 65 (ATG inicial) e término no 488; e 2) Fragmento 2: corresponde a 404 pb, com início no nucleotídeo 455 e término no 858, 53 pares de base a 5' do nucleotídeo do códon de terminação. Os iniciadores foram sintetizados pela Life Technologies do Brasil (S.P., Brasil):

Primeiro par de iniciadores:

F1: 5’ATG CTG GTT CTC TTT GTG 3'

R1: 5'AAC GGT CAT AGT CAC TGC 3'

Segundo par de iniciadores:

F2: 5'ATC ATA CAT TTC GGC AGT 3'

R2: 5'CTC CCT CAA GCT GGA AAA AGA 3'

Para a amplificação por PCR foi utilizado o kit de amplificação AmpliTaq Gold (Applied Biosystems, USA). As reações são feitas em volume de $50 \mu \mathrm{L}$ contendo $100 \mu \mathrm{g}$ de DNA genômico (diluído em água Dnase/Rnase free, Invintrogen), $100 \mathrm{mM}$ de Tris $\mathrm{HCl} \mathrm{pH} 8,3,500 \mathrm{mM}$ de $\mathrm{KCl}, 25 \mathrm{mM}$ de $\mathrm{MgCl}_{2}, 500 \mu \mathrm{M}$ de dNTP (Life Technologies, Gibco BRL), 0,5 $\mu \mathrm{M}$ de iniciadores (Forward e Reverse) e 5U de AmpliTaq Gold.

As condições de ciclagem para a amplificação da $1^{\mathrm{a}}$ metade do gene foram $95^{\circ} \mathrm{C}$ por 5 minutos, seguido de 35 ciclos de $95^{\circ} \mathrm{C}$ por 1 minuto, $64^{\circ} \mathrm{C}$ por 1 minuto e $72^{\circ} \mathrm{C}$ por 1 minuto, seguidos de uma extensão final de $72^{\circ} \mathrm{C}$ por 10 minutos.

A amplificação da segunda metade do gene de PRNP foi feita usando-se a condição de ciclagem $95^{\circ} \mathrm{C}$ por 5 minutos, seguido de 35 ciclos de $95^{\circ} \mathrm{C}$ por 1 minuto, $66^{\circ} \mathrm{C}$ por 1 minuto e $72^{\circ} \mathrm{C}$ por 1 minuto, seguidos de uma extensão final de $72^{\circ} \mathrm{C}$ por 10 minutos. 
Para confirmar a amplificação e quantificar as amostras, os produtos da PCR foram separados por eletroforese em gel de agarose $0,8 \%$, diluídos na proporção de 5:1 em tampão contendo brometo de etídio, e visualizados em luz UV para sua identificação.

B) DHPLC (Cromatografia Líquida de Fase Reversa Desnaturante)

As amostras de DNA amplificados por PCR foram submetidas à DHPLC usando-se o equipamento Wavenucleic acid Fragment Analysis System da Transgenomic (CA, USA) para a pesquisa da presença de variantes alélicas (fitas de DNA em heteroduplex) do PRNP. Para essa análise, os produtos de PCR são primeiramente aquecidos a $95^{\circ} \mathrm{C}$ por 5 minutos, para desnaturação total das fitas duplas de DNA e resfriados gradativamente até a temperatura ambiente para renaturação. Em seguida as amostras são colocadas no cromatógrafo onde, primeiramente $8 \mu \mathrm{L}$ destas são aquecidos a uma temperatura de $50^{\circ} \mathrm{C}$ para a verificação da qualidade do DNA amplificado (denominada doublestranded sizing single fragment) e em seguida $12 \mu \mathrm{L}$ do produto de PCR são aquecidos à temperatura de anelamento para a pesquisa de mutações/polimorfismos por formação de heteroduplex (HUBER et al. 1992). Esta temperatura foi calculada pelo software do aparelho e se mostrou ótima para a resolução total dos heteroduplex em $65^{\circ} \mathrm{C}$ para o fragmento 1 (primeira metade) e $61^{\circ} \mathrm{C}$ ou $63^{\circ} \mathrm{C}$ para o fragmento 2 (segunda metade). Os parâmetros de gradiente e fluxo de tampões (tampão A = acetato de trietilamônio - TEEA - a $5 \%$ e tampão $\mathrm{B}=$ acetonitrila a $25 \%$ ) foram ajustados utilizando-se o software Wavemaker system control software (Transgenomic Inc, CA, USA). Amostras que revelaram somente um pico de saída no cromatograma (homoduplex) 
foram misturadas em igual quantidade com DNA protótipo e desnaturadas a $95^{\circ} \mathrm{C}$ por 5 minutos para a formação de possíveis heteroduplex, caso a amostra contenha uma variante alélica em homozigose. A seguir as amostras são submetidas novamente à análise cromatográfica como descrito anteriormente.

Exemplo: amostras M129M ou V129V têm apenas um pico de saída no cromatograma. Para diferenciar entre esse dois genótipos, faz-se uma mistura com DNA protótipo (M129M). Se o cromatograma de saída apresentar um pico apenas, trata-se se amostra M129M. No entanto, se tiver dois picos de saída, trata-se de amostra V129V.

Os padrões gráficos para a identificação das variantes alélicas são apresentados a seguir (Figuras 5 e 6).

A metodologia da avaliação do PRNP por DHPLC é reprodutível e pode ser utilizada em outros estudos (Castro et al., 2004). 


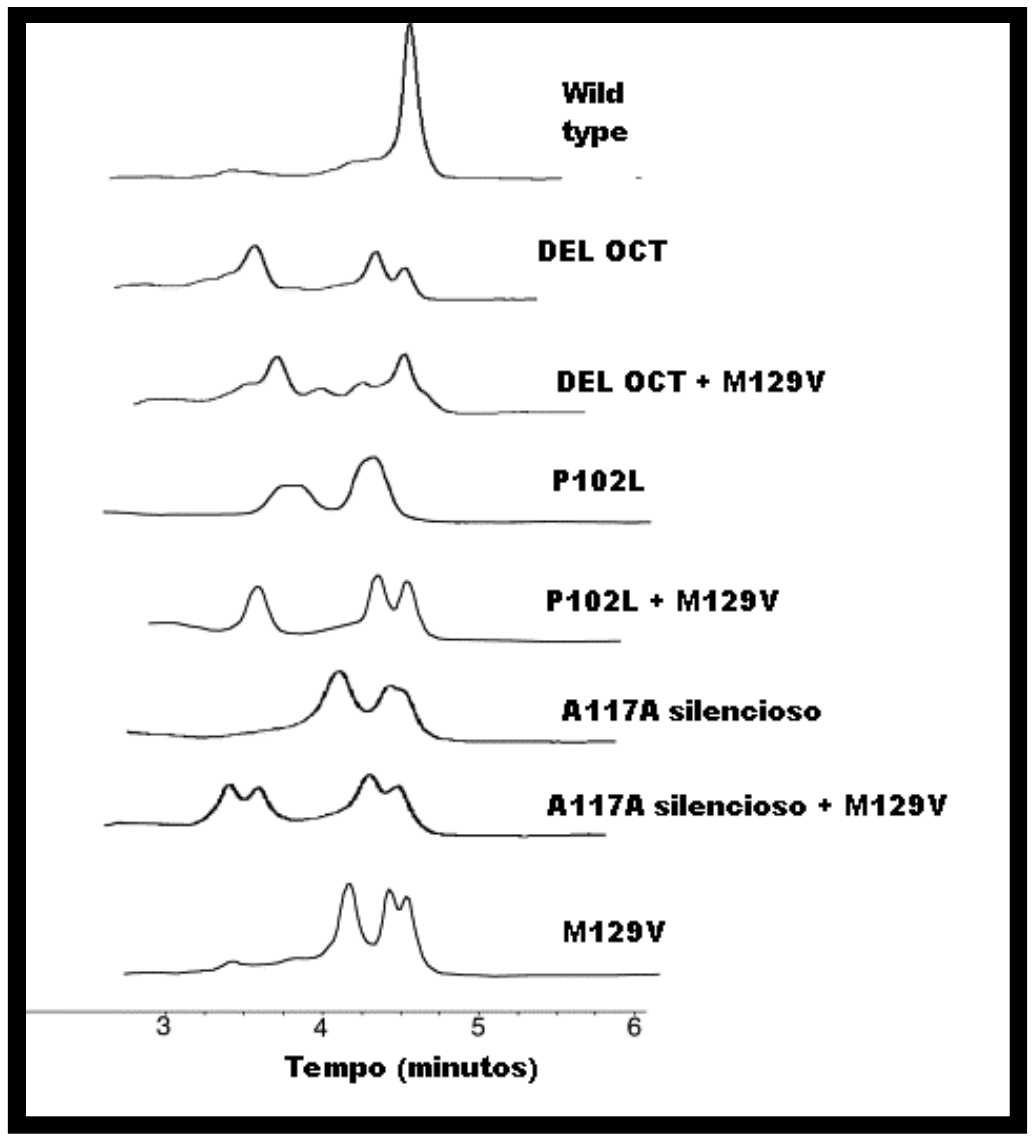

Figura 5. Perfil de saída dos cromatogramas das principais variantes alélicas pesquisadas - primeira metade do PRNP (DEL OCT = deleção de octapeptídeo; wild type = controle homoduplex) (modificado de Castro et al., 2004) 


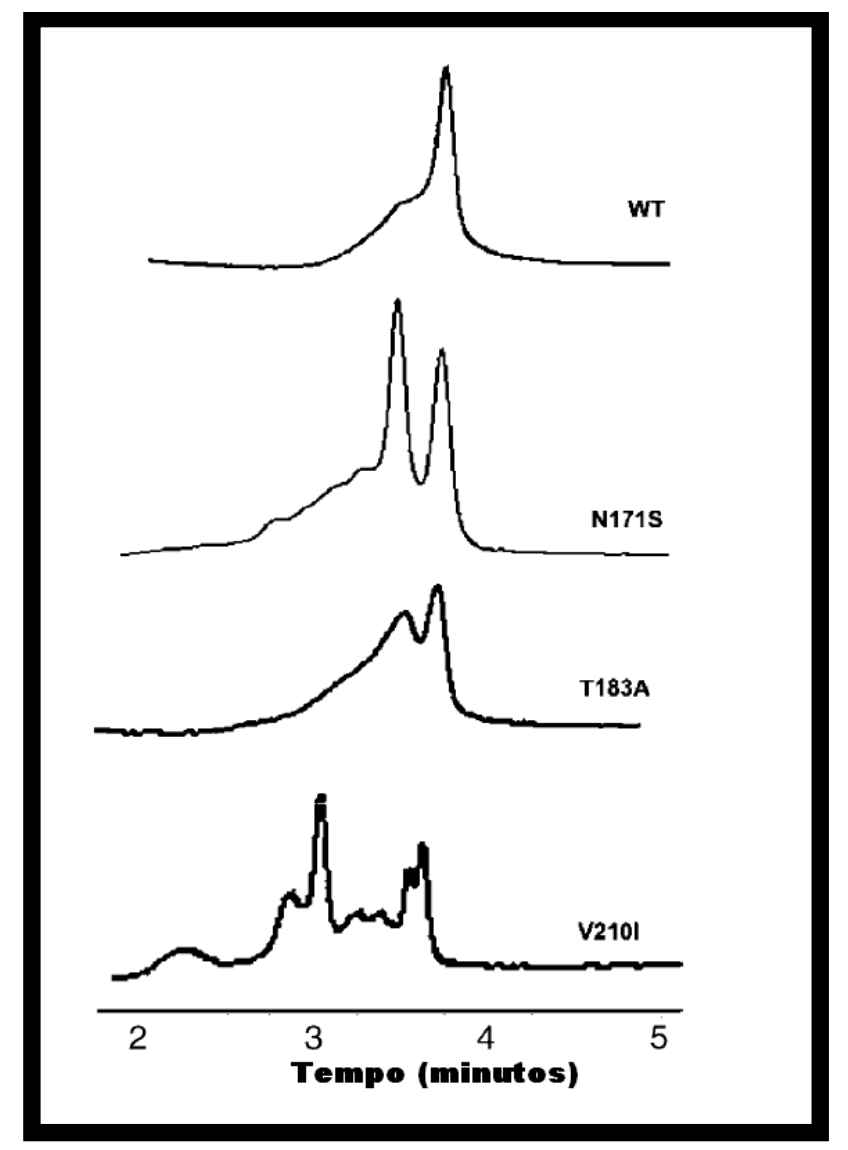

Figura 6. Perfil de saída dos cromatogramas das principais variantes alélicas pesquisadas - segunda metade do PRNP (WT = wild type = controle homoduplex) (modificado de Castro et al., 2004)

C) Sequenciamento do gene PRNP

Após a amplificação do DNA, como no item A, foi utilizado o kit DYEnamic ET terminator $^{\circledR}$ (Amersham Pharmacia Biotech, Inc, USA) para a reação de sequenciamento. As reações foram realizadas segundo as especificações do fabricante, em um volume final de $10 \mu \mathrm{L}$ contendo 0,2 pmol de DNA genômico e 0,5pmol de iniciador, adicionados à mistura reagente contendo os dNTPs fluorescentes (Amersham Pharmacia Biotech, Inc, USA).

A amplificação foi feita em termociclador DNA Thermal Cycler PTC-100 (MJ Research, Inc), utilizando-se o seguinte programa: desnaturação inicial de 
1 minuto a $94^{\circ} \mathrm{C}, 1$ minuto e 15 segundos a $60^{\circ} \mathrm{C}$ e 20 segundos a $94^{\circ} \mathrm{C}$ por 25 ciclos. Nestas reações foram usados iniciadores sintetizados pela Life Technologies do Brasil (S.P., Brasil): 1) primeira metade da sequência aberta de leitura de PRNP: F1seq - 5' CTG GTT CTC TTT GTG GCC 3' ou R1seq - 5' AAC GGT CCT CAT AGT CAC TGC 3'; 2) segunda metade da sequência aberta de leitura de PRNP: F2 seq - 5'TGG TGG TGG CTG GGG TCA AGG 3' e R2 seq - 5' CTC CCT CAA GCT GGA AAA AGA 3'.

Após esta reação de ciclagem, foi adicionado $1 \mu \mathrm{L}$ de AcNa/EDTA e $40 \mu 1$ de etanol a $95 \%$ e o material permaneceu por 15 minutos no escuro, a $4^{\circ} \mathrm{C}$. Foi posteriormente submetido à centrifugação a $10.600 x g$ por 15 minutos a $4^{\circ} \mathrm{C}$. O sobrenadante foi aspirado e o precipitado lavado com $250 \mu \mathrm{L}$ de etanol a $70 \%$, seguido de centrifugação por $10.600 x g$ por 5 minutos a $4^{\circ} \mathrm{C}$. O sobrenadante foi aspirado e o precipitado seco a $55^{\circ} \mathrm{C}$. As amostras foram aplicadas em gel e a leitura da sequência foi feita em sequenciador ABI 3100 Genetic Analyzer da Applied Biosystems (New Jersey, USA).

\subsubsection{Extratificação por genótipo da apoE}

A informação sobre o genótipo da apoE estava disponível para 81 pacientes com DA e 94 indivíduos cognitivamente normais. Esses genótipos foram pesquisados para o estudo anteriormente realizado em nosso grupo (Bahia et al., 2008).

\subsubsection{Análise estatística}

Foi realizada análise descritiva das variáveis do estudo para cada um dos 
grupos avaliados, controle e DA. Os resultados foram apresentados em tabelas de frequências para as variáveis qualitativas. Para as seguintes variáveis quantitativas, foram calculadas medidas de tendência central e de dispersão: escolaridade, tempo da doença, desempenho no MEEM e desempenho no teste de FV.

Para a comparação de frequências foi utilizado o teste qui-quadrado de Pearson. Em situações em que esse teste não era apropriado, o teste exato de Fisher foi utilizado.

Para comparação das medianas da escolaridade e dos escores obtidos nos testes cognitivos, em ambos os grupos, empregou-se o teste não paramétrico de Mann-Whitney, após verificação de não normalidade da amostra pelo teste de Kolmogorov-Smirnov. O teste de Kruskal-Wallis foi utilizado para comparar medianas entre três ou mais grupos.

Para testar a hipótese de associação entre as variáveis independentes (sexo, idade, escolaridade, genótipo do códon 129 do PRNP e tempo da doença) e cada variável desfecho (desempenho no teste do MEEM em relação à mediana e desempenho no teste de FV em relação à mediana), para cada um dos grupos, o teste qui-quadrado de Pearson foi utilizado. Para situações em que esse teste não era apropriado, o teste exato de Fisher foi utilizado.

As variáveis que à análise bivariada apresentaram valores de $p$ inferiores a 0,25 foram selecionadas para a análise múltipla. Esta foi realizada com modelo de regressão logística. $\mathrm{O}$ processo de modelagem foi iniciado com a variável que apresentava o menor valor de $p$ pelo teste de Wald e, em seguida, foram acrescentadas sucessivamente as demais variáveis com valor de $p$ inferior a 0,25 . As 
variáveis que apresentaram valor de $p<0,05$ à análise múltipla ficaram no modelo final. Finalmente foram estimados os "odds ratios" (OR) e seus respectivos intervalos de confiança (IC95\%) para cada uma dessas variáveis. O nível descritivo adotado para o estudo foi de $5 \%$. 
4 RESULTADOS 


\section{RESULTADOS}

\subsection{Variantes alélicas do PRNP}

Não houve diferença entre a frequência dos diversos polimorfismos do $P R N P$ estudados entre os grupos (Tabela 2). Em ambos os grupos, a distribuição dos diferentes genótipos do códon 129 respeita o equilíbrio de Hardy-Weinberg, sendo $p=0,65$ para o grupo DA e $p=0,26$ para o grupo controle.

Nenhum indivíduo apresentou a variante alélica N171S, tanto no grupo com DA quanto no grupo controle (Tabela 2).

Não houve diferença na frequência do polimorfismo do códon 117, bem como na frequência de deleção de um octapeptídeo repetido em heterozigose, entre os grupos DA e controle (Tabela 2).

Tabela 2. Variantes alélicas do $P R N P$ nos pacientes com DA e controles.

\begin{tabular}{|c|c|c|c|}
\hline Variante alélica & DA & Controles & $p$ \\
\hline \multicolumn{4}{|l|}{ Códon 129 (\%) } \\
\hline $\mathrm{M} / \mathrm{M}$ & $45(45,5)$ & $44(39,6)$ & 0,503 \\
\hline $\mathrm{M} / \mathrm{V}$ & $42(42,4)$ & $56(50,5)$ & \\
\hline $\mathrm{V} / \mathrm{V}$ & $12(12,1)$ & $11(9,9)$ & \\
\hline \multicolumn{4}{|l|}{ Códon 171 (\%) } \\
\hline $\mathrm{N} / \mathrm{N}$ & 99 (100) & $111(100)$ & \\
\hline $\mathrm{N} / \mathrm{S}$ & 0 & 0 & \\
\hline Códon 117 (\%) & & & $0,780^{\dagger}$ \\
\hline Normal & $94(94,9)$ & $108(97,3)$ & \\
\hline Silenciosa & $5(5,1)$ & $3(2,7)$ & \\
\hline Octarrepetição (\%) & & & $0,738^{\dagger}$ \\
\hline Normal & $94(94,9)$ & $107(96,4)$ & \\
\hline Deletado & $5(5,1)$ & $4(3,6)$ & \\
\hline
\end{tabular}

DA = doença de Alzheimer; $p=$ valor-p; $\mathrm{M}=$ metionina: $\mathrm{V}=$ valina; $\mathrm{N}=$ aspargina; $\mathrm{S}=$ serina; ${ }^{\dagger}$ teste exato de Fisher 
Como já mencionado, uma paciente apresentou mutação no códon 180 do PRNP, sendo diagnosticado gDCJ (Figura 7).

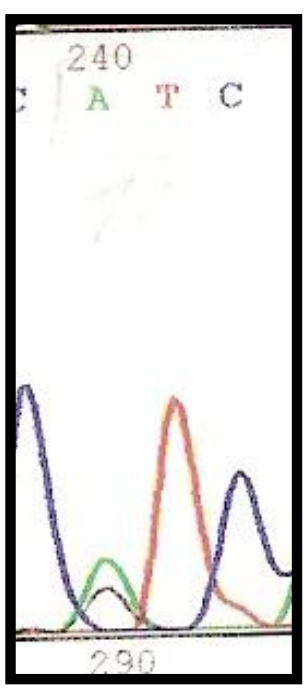

(A)

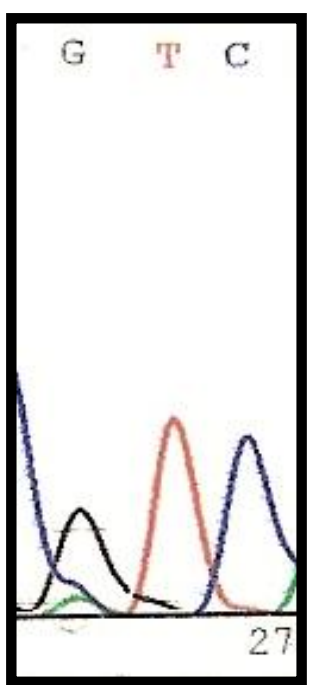

(B)

Figura 7. Eletroesferograma específico da região do códon 180 gene da paciente ID 211: (A) V180I mutado; (B) V180V.

\subsection{Análise do códon 129 entre os diferentes subgrupos da amostra}

A comparação entre a proporção dos diferentes polimorfismos do códon 129 foi realizada entre diferentes subgrupos, com estratificação da amostra pela idade. Nesta subanálise foram também analisados os diferentes grupos em relação à presença de homozigose ou heterozigose no códon 129, e a frequência dos diferentes alelos (metionina e valina).

Foram realizadas as seguintes comparações (Tabela 3):

1) DA e controles

2) DA senil e DA pré-senil

3) DA senil e controles com idade $\geq 65$ anos

4) DA pré-senil e controles com idade $<65$ anos 
Não houve diferença estatística entre as diferentes comparações em relação ao genótipo do códon 129, proporção de indivíduos homozigotos e heterozigotos, bem como frequência dos alelos metionina e valina (Tabelas 3 e 4).

Todas as proporções entre os diferentes genótipos do códon 129 respeitam o equilíbrio de Hardy-Weinberg (Tabela 5).

Tabela 3. Análise dos genótipos do códon 129 e dos alelos M e V em diferentes subgrupos da amostra.

\begin{tabular}{|c|c|c|c|c|c|c|c|c|}
\hline & \multirow[b]{2}{*}{$\mathbf{n}$} & \multicolumn{3}{|c|}{ "Genótipo do códon 129 (\%) } & \multirow[b]{2}{*}{$p$} & \multicolumn{2}{|c|}{ Alelos (\%) } & \multirow[b]{2}{*}{$p$} \\
\hline & & $\mathrm{M} / \mathrm{M}$ & $\mathrm{M} / \mathrm{V}$ & $\mathrm{V} / \mathrm{V}$ & & $\mathrm{M}$ & $\mathrm{V}$ & \\
\hline \multicolumn{9}{|l|}{ Total } \\
\hline DA & 99 & $45(45,5)$ & $42(42,2)$ & $12(12,1)$ & 0,50 & $132(66,7)$ & $66(33,3)$ & \multirow[b]{2}{*}{0,70} \\
\hline Controles & 111 & $44(39,6)$ & $56(50,5)$ & $11(9,9)$ & & $144(64,9)$ & $78(35,1)$ & \\
\hline \multicolumn{9}{|l|}{$<65$ anos } \\
\hline DA & 21 & $12(57,1)$ & $8(38,1)$ & $1(4,8)$ & 0,86 & $32(76,2)$ & $10(23,8)$ & \multirow[t]{2}{*}{0,60} \\
\hline Controles & 28 & $14(50,0)$ & $12(42,9)$ & $2(7,1)$ & & $40(71,4)$ & $16(28,6)$ & \\
\hline \multicolumn{9}{|l|}{$\geq 65$ anos } \\
\hline DA & 78 & $33(42,3)$ & $34(43,6)$ & $11(14,1)$ & 0,48 & $100(64,1)$ & $56(35,9)$ & \multirow[b]{2}{*}{0,79} \\
\hline Controles & 83 & $30(36,1)$ & $44(53,0)$ & $9(10,8)$ & & $104(62,7)$ & $62(37,3)$ & \\
\hline \multicolumn{9}{|l|}{ DA } \\
\hline$<65$ anos & 21 & $12(57,1)$ & $8(38,1)$ & $1(4,8)$ & 0,35 & $32(76,2)$ & $10(23,8)$ & \multirow[b]{2}{*}{0,14} \\
\hline$\geq 65$ anos & 78 & $33(42,3)$ & $34(43,6)$ & $11(14,1)$ & & $100(64,1)$ & $56(35,9)$ & \\
\hline
\end{tabular}

$\mathrm{n}=$ quantidade de pacientes; $\mathrm{M}=$ metionina; $\mathrm{V}=$ valina; $p=$ valor- $\mathrm{p}$; $\mathrm{DA}=$ doença de Alzheimer 
Tabela 4. Análise dos genótipos do códon 129 em homozigose e heterozigose em diferentes subgrupos da amostra.

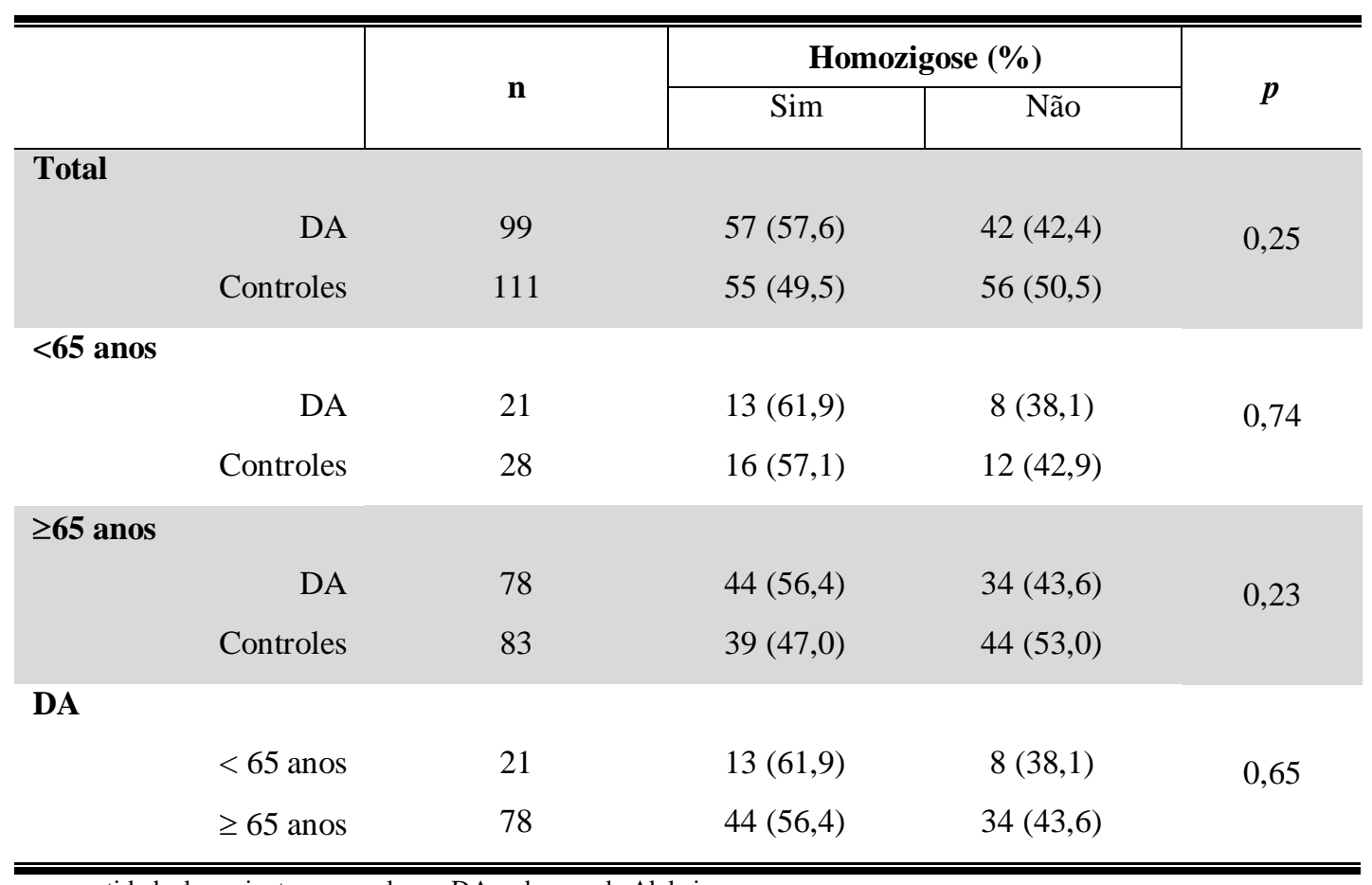

$\mathrm{n}=$ quantidade de pacientes; $p=$ valor-p; DA = doença de Alzheimer

Tabela 5. Equilíbrio de Hardy-Weinberg dos diferentes genótipos do códon 129 nos subgrupos da amostra.

\begin{tabular}{|c|c|c|c|c|c|}
\hline & \multirow{2}{*}{$\mathbf{n}$} & \multicolumn{3}{|c|}{ Genótipo do códon 129 (\%) } & \multirow[b]{2}{*}{$p$} \\
\hline & & $\mathrm{M} / \mathrm{M}$ & $\mathrm{M} / \mathrm{V}$ & $\mathrm{V} / \mathrm{V}$ & \\
\hline \multicolumn{6}{|l|}{ DA } \\
\hline Total & 99 & $45(45,5)$ & $42(42,2)$ & $12(12,1)$ & 0,651 \\
\hline$<65$ anos & 21 & $12(57,1)$ & $8(38,1)$ & $1(4,8)$ & 0,819 \\
\hline$\geq 65$ anos & 78 & $33(42,3)$ & $34(43,6)$ & $11(14,1)$ & 0,641 \\
\hline \multicolumn{6}{|l|}{ Controles } \\
\hline Total & 111 & $44(39,6)$ & $56(50,5)$ & $11(9,9)$ & 0,260 \\
\hline$<65$ anos & 28 & $14(50,0)$ & $12(42,9)$ & $2(7,1)$ & 0,791 \\
\hline$\geq 65$ anos & 83 & $30(36,1)$ & $44(53,0)$ & $9(10,8)$ & 0,226 \\
\hline
\end{tabular}




\subsection{Desempenho nos testes cognitivos e genótipo do códon 129}

O desempenho nos testes cognitivos em relação ao genótipo do códon 129 foi avaliado no grupo com DA e no grupo controle de duas maneiras: comparação entre as medidas de tendência central da pontuação obtida em cada teste e regressão logística, após análise bivariada.

Os dados do desempenho no MEEM estavam disponíveis para 92 pacientes com DA e 66 controles. Os dados de FV estavam disponíveis para 70 pacientes com DA e 66 controles.

Para a análise bivariada, o ponto para dicotomização dos grupos foi a mediana no desempenho de cada teste cognitivo.

4.3.1 Comparação entre as medidas de tendência central dos testes cognitivos no grupo DA

A mediana do desempenho no teste do MEEM foi significativamente melhor nos pacientes com genótipo V129V. Os pacientes com genótipo M/V apresentaram desempenho intermediário no MEEM e os pacientes com genótipo M129M apresentaram o pior desempenho no MEEM. Houve também diferença com significância estatística quanto à mediana do tempo de doença, sendo que os pacientes com genótipo V129V apresentavam menor tempo de doença, os pacientes M129M apresentavam maior tempo de doença e os pacientes M129V, tempo intermediário de doença. As demais variáveis não diferiram entre os grupos, inclusive o desempenho no teste de FV. (Tabela 6) 
Tabela 6. Desempenho nos testes cognitivos e aspectos demográficos do grupo com DA segundo genótipo do códon 129.

\begin{tabular}{c|c|c|c|c|c}
\hline \hline MEEM & $\mathbf{n}$ & Média (DP) & Mediana & Intervalo & $\boldsymbol{p}$ \\
\hline M/M & 44 & $14,8(6,1)$ & 16,5 & $0-24$ & \\
M/V & 36 & $18,1(4,9)$ & 19,0 & $3-25$ & $\mathbf{0 , 0 0 6}^{*}$ \\
V/V & 12 & $19,5(5,7)$ & 21,0 & $6-26$ & \\
& & & & \\
\hline
\end{tabular}

grupo 1 versus grupo $2 p<0,001$; grupo 2 versus grupo $3 p<0,001$; grupo 1 versus grupo $3 p<0,001$

\begin{tabular}{|c|c|c|c|c|c|}
\hline FV & $\mathbf{N}$ & Média (DP) & Mediana & Intervalo & $p$ \\
\hline $\mathrm{M} / \mathrm{M}$ & 33 & $7,0(3,7)$ & 7,0 & $0-15$ & \multirow{3}{*}{0,077} \\
\hline $\mathrm{M} / \mathrm{V}$ & 27 & $8,6(3,9)$ & 8,0 & $0-18$ & \\
\hline $\mathrm{V} / \mathrm{V}$ & 10 & $9,9(4,4)$ & 11,0 & $2-15$ & \\
\hline \multicolumn{6}{|c|}{ Tempo de doença } \\
\hline $\mathrm{M} / \mathrm{M}$ & 44 & $35,1(20,4)$ & 33,0 & $6-96$ & \multirow{3}{*}{$\mathbf{0 , 0 2 2}$} \\
\hline $\mathrm{M} / \mathrm{V}$ & 35 & $25,4(18,7)$ & 24,0 & $6-72$ & \\
\hline $\mathrm{V} / \mathrm{V}$ & 12 & $28,5(20,3)$ & 21,0 & $12-72$ & \\
\hline
\end{tabular}

grupo 1 versus grupo $2 p<0,001$ grupo 2 versus grupo $3 p<0,001$ grupo 1 versus grupo $3 p<0,001$

\begin{tabular}{cccccccc}
\hline Idade & & $\mathbf{N}$ & Média (DP) & Mediana & Intervalo & $\boldsymbol{p}$ \\
\hline $\mathrm{M} / \mathrm{M}$ & 44 & $71,2(9,5)$ & 73,5 & $50-90$ & \\
$\mathrm{M} / \mathrm{V}$ & 36 & $73,9(9,3)$ & 75,5 & $52-87$ & $0,393^{*}$ \\
$\mathrm{~V} / \mathrm{V}$ & 12 & $73,0(8,7)$ & 73,5 & $51-88$ & \\
\hline
\end{tabular}

Escolaridade

\begin{tabular}{cccccc|c}
\hline & M/M & 44 & $6,6(5,7)$ & 4 & $0-17$ & \\
& M/V & 35 & $6,2(5,2)$ & 4 & $0-17$ & \multirow{2}{*}{$0,922^{*}$} \\
& V/V & 12 & $4,9(3,3)$ & 4 & $2-15$ & \multicolumn{1}{c}{$\boldsymbol{p}$} \\
\hline Sexo & & N & Feminino & Masculino & & \multirow{2}{*}{0,369} \\
& M/M & 44 & $29(65,9)$ & $15(34,1)$ & & \\
& M/V & 36 & $22(61,1)$ & $14(38,9)$ & & \\
& V/V & 12 & $10(83,3)$ & $2(16,7)$ & & \\
\hline \hline
\end{tabular}

$\mathrm{n}=$ quantidade de pacientes; $p=$ valor-p; $\mathrm{DP}=$ desvio padrão; $\mathrm{M}=$ metionina; $\mathrm{V}=$ valina; $\mathrm{DA}=$ doença de Alzheimer; $\mathrm{FV}=$ fluência verbal; * Kruskal Wallis

4.3.2 Comparação entre as medidas de tendência central dos testes cognitivos no grupo controle

Não houve diferença com significância estatística entre os diferentes genótipos do códon 129 em relação ao desempenho nos testes cognitivos estudados, 
no grupo controle. Houve predomínio do sexo masculino no genótipo M/V nesta amostra da população controle, sendo que a distribuição entre os diferentes genótipos do códon 129 no sexo masculino não respeita o equilíbrio de Hardy-Weinberg ( $p=0,017)$. As demais variáveis também não diferiram entre os grupos (Tabela 7).

Tabela 7. Desempenho nos testes cognitivos e aspectos demográficos do grupo controle segundo genótipo do códon 129.

\begin{tabular}{|c|c|c|c|c|c|}
\hline & $\mathbf{n}$ & Média (DP) & Mediana & Intervalo & $p$ \\
\hline \multicolumn{6}{|l|}{ MEEM } \\
\hline $\mathrm{M} / \mathrm{M}$ & 27 & $27,3(2,0)$ & 28 & $21-30$ & \multirow{3}{*}{$0,930 *$} \\
\hline $\mathrm{M} / \mathrm{V}$ & 33 & $27,5(1,9)$ & 28 & $23-30$ & \\
\hline $\mathrm{V} / \mathrm{V}$ & 6 & $26,8(3,6)$ & 28 & $20-30$ & \\
\hline \multicolumn{6}{|l|}{ FV } \\
\hline $\mathrm{M} / \mathrm{M}$ & 27 & $17,0(4,1)$ & 15,0 & $12-25$ & \multirow{3}{*}{$0,986^{*}$} \\
\hline $\mathrm{M} / \mathrm{V}$ & 33 & $17,0(3,6)$ & 17,0 & $12-24$ & \\
\hline $\mathrm{V} / \mathrm{V}$ & 6 & $16,8(1,9)$ & 16,5 & $15-20$ & \\
\hline \multicolumn{6}{|l|}{ Idade } \\
\hline $\mathrm{M} / \mathrm{M}$ & 27 & $68,2(7,2)$ & 66,0 & $57-81$ & \multirow{3}{*}{$0,490 *$} \\
\hline $\mathrm{M} / \mathrm{V}$ & 33 & $70,4(7,2)$ & 70,0 & $60-90$ & \\
\hline $\mathrm{V} / \mathrm{V}$ & 6 & $70,0(5,3)$ & 71,5 & $60-74$ & \\
\hline \multicolumn{6}{|c|}{ Escolaridade } \\
\hline $\mathrm{M} / \mathrm{M}$ & 27 & $7,6(4,4)$ & 8,0 & $0-16$ & \multirow{3}{*}{0,634} \\
\hline $\mathrm{M} / \mathrm{V}$ & 33 & $6,9(4,0)$ & 7,0 & $0-16$ & \\
\hline $\mathrm{V} / \mathrm{V}$ & 6 & $5,8(4,4)$ & 4,5 & $0-11$ & \\
\hline Sexo & n & Feminino & Masculino & & $p$ \\
\hline $\mathrm{M} / \mathrm{M}$ & 27 & $23(85,2)$ & $4(14,8)$ & & \multirow{3}{*}{0,028} \\
\hline $\mathrm{M} / \mathrm{V}$ & 33 & $18(54,5)$ & $15(45,5)$ & & \\
\hline $\mathrm{V} / \mathrm{V}$ & 6 & $5(83,3)$ & $1(16,7)$ & & \\
\hline
\end{tabular}

$\mathrm{n}=$ quantidade de controles; $\mathrm{DP}=$ desvio padrão; $p$ = valor-p; MEEM = miniexame do estado mental; FV = fluência verbal; $\mathrm{M}=$ metionina; $\mathrm{V}=$ valina; * Kruskal Wallis 
4.3.3 Análise bivariada e regressão logística dos grupos DA e controle em relação ao desempenho nos testes cognitivos

Para a análise bivariada, a nota de corte estabelecida nos testes cognitivos foi a mediana da amostra (Tabela 8).

Tabela 8. Estatística descritiva dos testes cognitivos dos grupos DA e controle.

\begin{tabular}{|c|c|c|c|}
\hline Teste & DA & Controles & $p^{*}$ \\
\hline MEEM & & & $<0,001$ \\
\hline $\mathrm{n}$ & 92 & 66 & \\
\hline média (DP) & $16,7(5,9)$ & $27,3(2,1)$ & \\
\hline Mediana & 18 & 28 & \\
\hline mín - máx & $0-26$ & $20-30$ & \\
\hline Fluência Verbal & & & $<0,001$ \\
\hline $\mathrm{n}$ & 70 & 66 & \\
\hline média (DP) & $8,0(3,9)$ & $17,0(3,7)$ & \\
\hline Mediana & 7 & 17 & \\
\hline mín - máx & $0-18$ & $12-25$ & \\
\hline
\end{tabular}

\section{A) Análise bivariada e regressão logística dos pacientes com DA e desempenho no teste do MEEM}

Dentre os 92 pacientes com DA e resultado conhecido para o MEEM, 49 obtiveram escore igual ou superior ao valor mediano 18 (Prevalência: 53,3\%; IC95\%: 42,6-63,7).

À análise bivariada para o desfecho "valor igual ou superior ao valor mediano no MEEM”, não foi observada associação com significância estatística para sexo e 
idade dos pacientes, tampouco para os diferentes genótipos do códon 129 do PRNP (Tabela 9).

Verificou-se, entretanto, que os pacientes com melhor resultado cognitivo possuíam menos tempo de doença quando comparados aqueles com piores escores $(p=0,003)$ e pacientes com escolaridade menor do que 4 anos apresentavam pior desempenho no MEEM $(p<0,001)$ (Tabela 9).

Tabela 9. Pacientes com DA e desempenho no teste do MEEM.

\begin{tabular}{|c|c|c|c|}
\hline \multirow{2}{*}{ Variáveis } & \multicolumn{2}{|c|}{ MEEM } & \multirow{2}{*}{$p$} \\
\hline & $<18$ & $\geq 18$ & \\
\hline Sexo & & & 0,510 \\
\hline Masculino & $13(30,2)$ & $18(36,7)$ & \\
\hline Feminino & $30(69,8)$ & $31(63,3)$ & \\
\hline Idade (anos) & & & 0,466 \\
\hline$<65$ & $11(25,6)$ & $9(18,4)$ & \\
\hline 65 a 74 & $11(25,6)$ & $18(36,7)$ & \\
\hline$\geq 75$ & $21(48,8)$ & $22(44,9)$ & \\
\hline Escolaridade (anos) & & & $<0,001$ \\
\hline$<4$ & $21(50,0)$ & $8(16,4)$ & \\
\hline$\geq 4$ & $21(50,0)$ & $41(83,6)$ & \\
\hline Genótipo do códon 129 & & & 0,108 \\
\hline $\mathrm{M} / \mathrm{M}$ & $25(58,1)$ & $19(38,8)$ & \\
\hline $\mathrm{M} / \mathrm{V}$ & $15(34,9)$ & $21(42,8)$ & \\
\hline $\mathrm{V} / \mathrm{V}$ & $3(7,0)$ & $9(18,4)$ & \\
\hline Tempo de doença (meses) ${ }^{\#}$ & & & $\mathbf{0 , 0 0 3}$ \\
\hline$\leq 36$ & $27(64,3)$ & $44(89,8)$ & \\
\hline$>36$ & $15(35,7)$ & $5(10,2)$ & \\
\hline Total & $43(100)$ & $49(100)$ & \\
\hline
\end{tabular}

Com a finalidade de identificar as variáveis independentemente associadas ao melhor desempenho no MEEM, procedeu-se à análise de regressão logística 
utilizando todas as variáveis que apresentaram valores de $p$ menores que 0,25 à análise bivariada.

O modelo de regressão múltipla mostrou que o melhor desempenho no MEEM, na amostra estudada de indivíduos com DA, esteve independentemente associado ao tempo de diagnóstico da doença $(p<0,001)$ e à escolaridade do paciente $(p<0,001)($ Tabela 10).

Tabela 10. Análise de regressão logística para fatores associados ao melhor desempenho cognitivo no MEEM em indivíduos com DA.

\begin{tabular}{l|c|c|c}
\hline \hline Variáveis & OR $_{\mathbf{b r}}$ & OR $_{\text {aj }}(\mathbf{I C 9 5 \%})$ & $\boldsymbol{p}$ \\
\hline $\begin{array}{l}\text { Tempo da doença (meses) } \\
\quad>36\end{array}$ & 1,0 & & $<\mathbf{0 , 0 0 1}$ \\
$\quad \leq 36$ & 4,9 & 1,0 & \\
$\quad \begin{array}{l}\text { Escolaridade (anos) } \\
\quad<4\end{array}$ & 1,0 & & \\
$\quad \geq 4$ & 5,1 & $7,4(2,2-25,1)$ & \\
\hline \hline
\end{tabular}

$\mathrm{OR}_{\mathrm{BR}}=$ "odds ratio" bruto; $\mathrm{OR}_{\mathrm{aj}}=$ "odds ratio" ajustado; $p=$ valor-p; $\mathrm{IC}=$ intervalo de confiança

B) Análise bivariada e regressão logística dos pacientes com DA e desempenho no teste de FV

Setenta pacientes com DA apresentavam resultado para o teste de FV. Dentre estes, 45 obtiveram escore igual ou superior ao valor mediano 7 (Prevalência: 64,3\%; IC95\%: 51,9-75,4).

O desempenho no teste não apresentou associação estatisticamente 
significativa com sexo, idade, escolaridade e tempo de doença dos pacientes, tampouco com o genótipo do códon 129 do PRNP (Tabela 11).

Tabela 11. Pacientes com DA e desempenho no teste de FV

\begin{tabular}{|c|c|c|c|}
\hline \multirow{2}{*}{ Variáveis } & \multicolumn{2}{|c|}{ FV } & \multirow{2}{*}{$p$} \\
\hline & $<7$ & $\geq 7$ & \\
\hline \multicolumn{3}{|l|}{ Sexo } & \multirow[t]{3}{*}{0,174} \\
\hline Masculino & $10(40,0)$ & $11(24,4)$ & \\
\hline Feminino & $15(60,0)$ & $34(75,6)$ & \\
\hline \multicolumn{3}{|l|}{ Idade (anos) } & \multirow[t]{4}{*}{0,389} \\
\hline$<65$ & $5(20,0)$ & $8(17,8)$ & \\
\hline 65 a 74 & $6(24,0)$ & $18(40,0)$ & \\
\hline$\geq 75$ & $14(56,0)$ & $19(42,2)$ & \\
\hline \multicolumn{3}{|l|}{ Escolaridade (anos) } & \multirow[t]{3}{*}{0,496} \\
\hline$<4$ & $8(32,0)$ & $11(24,4)$ & \\
\hline$\geq 4$ & $17(68,0)$ & $34(75,6)$ & \\
\hline \multicolumn{3}{|l|}{ Genótipo do códon 129} & \multirow[t]{4}{*}{0,409} \\
\hline $\mathrm{M} / \mathrm{M}$ & $14(56,0)$ & $19(42,2)$ & \\
\hline $\mathrm{M} / \mathrm{V}$ & $9(36,0)$ & $18(40,0)$ & \\
\hline $\mathrm{V} / \mathrm{V}$ & $2(8,0)$ & $8(17,8)$ & \\
\hline \multicolumn{3}{|l|}{ Tempo de doença (meses) } & \multirow[t]{3}{*}{0,384} \\
\hline$\leq 36$ & $6(24,0)$ & $7(15,6)$ & \\
\hline$>36$ & $19(76,0)$ & $38(84,4)$ & \\
\hline Total & $25(100)$ & $45(100)$ & \\
\hline
\end{tabular}

$\mathrm{FV}=$ fluência verbal; $p=$ valor-p; $\mathrm{M}=$ metionina; $\mathrm{V}=$ valina

\section{C) Análise bivariada e regressão logística dos controles e desempenho no teste do MEEM}

Dos 111 indivíduos cognitivamente normais incluídos neste estudo, 66 $(59,5 \%)$ apresentavam resultado para o teste de MEEM. Destes, 39 tinham escore igual ou superior ao valor mediano 28 (Prevalência: 59,1\%; IC95\%: 46,3 - 71,0). 
À análise bivariada para o desfecho "valor igual ou superior ao valor mediano no MEEM”, não foi observada associação com significância estatística para sexo e genótipo do códon 129 do PRNP. Embora sem significância estatística $(p=0,060)$, os dados sugerem que os indivíduos com pior desempenho no MEEM eram mais velhos que os demais. Além disso, verificou-se também que a escolaridade era maior $(p<0,001)$ dentre os que apresentaram resultado igual ou superior a 28 no MEEM (Tabela 12).

Tabela 12. Controles e desempenho no teste do MEEM

\begin{tabular}{|c|c|c|c|}
\hline \multirow{2}{*}{ Variáveis } & \multicolumn{2}{|c|}{ MEEM } & \multirow{2}{*}{$p$} \\
\hline & $<28$ & $\geq 28$ & \\
\hline \multicolumn{3}{|l|}{ Sexo } & 0,125 \\
\hline Masculino & $11(40,7)$ & $9(23,1)$ & \\
\hline Feminino & $16(59,3)$ & $30(76,9)$ & \\
\hline \multicolumn{3}{|l|}{ Idade (anos) } & 0,060 \\
\hline$<65$ & $6(22,2)$ & $15(38,5)$ & \\
\hline 65 a 74 & $10(37,1)$ & $18(46,1)$ & \\
\hline$\geq 75$ & $11(40,7)$ & $6(15,4)$ & \\
\hline \multicolumn{4}{|l|}{ Escolaridade (anos) } \\
\hline$<6,5$ & $22(81,5)$ & $11(28,2)$ & $<0,001$ \\
\hline$\geq 6,5$ & $5(18,5)$ & $28(71,8)$ & \\
\hline \multicolumn{4}{|l|}{ Genótipo do códon 129} \\
\hline $\mathrm{M} / \mathrm{M}$ & $12(44,4)$ & $15(38,4)$ & 0,855 \\
\hline $\mathrm{M} / \mathrm{V}$ & $13(48,2)$ & $20(51,3)$ & \\
\hline $\mathrm{V} / \mathrm{V}$ & $2(7,4)$ & $4(10,3)$ & \\
\hline Total & $27(100)$ & $39(100)$ & \\
\hline
\end{tabular}

O modelo de regressão múltipla identificou, na amostra estudada do grupo controle, apenas a variável escolaridade como independentemente associada ao melhor desempenho no MEEM. Indivíduos com escolaridade igual ou superior a 6,5 
anos apresentaram OR=11,2 (IC95\%: 3,4 - 37,0) em relação a melhor desempenho no MEEM.

\section{D) Análise bivariada e regressão logística dos controles e desempenho do teste de FV}

Dos 111 indivíduos cognitivamente normais incluídos neste estudo, 66 (59,5\%) apresentavam resultado para o teste de FV. Desta amostra, 35 (Prevalência: 53,0\%; IC95\%: 40,3 - 65,4) apresentaram escore igual ou superior ao valor mediano 17.

À análise bivariada observou-se que os indivíduos com melhor desempenho no teste de fluência verbal possuíam maior escolaridade (Tabela 13).

Tabela 13. Controles e desempenho no teste de FV.

\begin{tabular}{|c|c|c|c|}
\hline \multirow{2}{*}{ Variáveis } & \multicolumn{2}{|c|}{ FV } & \multirow{2}{*}{$p$} \\
\hline & $<17$ & $\geq 17$ & \\
\hline Sexo & & & 0,833 \\
\hline Masculino & $9(29,0)$ & $11(31,4)$ & \\
\hline Feminino & $22(71,0)$ & $24(68,6)$ & \\
\hline Idade (anos) & & & 0,223 \\
\hline$<65$ & $8(25,8)$ & $13(37,1)$ & \\
\hline 65 a 74 & $12(38,7)$ & $16(45,7)$ & \\
\hline$\geq 75$ & $11(35,5)$ & $6(17,1)$ & \\
\hline \multicolumn{4}{|l|}{ Escolaridade (anos) } \\
\hline$<6,5$ & $21(67,7)$ & $12(34,3)$ & $\mathbf{0 , 0 0 7}$ \\
\hline$\geq 6,5$ & $10(32,3)$ & $23(65,7)$ & \\
\hline \multicolumn{4}{|l|}{ Genótipo } \\
\hline $\mathrm{M} / \mathrm{M}$ & $14(45,2)$ & $13(37,1)$ & 0,758 \\
\hline $\mathrm{M} / \mathrm{V}$ & $14(45,2)$ & $19(54,3)$ & \\
\hline $\mathrm{V} / \mathrm{V}$ & $3(9,6)$ & $3(8,6)$ & \\
\hline Total & $31(100)$ & $35(100)$ & \\
\hline
\end{tabular}


O modelo de regressão múltipla identificou, na amostra estudada do grupo controle, apenas a variável escolaridade como independentemente associada ao melhor desempenho no teste de FV. Indivíduos com escolaridade igual ou superior a 6,5 anos apresentaram $\mathrm{OR}=4,0$ (IC95\%: 1,4 - 11,2) em relação a melhor desempenho no teste de FV.

\subsection{Extratificação do polimorfismo do códon 129 do $P R N P$ em relação ao alelo $\varepsilon 4$ do gene da apoE}

Não houve diferença entre a frequência dos diferentes polimorfismos do $P R N P$ em relação à presença do alelo $\varepsilon 4$ entre os grupos DA e indivíduos cognitivamente normais (Tabela 14). Nessa subamostra, a presença do alelo $\varepsilon 4$ foi associada à DA (Tabela 15).

Tabela 14. Extratificação dos genótipos do códon 129 em pacientes com DA e controles em relação ao genótipo da apoE.

\begin{tabular}{|c|c|c|c|c|}
\hline & M/M (\%) & $\mathrm{M} / \mathrm{V}(\%)$ & $\mathrm{V} / \mathrm{V}(\%)$ & $p$ \\
\hline ApoE $\varepsilon 4+$ & & & & \\
\hline $\begin{array}{r}\text { DA } \\
\text { Controles }\end{array}$ & $\begin{array}{c}19(46,3) \\
6(35,3)\end{array}$ & $\begin{array}{l}19(46,3) \\
10(58,9)\end{array}$ & $\begin{array}{l}3(7,3) \\
1(5,9)\end{array}$ & $0,81^{*}$ \\
\hline $\begin{array}{r}\text { ApoE } \varepsilon 4- \\
\text { DA } \\
\text { Controles }\end{array}$ & $\begin{array}{l}17(42,5) \\
29(37,7)\end{array}$ & $\begin{array}{l}17(42,5) \\
40(51,9)\end{array}$ & $\begin{array}{c}6(15) \\
8(10,4)\end{array}$ & 0,57 \\
\hline
\end{tabular}

M = metionina; $\mathrm{V}$ = valina; $p$ = valor-p; DA = doença de Alzheimer; *: teste exato de Fisher; 
Tabela 15. Genótipo da apoE nos pacientes com DA e controles.

\begin{tabular}{l|c|c|c}
\hline \hline & DA (\%) & Controles (\%) & $p$ \\
\hline apoE $\boldsymbol{\varepsilon 4 +}$ & $41(50,6)$ & $17(18,1)$ & $<0,0001$ \\
\hline apoE $\boldsymbol{\varepsilon 4 - ~}$ & $40(49,4)$ & $77(81,9)$ \\
& & \\
\hline \hline DA = doença de Alzheimer; $p$ = valor-p
\end{tabular}




\section{DISCUSSÃO}




\section{DISCUSSÃO}

\subsection{Polimorfismos do códon 117, 171 e da região de 5 octapeptídeos repetidos}

O códon 117 apresentou polimorfismo silencioso em cinco $(5,1 \%)$ pacientes com DA e três $(2,7 \%)$ indivíduos controles. Esse polimorfismo é descrito em cerca de 4 a 6\% da população normal branca (Georgsson et al., 2006; Bishop et al., 2009).

O polimorfismo N171S não foi encontrado na amostra estudada. Em pacientes brasileiros com epilepsia sintomática secundária a malformações corticais, esse polimorfismo ocorreu em 6,2\% dos casos (Walz et al., 2007).

A deleção de um octapeptídeo repetido em heterozigose foi encontrada em cinco $(5,1 \%)$ pacientes com DA e quatro $(3,6 \%)$ indivíduos controles. A frequência desse polimorfismo em outros estudos é menor, variando de 0 a $1,5 \%$ na população branca (Georgsson et al., 2006; Bishop et al., 2009).

A frequência aparentemente aumentada de deleção de um octapeptídeo repetido em heterozigose em relação a outros estudos em população caucasiana também ocorreu no estudo com pacientes com epilepsia sintomática secundária a mal formações corticais, sendo $5,7 \%$ no grupo controle e $5 \%$ no grupo de pacientes (Walz et al., 2004). É possível que essa frequência seja característica de nossa população. Estudos genéticos populacionais são necessários para determinar a frequência dos diversos polimorfismos do PRNP em nosso meio. 


\subsection{Polimorfismo do códon 129}

Este é o primeiro estudo que analisa o polimorfismo do códon 129 do PRNP em pacientes com DA em população brasileira.

A população analisada é representativa da população brasileira em relação à distribuição dos diferentes genótipos do códon 129. A Tabela 16 apresenta a comparação entre a proporção dos genótipos da população controle deste estudo e da população brasileira (de Paula et al., 2005)

Tabela 16. Distribuição dos genótipos do códon 129 na população brasileira e neste estudo.

\begin{tabular}{l|c|c|c|c}
\hline \hline & \multirow{2}{*}{$\mathbf{n}$} & \multicolumn{3}{|c}{ Genótipo do códon 129 (N) } \\
\cline { 3 - 5 } & & M/M & M/V & V/V \\
\hline de Paula et al. (2005) & 191 & 46 & 48 & 6 \\
Este estudo & 111 & 44 & 56 & 11 \\
\hline \hline
\end{tabular}

$\mathrm{n}=$ quantidade de pacietnes; $\mathrm{M}=$ metionina; $\mathrm{V}=$ valina

A associação entre os diversos polimorfismos do códon 129 e a DA é assunto controverso na literatura médica. Alguns estudos com grupo de indivíduos idosos ou voluntários saudáveis mostraram associação entre o desempenho cognitivo e o genótipo do códon 129 do PRNP. Diversos estudos buscaram estabelecer a associação entre DA e os diferentes polimorfismos do códon 129, com resultados discrepantes:

Em estudo em população de indivíduos cognitivamente normais, o desempenho em testes cognitivos foi pior nos que tinham o genótipo M129M 
(Rujescu et al., 2003). Estudo em população idosa francesa associou a homozigose para valina o pior desempenho no teste do MEEM, com OR de 2,68 para declínio cognitivo em pacientes V129V (Berr et al., 1998). Nesta mesma população, idosos cognitivamente normais, que apresentavam pelo menos um alelo $\mathrm{V}$ e foram submetidos ao exame anatomopatológico, apresentavam maior carga de lesões amilóides do que os indivíduos M129M (Berr et al., 2003).

Este achado também foi corroborado na população do estudo epidemiológico de Roterdã, onde os indivíduos com idade entre 55 e 64 anos com V129V apresentaram maior declínio cognitivo após média de 6,5 anos de seguimento. Também houve maior incidência de demência nos indivíduos V129V (Croes et al., 2003).

Os primeiros estudos que compararam pacientes com DA e controles quanto ao polimorfismo do códon 129 não mostraram distribuição genotípica diferente nos pacientes com DA (Combarros et al., 2000; Casadei et al., 2001). Na casuística de Casadei e colaboradores, entretanto, os pacientes com pelo menos um alelo V apresentavam início da doença mais precoce e deterioração mais rápida do quadro demencial (Casadei et al., 2001).

Estudo posterior em população americana não encontrou associação entre os polimorfismos e DA (Li et al., 2005). Estudo caso-controle em população italiana não demonstrou associação entre o códon 129 e DA, porém os pacientes V129V apresentaram maior taxa de declínio cognitivo (Del Bo et al., 2006). Del Bo e colaboradores realizaram metanálise que evidenciou modesta associação entre homozigose (M129M e V129V) e DA, com OR =1,29 (IC95\% = 1,0-1,6, $p=0,05)$, na 
população caucasiana. Também houve associação modesta entre o alelo M e o genótipo M129M e DA, independentemente do grupo étnico (Del Bo et al., 2006).

Em algumas populações europeias, o polimorfismo do códon 129 do PRNP foi associado a maior risco de DA. Em análise restrita a pacientes com DAPS, pacientes com história familiar para DA (em parentes de primeiro grau) e homozigose (M129M ou V129V) no códon 129 apresentavam maior risco de DA, sendo que a associação foi mais forte em pacientes V129V. Os pacientes sem história familiar (n=44) não apresentaram diferenças na distribuição dos genótipos do códon 129 do PRNP (Dermaut et al., 2003).

Em estudo em população alemã, a homozigose para metionina representou fator de risco genético para ocorrência de DAPS, porém sem associação com DAS (Riemenschneider et al., 2004).

A homozigose para metionina esteve associada ao risco de DAS em estudo polonês, sendo que não foi encontrada tal associação em pacientes com DAPS na mesma amostra (Gacia et al., 2006).

Em populações asiáticas, os diferentes polimorfismos do códon 129 não estão associados com DA. É possível que essa diferença esteja associada à origem étnica diferente dessa população quando comparada aos grupos europeus. O genótipo V129V é extremamente infrequente nas populações asiáticas e não é encontrado na maioria dos estudos genéticos dessa região (Ohkubo et al., 2003; Jeong et al., 2005; Ahn et al., 2006; Jeong et al., 2007; Wang et al., 2007).

Estudo cooperativo recente entre EUA e Itália que analisou nova casuística italiana não encontrou associação entre o códon 129 e DA. Esse estudo analisou também 109 casos de DA definida e 58 controles com confirmação 
anatomopatológica, descartando associação relevante entre o códon 129 do PRNP e DA (Poleggi et al., 2008).

No presente estudo, não houve associação entre o polimorfismo do códon 129 e DA, havendo concordância com a maioria dos estudos na literatura médica atual. A Tabela 17 resume os resultados dos principais estudos publicados, além dos resultados deste estudo.

Alguns trabalhos apontam para possível associação entre DAPS e os polimorfismos do códon 129, o que motivou a realização de duas subanálises: 1) comparação de pacientes com DAS em relação a pacientes com DAPS; 2) comparação dos grupos de pacientes com DAS e DAPS e seus respectivos grupos controle, pareados para idade. Não houve associação entre DAPS ou DAS e os polimorfismos do códon 129 do PRNP nesta casuística.

A comparação entre homozigotos e heterozigotos também não se mostrou diferente entre os grupos DA e controle, tampouco entre os diferentes subgrupos analisados. A frequência dos alelos $\mathrm{M}$ e $\mathrm{V}$ também foi verificada nos diferentes grupos, não havendo diferença estatisticamente significativa entre os alelos e a ocorrência de DA. 
Tabela 17. Resultado dos estudos caso-controle sobre associação do genótipo do códon 129 do PRNP em pacientes com DA esporádica (modificado de Poleggi et al., 2008).

\begin{tabular}{|c|c|c|c|c|c|c|c|}
\hline \multirow{2}{*}{ Referência } & \multirow[b]{2}{*}{ País } & \multirow{2}{*}{$\begin{array}{c}\text { Amostra } \\
\text { (n) }\end{array}$} & \multirow{2}{*}{$\begin{array}{c}\text { Idade } \\
\text { media } \\
\text { (anos) } \\
\text { (DP) }\end{array}$} & \multicolumn{3}{|c|}{ Códon $129(\%)$} & \multirow{2}{*}{$\begin{array}{c}\text { Associação } \\
\text { com DA } \\
\text { esporádica }\end{array}$} \\
\hline & & & & $\mathbf{M} / \mathbf{M}$ & $\mathbf{M} / \mathbf{V}$ & $\mathbf{V} / \mathbf{V}$ & \\
\hline \multirow{2}{*}{$\begin{array}{l}\text { Combarros et al. } \\
(2000)\end{array}$} & \multirow[t]{2}{*}{ Espanha } & DA provável (278) & $72(9)$ & 43 & 45 & 12 & Sem \\
\hline & & Controles (268) & $80(8)$ & 42 & 42 & 16 & associação \\
\hline \multirow{2}{*}{$\begin{array}{l}\text { Casadei et al. } \\
\text { (2001) }\end{array}$} & \multirow[t]{2}{*}{ Itália } & DA provável (212) & $68(8)$ & 59 & 35 & 6 & Sem \\
\hline & & Controles (201) & $67(10)$ & 51 & 39 & 10 & associação \\
\hline \multirow{2}{*}{$\begin{array}{l}\text { Dearmaut et al. } \\
\text { (2003) }\end{array}$} & \multirow[t]{2}{*}{ Holanda } & DAPS provável (44) & ND & 39 & 47 & 14 & Sem \\
\hline & & Controles (282) & $61(55-66)$ & 40 & 50 & 10 & associação \\
\hline \multirow{2}{*}{$\begin{array}{l}\text { Ohkubo et al. } \\
\text { (2003) }\end{array}$} & \multirow[t]{2}{*}{ Japão } & DA provável (548) & $70(9)$ & 93 & 7 & 0 & Sem \\
\hline & & Controles (466) & $68(10)$ & 94 & 6 & 0 & associação \\
\hline \multirow{2}{*}{$\begin{array}{l}\text { Golanska et al. } \\
\text { (2004) }\end{array}$} & \multirow[t]{2}{*}{ Polônia } & DA provável (79) & ND & 51 & 33 & 16 & Homozigose \\
\hline & & Controles (107) & $73-74$ & 36 & 56 & 8 & \\
\hline \multirow{3}{*}{$\begin{array}{l}\text { Riemenschneider } \\
\text { et al. (2004) }\end{array}$} & \multirow[t]{3}{*}{ Alemanha } & DA provável (482) & $70(10)$ & 48 & 41 & 11 & Homozigose \\
\hline & & Controles (189) & $67(12)$ & 40 & 47 & 13 & para metionina \\
\hline & & Controles (722) & $64(8)$ & 41 & 45 & 14 & em DAPS \\
\hline \multirow[t]{2}{*}{$\begin{array}{l}\text { Li et al. } \\
\text { (2005) }\end{array}$} & \multirow[t]{2}{*}{ EUA } & $\begin{array}{l}\text { DA possível/provável } \\
\text { (281) }\end{array}$ & $70(11)$ & 50 & 42 & 8 & $\begin{array}{l}\text { Sem } \\
\text { associação }\end{array}$ \\
\hline & & Controles (415) & $72(13)$ & 50 & 42 & 8 & \\
\hline \multirow{2}{*}{$\begin{array}{l}\text { Ahn et al. } \\
(2006)\end{array}$} & \multirow[t]{2}{*}{ Coreia } & DA provável (297) & $73(9)$ & 93 & 7 & 0 & Sem \\
\hline & & Controles (217) & $67(7)$ & 95 & 5 & 0 & associação \\
\hline \multirow{2}{*}{$\begin{array}{l}\text { Del Bo et al. } \\
\text { (2006) }\end{array}$} & \multirow[t]{2}{*}{ Itália } & DA provável (258) & $75(7)$ & 45 & 45 & 10 & Sem \\
\hline & & Controles (318) & $72(11)$ & 44 & 47 & 9 & associação \\
\hline \multirow{3}{*}{$\begin{array}{l}\text { Gacia et al. } \\
(2006)\end{array}$} & \multirow[t]{3}{*}{ Polônia } & DAPS provável (53) & $52(9)$ & 49 & 38 & 13 & Homozigose \\
\hline & & DAS provável (113) & $72(4)$ & 56 & 33 & 11 & para metionina \\
\hline & & Controles (194) & $73(5)$ & 38 & 53 & 9 & em DAS \\
\hline \multirow{2}{*}{$\begin{array}{l}\text { Jeong et al. } \\
(2007)\end{array}$} & \multirow[t]{2}{*}{ Coreia } & DA provável (271) & $74(9)$ & 94 & 6 & 0 & Sem \\
\hline & & Controles (236) & $71(8)$ & 95 & 5 & 0 & associação \\
\hline \multirow{5}{*}{$\begin{array}{l}\text { Poleggi et al. } \\
\text { (2008) }\end{array}$} & Itália & DA provável (195) & $65(7)$ & 45 & 47 & 8 & Sem \\
\hline & & Controles (124) & $66(13)$ & 49 & 37 & 14 & associação \\
\hline & EUA & DA definida (109) & $81(8)$ & 47 & 47 & 6 & \\
\hline & & Controles com AP & & & & & \\
\hline & & (58) & $84(9)$ & 52 & 43 & 5 & \\
\hline Este estudo & Brasil & DA provável (99) & $72(9)$ & 45 & 42 & 12 & Sem \\
\hline & & Controles (111) & $71(8)$ & 44 & 56 & 11 & associação \\
\hline
\end{tabular}


Por se tratar de estudo em que foi utilizada, em parte, amostra de pacientes e controles utilizada em estudo anterior (Bahia et al., 2008), os dados sobre o desempenho cognitivo dos participantes do estudo não estavam disponíveis em sua totalidade. Dessa forma, a análise entre os diferentes genótipos do códon 129 e o desempenho cognitivo foi realizada em 92 pacientes com DA e 66 controles para o teste do MEEM, e em 70 pacientes com DA e 66 controles para o teste de FV.

A mediana do desempenho no teste do MEEM foi significativamente pior nos pacientes com genótipo M129M, favorecendo a hipótese de que a homozigose está relacionada a pior desempenho cognitivo. No entanto, os pacientes homozigóticos V129V foram os que apresentaram melhor desempenho no MEEM, contrariando a mesma hipótese. Neste estudo, esse achado contraditório pode ser explicado pela diferença entre o tempo médio de doença dos diferentes genótipos. Os pacientes M129M apresentavam DA há mais tempo e os pacientes V129V, há menos tempo. Como a deterioração cognitiva está associada ao tempo de doença, é esperado que o pior desempenho cognitivo esteja associado à maior tempo de doença.

Ao realizarmos a análise multivariada por modelo de regressão múltipla, apenas as variáveis tempo de doença e escolaridade foram associadas ao desempenho no MEEM, não havendo influência do genótipo no códon 129. Os pacientes com escolaridade de 4 anos ou mais apresentaram chance 6,2 vezes maior de melhor desempenho no MEEM e os pacientes com tempo de doença de até 36 meses apresentaram chance 6,4 vezes maior de melhor desempenho no MEEM. As duas variáveis relevantes no modelo de regressão múltipla influenciam diretamente o desempenho no teste do MEEM, portanto, este achado é esperado dentro da amostra.

A escolaridade foi a única variável que se mostrou associada ao desempenho 
no MEEM no grupo controle. Os indivíduos com escolaridade mínima de 7 anos apresentaram chance 10,2 vezes maior de melhor desempenho no MEEM.

Não houve associação entre o desempenho no teste de FV e os diferentes genótipos do códon 129 no grupo com DA, bem como com escolaridade ou tempo de doença. Embora seja esperado que o desempenho neste teste seja melhor quanto maior a escolaridade e pior quanto maior o tempo de doença, a falta de associação pode ser explicada pelo tamanho reduzido da amostra $(n=70)$.

No grupo controle, o melhor desempenho no teste de FV esteve relacionado com maior escolaridade, sendo que o OR para melhor desempenho no teste foi de 4,0 (IC95\%: 1,4 - 11,2) para os indivíduos com sete anos ou mais de escolaridade.

A extratificação em relação ao genótipo da apoE não mostrou associação entre DA e os diferentes polimorfismos do códon 129 do PRNP. Os dados encontrados estão em concordância com os dados de população espanhola e de população italiana (Combarros et al., 2000; Del Bo et al., 2006), embora em pacientes alemães com $\mathrm{DA}$, o alelo $\mathrm{M}$ foi mais frequente naqueles que não apresentavam o alelo $\varepsilon 4$ (Riemenschneider et al., 2004). Na amostra estudada, maior número de pacientes com DA apresentavam pelo menos um alelo $\varepsilon 4$ do gene da apoE, corroborando representatividade da amostra em relação ao principal fator de risco genético para DA.

\subsection{Mutação do códon 180}

A mutação no códon 180 (V180I) confirma o diagnóstico de gDCJ em uma 
das pacientes que integrava a amostra inicial de pacientes com DA. Embora fenotipicamente a paciente apresentasse quadro clínico de DA provável, a determinação desta mutação no PRNP é suficiente para o diagnóstico de gDCJ.

Esta mutação é pouco frequente e foi descrita em pacientes japoneses (Kitamoto et al., 1993), além de um caso francês e um caso sul coreano (Chasseigneaux et al., 2006; Yang et al., 2010). No Japão, a V180I é a mutação do PRNP mais comum, entretanto, apenas 2,2\% dos pacientes com essa mutação apresentam história familiar positiva (Nozaki et al., 2010). A paciente excluída da amostra é japonesa, favorecendo a hipótese de mutação herdada e não de mutação de novo.

Em relação à eDCJ, os pacientes com V180I apresentam curso mais prolongado da doença e menor probabilidade de alteração do eletroencefalograma e de presença da proteína 14.3.3 no líquido cefalorraquidiano (Jin et al., 2004; Nozaki et al., 2010), o que pode justificar a confusão diagnóstica com o quadro de DA.

Acredita-se que cerca de $50 \%$ dos casos de gDCJ não tenham história familiar da doença, e atualmente recomenda-se a análise do PRNP em todos os casos suspeitos de doença priônica (Kovács et al., 2005). 


\section{CONCLUSÕES}




\section{CONCLUSÕES}

As principais conclusões deste estudo são:

1) Não foi observada frequência diferente dos polimorfismos do códon 129 do PRNP entre pacientes com DA e indivíduos cognitivamente normais, dando apoio aos demais estudos realizados em outros países que não demonstraram associação entre esses polimorfismos e DA.

A frequência dos polimorfismos dos códons 117 e 171 do $P R N P$ foi semelhante à observada em diferentes populações.

A frequência aumentada da deleção de um octapeptídeo repetido do PRNP em nossa população está de acordo com estudo prévio em população brasileira, podendo representar frequência característica de nossa população.

2) O encontro da mutação no códon 180 do $P R N P$ (V180I) de uma paciente da amostra inicial confirma a possibilidade de semelhança clínica entre casos atípicos de DCJ e DA.

3) Não houve diferença no desempenho cognitivo dos pacientes com DA em relação aos polimorfismos do códon 129 do $P R N P$, tornando menos provável a hipótese de associação entre esses polimorfismos e variabilidade fenotípica na DA.

4) Não houve diferença no desempenho cognitivo dos idosos cognitivamente normais em relação aos polimorfismos do códon 129 do 
$P R N P$, tornando menos provável a hipótese de associação entre esses polimorfismos e capacidade cognitiva.

5) Não houve associação entre os diferentes polimorfismos do códon 129 do PRNP e DA após extratificação segundo o alelo $\varepsilon 4$, dando apoio aos dados demais estudos que não comprovaram esta associação. 


\section{REFERÊNCIAS BIBLIOGRÁFICAS}




\section{REFERÊNCIAS BIBLIOGRÁFICAS ${ }^{1}$}

Aguzzi A, Weissmann C. Prion research: the next frontiers. Nature. 1997;389:795-8.

Ahn K, Kim E, Kwon YA, Kim DK, Lee JE, Jo SA. No association of prion protein gene polymorphisms with Alzheimer's disease in Korean population. Exp Mol Med. 2006;38:727-31.

Alperovitch A, Zerr I, Pocchiari M, Mitrova E, de Pedro Cuesta J, Hegyi I, Collins S, Kretzschmar H, van Duijn C, Will RG. Codon 129 prion protein genotype and sporadic Creutzfeldt-Jakob disease. Lancet. 1999;353:1673-4.

American Psychiatric Association. Diagnostic and statistical manual of mental disorders: DSMIV. $4^{\text {th }}$ ed, Washington, DC, 139-43, 1994.

Asante EA, Linehan JM, Gowland I, Joiner S, Fox K, Cooper S, Osiguwa O, Gorry M, Welch J, Houghton R, Desbruslais M, Brandner S, Wadsworth JD, Collinge J. Dissociation of pathological and molecular phenotype of variant CreutzfeldtJakob disease in transgenic human prion protein 129 heterozygous mice. Proc Natl Acad Sci USA. 2006;103:10759-64.

Bahia VS, Kok F, Marie SN, Shinjo SO, Caramelli P, Nitrini R. Polymorphisms of APOE and LRP genes in Brazilian individuals with Alzheimer disease. Alzheimer Dis Assoc Disord. 2008;22:61-5.

\footnotetext{
${ }^{1}$ De acordo com:
}

Adaptado de International Committee of medical Journals Editors (Vancouver).

Universidade de São Paulo. Faculdade de Medicina. Serviço de biblioteca e Documentação. Estrutura e apresentação de dissertações e teses. Elaborado por Anneliese Carneiro da Cunha, Maria Julia A.L. Freddi, Maria F. Crestana, Marinalva de S. Aragão, Suely C. Cardoso, Valéria Vilhena. São Paulo, Serviço de biblioteca e Documentação, 1996. 
Balducci C, Beeg M, Stravalaci M, Bastone A, Sclip A, Biasini E, Tapella L, Colombo L, Manzoni C, Borsello T, Chiesa R, Gobbi M, Salmona M, Forloni G. Synthetic amyloid- $\beta$ oligomers impair long-term memory independently of cellular prion protein. Proc Natl Acad Sci USA. 2010;107:2295-300.

Berr C, Richard F, Dufouil C, Amant C, Alperovitch A, Amouyel P. Polymorphism of the prion protein is associated with cognitive impairment in the elderly. The EVA study. Neurology. 1998;51:734-7.

Bertolucci PH, Brucki SM, Campacci SR, Juliano Y. O mini-exame do estado mental em uma população geral. Arq Neuropsiquiatr. 1994;52:1-7.

Bishop MT, Pennington C, Heath CA, Will RG, Knight RSG. PRNP variation in UK sporadic and variant Creutzfeldt Jakob disease highlights genetic risk factors and a novel non-synonymous polymorphism. BMC Med Gen. 2009;10:146.

Braak H, Braak E. Diagnostic criteria for neuropathologic assessment of Alzheimer's disease. Neurobiol Aging. 1997;18:S85-S88.

Brown DR, Wong BS, Hafiz F, Clive C, Haswell SJ, Jones IM. Normal prion protein has an activity like that of superoxide dismutase. Biochem J. 1999;344:1-5.

Brown DR. Prion and prejudice: normal protein and the synapse. Trends Neurosci. 2001;24:85-90.

Brucki SM, Malheiros SM, Okamoto IH, Bertolucci PH. Normative data on the verbal fluency test in the animal category in our milieu. Arq Neuropsiquiatr. $1997 ; 55: 56-61$.

Büeler H, Fischer M, Lang Y, Bluethmann H, Lipp HP, DeArmond SJ, Prusiner SB, Aguet M, Weissmann C. Normal development and behaviour of mice lacking the neuronal cell-surface PrP protein. Nature. 1992;356:577-82. 
Burns A, Iliffe S. Alzheimer's disease. BMJ. 2009;338:b158.

Campion D, Dumanchin C, Hannequin D, Dubois B, Belliard S, Puel M, ThomasAnterion C, Michon A, Martin C, Charbonnier F, Raux G, Camuzat A, Penet C, Mesnage V, Martinez M, Clerget-Darpoux F, Brice A, Frebourg T. Early-onset autosomal dominant Alzheimer disease: prevalence, genetic heterogeneity, and mutation spectrum. Am J Hum Genet. 1999;65:664-70.

Calella AM, Farinelli M, Nuvolone M, Mirante O, Moos R, Falsig J, Mansuy IM, Aguzzi A. Prion protein and $\mathrm{A} \beta$-related synaptic toxicity impairment. $E M B O$ Mol Med. 2010;2:306-14.

Casadei VM, Ferri C, Calabrese E, Grimaldi LM, Franceschi M, Veglia F. Prion protein gene polymorphism and Alzheimer's disease: one modulatory trait or cognitive decline? J Neurol Neurosurg Psychiatry. 2001;71:278-83.

Castro RM, Landemberger MC, Walz R, Carlotti CG Jr, Huang N, Cunha DR, Moura R, Caballero OL, Sakamoto AC, Nitrini R, Brentani RR, Martins VR. High capacity and low cost detection of prion protein gene variant alleles by denaturing HPLC. J Neurosci Methods. 2004;139:263-9.

Chasseigneaux S, Haik S, Laffont-Proust I, De Marco O, Lenne M, Brandel JP, Hauw JJ, Laplanche JL, Peoc'h K. V180I mutation of the prion protein gene associated with atypical $\operatorname{PrP}^{S c}$ glycosylation. Neurosci Lett 2006;408:165-9.

Chen S, Yadav SP, Surewicz WK. Interaction between human prion protein and amyloid- $\beta$ (A $\beta)$ oligomers: role of N-terminal residues. $J$ Biol Chem. 2010;285:26377-83.

Chen ZL, Strickland S. Neuronal death in hippocampus is promoted by plasmincatalysed degradation of LN. Cell. 1997;91:917-25. 
Chiarini LB, Freitas ARO, Zanata SM, Brentani RR, Martins VR, Linden R. Cellular prion protein transduces neuroprotective signals. EMBO J. 2002;21:3317-26.

Chiesa R, Piccardo P, Biasini E, Ghetti B, Harris DA. Aggregated, wild-type prion protein causes neurological dysfunction and synaptic abnormalities. J Neurosci. 2008;28:13258-67.

Choi IG, Woo SI, Kim HJ, Kim DJ, Park BL, Cheong HS, Pasaje CF, Park TJ, Bae JS, Chai YG, Shin HD. Lack of association between PRNP M129V polymorphism and multiple sclerosis, mild cognitive impairment, alcoholism and schizophrenia in a Korean population. Dis Markers. 2010;28:315-21.

Choi CJ, Anantharam V, Saetveit NJ, Houk RS, Kanthasamy A, Kanthasamy AG. Normal cellular prion protein protects against manganese-induced oxidative stress and apoptotic cell death. Toxicol Sci. 2007;98:495-509.

Colling SB, Collinge J, Jefferys JGR. Hippocampal slices from prion null mice: disrupted $\mathrm{Ca}^{2+}$-activated $\mathrm{K}^{+}$currents. Neurosci Lett. 1996;209:49-52.

Colling SB, Khana M, Collinge J, Jefferys JGR. Mossy fibre reorganization in the hippocampus of prion protein null mice. Brain Res. 1997;755:28-35.

Collinge J, Whittington MA, Sidle KC, Smith CJ, Palmer MS, Clarke AR, Jefferys JG. Prion protein is necessary for normal synaptic function. Nature. 1994;370:295-7.

Collins SJ, Lawson VA, Masters CL. Transmissible spongiform encephalopathies. Lancet. 2004;363:51-61.

Combarros O, Sánchez-Guerra M, Llorca J, Alvarez-Arcaya A, Berciano J, Peña N, Fernández-Viadero C. Polymorphism at codon 129 of the prion protein gene is not associated with sporadic AD. Neurology. 2000;55:593-5. 
Corneveaux JJ, Myers AJ, Allen AN, Pruzin JJ, Ramirez M, Engel A, Nalls MA, Chen K, Lee W, Chewning K, Villa SE, Meechoovet HB, Gerber JD, Frost D, Benson HL, O'Reilly S, Chibnik LB, Shulman JM, Singleton AB, Craig DW, Van Keuren-Jensen KR, Dunckley T, Bennett DA, De Jager PL, Heward C, Hardy J, Reiman EM, Huentelman MJ. Association of CR1, CLU and PICALM with Alzheimer's disease in a cohort of clinically characterized and neuropathologically verified individuals. Human Mol Genet. 2010;19:32953301.

Croes EA, Dermaut B, Houwing-Duistermaat JJ, Van den Broeck M, Cruts M, Breteler MM, Hofman A, van Broeckhoven C, van Duijn CM. Early cognitive decline is associated with prion protein codon 129 polymorphism. Ann Neurol. 2003;54:275-6.

de Paula EV, Addas-Carvalho M, Costa DSP, Saad STO, Gilli SCO. Genotype frequencies at codon 129 of the prion protein gene in Brazil: implications in susceptibility to variant Creutzfeldt-Jakob disease compared to European and Asian populations. Eur J Epidemiol. 2005;20:593-5.

Del Bo R, Scarlato M, Ghezzi S, Martinelli-Boneschi F, Fenoglio C, Galimberti G, Galbiati S, Virgilio R, Galimberti D, Ferrarese C, Scarpini E, Bresolin N, Comi GP. Is M129V of PRNP gene associated with Alzheimer disease? A case-control study and meta-analysis. Neurobiol Aging. 2006;27:770.e1-770.e5.

Dermaut B, Croes EA, Rademakers R, Van den Broeck M, Cruts M, Hofman A, van Duijn CM, Van Broeckhoven C. PRNP Val129 homozygosity increases risk for early-onset Alzheimer's disease. Ann Neurol. 2003;53:409-12. 
Doh-ura K, Tateishi J, Sasaki H, Kitamoto T, Sakaki Y. Pro-Leu change at position 102 of prion protein is the most common but not the sole mutation related to Gerstmann-Straüssler syndrome. Biochem Biophys Res Commun. 1989;163:9749.

Evans DA, Funkenstein HH, Albert MS, Scherr PA, Cook NR, Chown MJ, Hebert LE, Hennekens $\mathrm{CH}$, Taylor JO. Prevalence of Alzheimer's disease in a community population of older persons: higher than previously reported. JAMA. 1989;10:2551-6.

Fleminger S, Oliver DL, Lovestone S, Rabe-Hesketh S, Giora A. Head injury as a risk factor for Alzheimer's disease: the evidence 10 years on; a partial replication. J Neurol Neurosurg Psychiatry. 2003;74:857-62.

Gacia M, Safranow K, Styczyńska M, Jakubowska K, Pepłońska B, ChodakowskaZebrowska M, Przekop I, Słowik A, Golańska E, Hułas-Bigoszewska K, Chlubek D, Religa D, Zekanowski C, Barcikowska M. Prion protein gene M129V allele is a risk factor for Alzheimer's disease. J Neural Transm. 2006;113:1747-51.

Georgsson G, Tryggvason T, Jonasdottir AD, Gudmundsson S, Thorgeirsdottir S. Polymorphism of PRNP codons in the normal Icelandic population. Acta Neurol Scand. 2006: 113: 419-25.

Gimbel DA, Nygaard HB, Coffey EE, Gunther EC, Laurén J, Gimbel ZA, Strittmatter SM. Memory impairment in transgenic Alzheimer mice requires cellular prion protein. J Neurosci. 2010;30:6367-74.

Glatzel M, Stoeck K, Seeger H, Lührs T, Aguzzi A. Human prion diseases. Molecular and clinical aspects. Arch Neurol. 2005;62:545-52. 
Goate A, Chartier-Harlin MC, Mullan M, Brown J, Crawford F, Fidani L, Giuffra L, Haynes A, Irving N, James L, Mant R, Newton P, Rooke K, Roques P, Talbot C, Pericak-Vance M, Roses A, Williamson R, Rossor M, Owen M, Hardy J. Segregation of a missense mutation in the amyloid precursor protein gene with familial Alzheimer's disease. Nature. 1991;349:704-6.

Golanska E, Hulas-Bigoszewska K, Rutkiewicz E, Styczynska M, Peplonska B, Barcikowska M, Bratosiewicz-Wasik J, Liberski PP. Polymorphisms within the prion (PrP) and prion-like protein (Doppel) genes in AD. Neurology. 2004;62:313-5.

Goldfarb LG, Petersen RB, Tabaton M, Brown P, LeBlanc AC, Montagna P, Cortelli P, Julien J, Vital C, Pendelbury WW, Haffia M, Wills PR, Hauw JJ, McKeever PE, Monari L, Schrank B, Swergold GD, Autilio-Gambetti L, Gajdusek DC, Lugaresi E, Gambettit P. Fatal familial insomnia and familial Creutzfeldt-Jakob disease: disease phenotype determined by a DNA polymorphism. Science. $1992 ; 258: 806-8$.

Gossrau G, Herting B, Möckel S, Kempe A, Koch R, Reichmann H, Lampe JB. Analysis of the polymorphic prion protein gene codon 129 in idiopathic Parkinson's disease. J Neural Transm. 2006;113:331-7.

Graner E, Mercadante AF, Zanata SM, Martins VR, Jay DG, Brentani RR. Laminininduced PC-12 cell neurite behaviour following laser inactivation of cellular prion protein. FEBS Letters. 2000;482:275-81. 
Graner E, Mercadante AF, Zanata SM, Forlenza OV, Cabral AL, Veiga SS, Juliano MA, Roesler R, Walz R, Minetti A, Izquierdo I, Martins VR, Brentani RR. Cellular prion protein binds laminin and mediates neuritogenesis. Brain Res Mol Brain Res. 2000;76:85-92.

Grubenbecher S, Stüve O, Hefter H, Korth C. Prion protein gene codon 129 modulates clinical course of neurological Wilson disease. NeuroReport. 2006;17:549-52.

Gunther EC, Strittmatter SM. $\beta$-amyloid oligomers and cellular prion protein in Alzheimer's disease. J Mol Med. 2010;88:331-8.

Hadlow WJ. Scrapie and Kuru. Lancet. 1959;2:289-90.

Herrera Jr. E, Caramelli P, Silveira ASB, Nitrini R. Epidemiological survey of dementia in a community-dwelling Brazilian population. Alzheimer Dis Assoc Disord. 2002;16:103-8.

Hofman A, Rocca WA, Brayne C, Breteler MM, Clarke M, Cooper B, Copeland JR, Dartigues JF, da Silva Droux A, Hagnell O, Heeren TJ, Engendal K, Jonker C, Undesay J, Lobo A, Mann AH, Mölsä PK, Morgan K, O’Connor DW, Sulkava R, Kay DWK, Amaducci L for the Eurodem Prevalence Research Group. The prevalence of dementia in Europe: a collaborative study of 1980-1990 findings. Eurodem Prevalence Research Group. Int Epidemiol. 1991;20:736-748.

Hsiao K, Prusiner S. Inherited human prion diseases. Neurology. 1990;40:1820-7.

Jeong BH, Nam JH, Lee YJ, Lee KH, Jang MK, Carp RI, Lee HD, Ju YR, Ahn Jo S, Park KY, Kim YS. Polymorphism of the prion protein gene $(P R N P)$ in a Korean population. J Hum Genet. 2004;49:319-24. 
Jeong BH, Lee K-H, Jeong Y-E, Hwang K-A, Lee Y-J, Carp RI, Ju Y-R, Kim Y-S. Polymorphisms at codons 129 and 219 of the prion protein gene (PRNP) are not associated with sporadic Alzheimer's disease in the Korean population. Eur $J$ Neurol. 2007;14:621-626.

Jin K, Shiga Y, Shibuya S, Chida K, Sato Y, Konno H, Doh-ura K, Kitamoto T, Itoyama Y. Clinical features of Creutzfeldt-Jakob disease with V180I mutation. Neurology. 2004;62:502-505.

Jorm AF, Jolley D. The incidence of dementia: a meta-analysis. Neurology. 1998;51:728-33.

Kalaria RN, Maestre GE, Arizaga R, Friedland RP, Galasko D, Hall K, Luchsinger JA, Ogunniyi A, Perry EK, Potocnik F, Prince M, Stewart R, Wimo A, Zhang ZX, Antuono P; World Federation of Neurology Dementia Research Group. Alzheimer's disease and vascular dementia in developing countries: prevalence, management, and risk factors. Lancet Neurol. 2008;7:812-26.

Kaski D, Mead S, Hyare H, Cooper S, Overell J, Knight R, Collinge J, Rudge P. Variant CJD in an individual heterozygous for PRNP codon 129. Lancet. $2009 ; 374: 2128$

Katzman R. The prevalence and malignancy of Alzheimer disease - a major killer. Arch Neurol. 1976;33:217-8.

Kessels HW, Nguyen LN, Nabavi S, Malinow R. The prion protein as a receptor for amyloid- $\beta$. Nature. 2010;466:E3-4.

Kitamoto T, Ohta M, Doh-ura K, Hitoshi S, Terao Y, Tateishi J. Novel missense variants of prion protein in Creutzfeldt-Jakob disease or Gerstmann-Sträussler syndrome. Biochem Biophys Res Commun. 1993;191:709-14. 
Klamt F, Dal-Pizzol F, Conte da Frota ML Jr, Walz R, Andrades ME, da Silva EG, Brentani RR, Izquierdo I, Fonseca Moreira JC. Imbalance of antioxidant defense in mice lacking cellular prion protein. Free Radic Biol Med. 2001;30:1137-44.

Kong Q, Surewicz KA, Petersen RB, Zou W, Chen SG, Gambetti P. Inherited prion diseases. In: Prusiner SB, editor. Prion biology and diseases. Cold Spring Harbor, New York: Cold Spring Harbor Laboratory Press; 2004. pp. 673-775.

Kovács GG, Puopolo M, Ladogana A, Pocchiari M, Budka H, van Duijn C, Collins SJ, Boyd A, Giulivi A, Coulthart M, Delasnerie-Laupretre N, Brandel JP, Zerr I, Kretzschmar HA, de Pedro-Cuesta J, Calero-Lara M, Glatzel M, Aguzzi A, Bishop M, Knight R, Belay G, Will R, Mitrova E; EUROCJD. Genetic prion disease: the EUROCJD experience. Hum Genet. 2005;118:166-74.

Laurén J, Gimbel DA, Nygaard HB, Gilbert JW, Strittmatter SM. Cellular prion protein mediates impairment of synaptic plasticity by amyloid- $\beta$ oligomers. Nature. 2009;457:1128-32.

Lee H-S, Goldfarb LG. Global distribution of Fatal familial insomnia: founder or recurrent mutations. Neurogenetics. 2008;9:301-2.

Levy-Lahad E, Bird TD. Genetic factors in Alzheimer's disease: a review of recent advances. Ann Neurol. 1996;40:829-40.

Li X, Rowland LP, Mitsumoto H, Przedborski S, Bird TD, Schellenberg GD, Peskind E, Johnson N, Siddique T, Mesulam MM, Weintraub S, Mastrianni JA. Prion protein codon 129 genotype prevalence is altered in primary progressive aphasia. Ann Neurol. 2005;58:858-64.

Linden R, Martins VR, Prado MAM, Cammarota M, Izquierdo I, Brentani RR. Physiology of the Prion Protein. Physiol Rev. 2008;88:673-728. 
Lobo A, Launer LJ, Fratiglioni L, Andersen K, Di Carlo A, Breteler MM, Copeland JR, Dartigues JF, Jagger C, Martinez-Lage J, Soininen H, Hofman A. Prevalence of dementia and major subtypes in Europe: A collaborative study of populationbased cohorts. Neurologic Diseases in the Elderly Research Group. Neurology. 2000;54:S4-S9.

Lopes MH, Hajj GN, Muras AG, Mancini GL, Castro RM, Ribeiro KC, Brentani RR, Linden R, Martins VR. Interaction of cellular prion and stress-inducible protein 1 promotes neuritogenesis and neuroprotection by distinct signaling pathways. $J$ Neurosci. 2005;25:11330-9.

Luckenbill-Edds L. LN and the mechanism of neuronal outgrowth. Brain Res Brain Res Rev. 1997;23:1-27.

Martins VR, Mercadante AF, Cabral ALB, Freitas ARO, Castro RMRPS. Insights into the physiological function of cellular prion protein. Braz J Med Biol Res. 2001;34:585-95.

Martins VR, Berlado FH, Hajj GN, Lopes MH, Lee KS, Prado MA, Linden R. Prion protein: orchestrating neurotrophic activities. Curr Issues Mol Biol. 2010;12:6386.

Maurer K, Volk S, Gerbaldo H. Auguste D and Alzheimer's disease. Lancet. 1997;349:1546-49.

Mayuex R. Alzheimer's disease: epidemiology. In: Duyckaerts C, Litvan I, editor. Handbook of clinical neurology. Dementias. Elsevier, Amsterdã: 2008. pp. 195206. 
McKhann G, Drachman D, Folstein M, Katzman R, Price D, Stadlan EM. Clinical diagnosis of Alzheimer's disease: report of the NINCDS-ADRDA Work Group under the auspices of Department of Health and Human Services Task Force on Alzheimer's Disease. Neurology. 1984;34:939-44.

McLennan NF, Brennan PM, McNeill A, Davies I, Fotheringham A, Rennison KA, Ritchie D, Brannan F, Head MW, Ironside JW, Williams A, Bell JE. Prion protein accumulation and neuroprotection in hypoxic brain damage. Am J Pathol. 2004;165:227-35.

Mead S. Prion disease genetics. Eur J Hum Gen. 2006;14:273-81.

Merle U, Stremmel W, Gessner R. Influence of homozygosity for methionine at codon 129 of the human prion gene on the onset of neurological and hepatic symptoms in Wilson disease. Arch Neurol. 2006;63:982-5.

Mesulam MM. Aging, Alzheimer's Disease, and Dementia; in Principles of Behavioral and Cognitive Neurology. Oxford, New York, 1985. pp.439-522.

Moore RC, Lee IY, Silverman GL, Harrison PM, Strome R, Heinrich C, Karunaratne A, Pasternak SH, Chishti MA, Liang Y, Mastrangelo P, Wang K, Smit AF, Katamine S, Carlson GA, Cohen FE, Prusiner SB, Melton DW, Tremblay P, Hood LE, Westaway D. Ataxia in prion protein $(\mathrm{PrP})$-deficient mice is associated with upregulation of the novel PrP-like protein doppel. J Mol Biology. 1999;292:797-817.

Mouillet-Richard S, Ermonval M, Chebassier C, Laplanche JL, Lehmann S, Launay JM, Kellermann O. Signal transduction through prion protein. Science. 2000;289:1925-8. 
Nitrini R, Lefèvre BH, Mathias SC, Caramelli P, Carrilho PE, Sauaia N Massad E, Takiguti C, Da Silva IO, Porto CS, Magila MC, Scaff M. Testes neuropsicológicos de aplicação simples para o diagnóstico de demência. Arq Neuropsiquiatr. 1994;52:457-65.

Nygaard HB, Strittmatter SM. Cellular prion protein mediates the toxicity of $\beta$ amyloid oligomers - implications for Alzheimer disease. Arch Neurol. 2009;66:1325-8.

Ohkubo T, Sakasegawa Y, Asada T, Kinoshita T, Goto Y, Kimura H, Mizusawa H, Hachiya NS, Kaneko K. Absence of association between codon 129/219 polymorphism of the prion protein gene and Alzheimer's disease in Japan. Ann Neurol. 2003;54:553-4.

Palmer MS, Dryden AJ, Hughes JT, Collinge J. Homozygous prion protein genotype predisposing to sporadic Creutzfeldt-Jakob disease. Nature. 1991;352:340-2.

Papassotiropoulos A, Wollmer MA, Aguzzi A, Hock C, Nitsch RM, de Quervain DJF. The prion gene is associated with human long-term memory. Hum Mol Genet. 2005;14:2241-46.

Parkin ET, Watt NT, Hussain I, Eckman EA, Eckman CB, Manson JC, Baybutt HN, Turner AJ, Hooper NM. Cellular prion protein regulates $\beta$-secretase cleavage of the Alzheimer's amyloid precursor protein. Proc Natl Acad Sci USA. 2007;104:11062-7.

Pereira GS, Walz R, Bonan CD, Battastini AM, Izquierdo I, Martins VR, Brentani RR, Sarkis JJ. Changes in cortical and hippocampal ectonucleotidase activities in mice lacking cellular prion protein. Neurosci Lett. 2001;301:72-4. 
Poleggi A, Bizzarro A, Acciarri A, Antuono P, Bagnoli S, Cellini E, Forno GD, Giannattasio C, Lauria A, Matera MG, Nacmias B, Puopolo M, Seripa D, Sorbi S, Wekstein DR, Pocchiari M, Masullo C. Codon 129 polymorphism of prion protein gene in sporadic Alzheimer's disease. Eur J Neurol. 2008;15:173-8.

Prusiner SB. Novel proteinaceous infectious particles cause scrapie. Science. $1982 ; 216: 136-44$.

Prusiner SB. Molecular biology of prion diseases. Science. 1991;252:1515-22.

Prusiner SB. Prions. Proc Natl Acad Sci USA. 1998;95:13363-83.

Prusiner SB. Neurodegenerative diseases and prions. N Eng J Med. 2001;344:151626.

Querfurth HW, LaFerla FM. Alzheimer's disease. N Engl J Med. 2010;362:329-44.

Riemenschneider M, Klopp N, Xiang W, Wagenpfeil S, Vollmert C, Müller U, Förstl H, Illig T, Kretzschmar H, Kurz A. Prion protein codon 129 polymorphism and risk of Alzheimer disease. Neurology. 2004;63:364-6.

Rujescu D, Hartmann AM, Gonnermann C, Möller H-J, Giegling I. M129V variation in the prion protein may influence cognitive performance. Molec Psychiatr. 2003;8:937-41.

Sakaguchi S, Katamine S, Nishida N, Moriuchi R, Shigematsu K, Sugimoto T, Nakatani A, Kataoka Y, Houtani T, Shirabe S, Okada H, Hasegawa S, Miyamoto T, Noda T. Loss of cerebellar Purkinje cells in aged mice homozygous for a disrupted PrP gene. Nature. 1996;380:528-31.

Samaia HB, Brentani RR. Can loss-of-function prion-related disease exist? Mol Psychiatry. 1998;3:196-7. 
Saunders AM, Strittmatter WJ, Schmechel D, George-Hyslop PH, Pericak-Vance MA, Joo SH, Rosi BL, Gusella JF, Crapper-MacLachlan DR, Alberts MJ, Hulette C, Crain B, Goldgaber D, Roses AD. Association of apolipoprotein E allele epsilon 4 with late-onset familial and sporadic Alzheimer's disease. Neurology. $1993 ; 43: 1467-72$

Scholz SW, Xiromerisiou G, Fung HC, Eerola J, Hellström O, Papadimitriou A, Hadjigeorgiou GM, Tienari PJ, Fernandez HH, Mandel R, Okun MS, GwinnHardy K, Singleton AB. The human prion gene M129V polymorphism is not associated with idiopathic Parkinson's disease in three distinct populations. Neurosci Lett. 2006;395:227-9.

Seshadri S, Fitzpatrick AL, Ikram MA, DeStefano AL, Gudnason V, Boada M, Bis JC, Smith AV, Carassquillo MM, Lambert JC, Harold D, Schrijvers EM, Ramirez-Lorca R, Debette S, Longstreth WT Jr, Janssens AC, Pankratz VS, Dartigues JF, Hollingworth P, Aspelund T, Hernandez I, Beiser A, Kuller LH, Koudstaal PJ, Dickson DW, Tzourio C, Abraham R, Antunez C, Du Y, Rotter JI, Aulchenko YS, Harris TB, Petersen RC, Berr C, Owen MJ, Lopez-Arrieta J, Varadarajan BN, Becker JT, Rivadeneira F, Nalls MA, Graff-Radford NR, Campion D, Auerbach S, Rice K, Hofman A, Jonsson PV, Schmidt H, Lathrop M, Mosley TH, Au R, Psaty BM, Uitterlinden AG, Farrer LA, Lumley T, Ruiz A, Williams J, Amouyel P, Younkin SG, Wolf PA, Launer LJ, Lopez OL, van Duijn CM, Breteler MM; CHARGE Consortium; GERAD1 Consortium; EADI1 Consortium. Genome-wide analysis of genetic loci associated with Alzheimer disease. JAMA. 2010;303:1832-1840. 
Shibuya S, Higuchi J, Shin RW, Tateishi J, Kitamoto T. Codon 219 Lys allele of PRNP is not found in sporadic Creutzfeltd-Jakob disease. Ann Neurol. $1998 ; 43: 826-8$.

Shyu WC, Lin SZ, Chiang MF, Ding DC, Li KW, Chen SF, Yang HI, Li H. Overexpression of $\mathrm{PrP}^{\mathrm{c}}$ by adenovirus-mediated gene targeting reduces ischemic injury in a stroke rat model. $J$ Neurosci. 2005;25:8967-77.

Small DH, Cappai R. Alois Alzheimer and Alzheimer's disease: a centennial perspective. J Neurochem. 2006;99:708-10.

Smid J, Landemberger MC, Martins VR, Nitrini R. GSS family in Brazil: first report. Dement Neuropsychol. 2009;Suppl1:3.

Smid J, Martins VR, Landemberger MC, Riva D, Anghinah R, Nitrini R. Creutzfeldt-Jakob disease associated with a missense mutation at codon 200 of the prion protein gene in Brazil. Dement Neuropsychol. 2007;2:222-4.

Solforosi L, Criado JR, McGavern DB, Wirz S, Sánchez-Alavez M, Sugama S, DeGiorgio LA, Volpe BT, Wiseman E, Abalos G, Masliah E, Gilden D, Oldstone MB, Conti B, Williamson RA. Cross-linking cellular prion protein triggers neuronal apoptosis in vivo. Science. 2004;303:1514-6.

Stüve O, Korth C, Gabatto P, Cameron EM, Hu W, Eagar TN, Monson NL, Frohman EM, Racke MK, Zabetian CP, Oksenberg JR. Genetic polymorphism at codon 129 of the prion protein gene is not associated with multiple sclerosis. Arch Neurol. 2009;66:280-1.

Suh G-H, Shah A. A review of the epidemiological transition in dementia - crossnational comparisons of the indices related to Alzheimer's disease and vascular dementia. Acta Psychiatr Scand. 2001;104:4-11. 
Tobler I, Gaus SE, Deboer T, Achermann P, Fischer M, Rülicke T, Moser M, Oesch B, McBride PA, Manson JC. Altered circadian activity rhythms and sleep in mice devoid of prion protein. Nature. 1996;380:639-42.

Viles JH, Cohen FE, Prusiner SB, Goodin DB, Wright PE, Dyson HJ. Cooper binding to the prion protein: structural implications of four identical cooperative binding sites. Proc Natl Acad Sci USA. 1999;96:2042-47.

Wadsworth JD, Asante EA, Desbruslais M, Linehan JM, Joiner S, Gowland I, Welch J, Stone L, Lloyd SE, Hill AF, Brandner S, Collinge J. Human prion protein with valine 129 prevents expression of variant CJD phenotype. Science. 2004;306:1793-6.

Walz R, Amaral OB, Rockenbach IC, Roesler R, Izquierdo I, Cavalheiro EA, Martins VR, Brentani RR.. Increased sensitivity to seizures in mice lacking cellular prion protein. Epilepsia. 1999;40:1679-82.

Walz R, Castro RM, Velasco TR, Carlotti CG Jr, Sakamoto AC, Brentani RR, Martins VR. Cellular prion protein: implications in seizures and epilepsy. Cell Mol Neurobiol. 2002;22:249-57.

Walz R, Castro RM, Landemberger MC, Velasco TR, Terra-Bustamante VC, Bastos AC, Bianchin M, Wichert-Ana L, Araújo D, Alexandre V Jr, Santos AC, Machado HR, Carlotti CG Jr, Brentani RR, Martins VR, Sakamoto AC. Cortical malformations are associated with a rare polymorphism of cellular prion protein. Neurology. 2004;63:557-60. Erratum in: Neurology. 2007;69:414-6.

Wang K-C, Wang V, Sun M-C, Chiueh T-I, Soong B-W, Shan D-E. Polymorphism distribution of prion protein codon 117, 129 and 171 in Taiwan. Eur J Epidemiol. $2000 ; 22: 257-61$. 
Wechselberger C, Wurm S, Pfarr W, Höglinger O. The physiological functions of prion protein. Exp Cell Res. 2002;281:1-8.

Weise J, Sandau R, Schwarting S, Crome O, Wrede A, Schulz-Schaeffer W, Zerr I, Bähr M. Deletion of cellular prion protein results in reduced Akt activation, enhanced postischemic caspase-3 activation, and exacerbation of ischemic brain injury. Stroke. 2006;37:1296-300.

Windl O, Dempster M, Estibeiro JP, Lathe R, de Silva R, Esmonde T, Will R, Springbett A, Campbell TA, Sidle KC, Palmer MS, Collinge J. Genetic basis of Creutzfeldt-Jakob disease in the United Kingdom: a systematic analysis of predisposing mutations and allelic variation in PRNP gene. Hum Genet. $1996 ; 98: 259-64$.

Wong BS, Pan T, Liu T, Li R, Petersen RB, Jones IM, Gambetti P, Brown DR, Sy MS. Prion disease: a loss of antioxidant function? Biochem Biophys Res Commun. 2000;275:249-52.

Wong BS, Liu T, Li R, Pan T, Petersen RB, Smith MA, Gambetti P, Perry G, Manson JC, Brown DR, Sy MS. Increased levels of oxidative stress markers detected in the brains of mice devoid of prion protein. $J$ Neurochem. 2001;76:565-72.

Yang TI, Jung DS, Ahn BY, Jeong BH, Cho HJ, Kim YS, Na DL, Geschwind MD, Kim EJ. Familial Creutzfeldt-Jakob disease with V180I mutation. J Korean Med Sci. 2010;25:1097-100. 
Zanata SM, Lopes MH, Mercadante AF, Hajj GN, Chiarini LB, Nomizo R, Freitas AR, Cabral AL, Lee KS, Juliano MA, de Oliveira E, Jachieri SG, Burlingame A, Huang L, Linden R, Brentani RR, Martins VR. Stress-inducible protein 1 is a cell surface ligand for cellular prion that triggers neuroprotection. EMBO J. 2002;13:3307-16. 
APÊNDICE 
BANCOS DE DADOS

Quadro 1. Dados demográficos dos pacientes com DA

\begin{tabular}{|c|c|c|}
\hline ID & $\begin{array}{l}\text { Idade de início dos sintomas } \\
\text { (anos) }\end{array}$ & Sexo \\
\hline 1 & 59 & Maculino \\
\hline 2 & 59 & Masculino \\
\hline 3 & 53 & Masculino \\
\hline 4 & 74 & Feminino \\
\hline 5 & 75 & Masculino \\
\hline 6 & 70 & Masculino \\
\hline 7 & 77 & Feminino \\
\hline 8 & 76 & Feminino \\
\hline 9 & 72 & Feminino \\
\hline 10 & 81 & Feminino \\
\hline 11 & 80 & Feminino \\
\hline 12 & 80 & Feminino \\
\hline 13 & 88 & Masculino \\
\hline 14 & 86 & Masculino \\
\hline 15 & 81 & Masculino \\
\hline 16 & 87 & Feminino \\
\hline 17 & 73 & Feminino \\
\hline 18 & 66 & Feminino \\
\hline 19 & 85 & Masculino \\
\hline 20 & 90 & Feminino \\
\hline 21 & 81 & Feminino \\
\hline 22 & 84 & Feminino \\
\hline 23 & 80 & Feminino \\
\hline 24 & 76 & Feminino \\
\hline 25 & 81 & Feminino \\
\hline 26 & 81 & Feminino \\
\hline 27 & 81 & Feminino \\
\hline 28 & 82 & Feminino \\
\hline 29 & 75 & Feminino \\
\hline 30 & 70 & Feminino \\
\hline 31 & 74 & Masculino \\
\hline 32 & 75 & Feminino \\
\hline 33 & 52 & Feminino \\
\hline 34 & 51 & Masculino \\
\hline 35 & 79 & Feminino \\
\hline 36 & 74 & Feminino \\
\hline 37 & 59 & Masculino \\
\hline 38 & 73 & Feminino \\
\hline 39 & 71 & Masculino \\
\hline 40 & 69 & Feminino \\
\hline 41 & 77 & Feminino \\
\hline
\end{tabular}




\begin{tabular}{|c|c|c|}
\hline 42 & 78 & Masculino \\
\hline 43 & 60 & Feminino \\
\hline 44 & 66 & Feminino \\
\hline 45 & 71 & Feminino \\
\hline 46 & 63 & Masculino \\
\hline 47 & 55 & Masculino \\
\hline 48 & 72 & Feminino \\
\hline 49 & 75 & Feminino \\
\hline 50 & 54 & Feminino \\
\hline 51 & 78 & Feminino \\
\hline 52 & 60 & Feminino \\
\hline 53 & 71 & Masculino \\
\hline 54 & 73 & Feminino \\
\hline 55 & 86 & Masculino \\
\hline 56 & 73 & Masculino \\
\hline 57 & 71 & Feminino \\
\hline 58 & 82 & Feminino \\
\hline 59 & 74 & Feminino \\
\hline 60 & 50 & Feminino \\
\hline 61 & 70 & Masculino \\
\hline 62 & 69 & Feminino \\
\hline 63 & 69 & Masculino \\
\hline 64 & 86 & Feminino \\
\hline 65 & 76 & Masculino \\
\hline 66 & 71 & Feminino \\
\hline 67 & 77 & Feminino \\
\hline 68 & 66 & Feminino \\
\hline 69 & 60 & Feminino \\
\hline 70 & 53 & Feminino \\
\hline 71 & 64 & Masculino \\
\hline 72 & 64 & Feminino \\
\hline 73 & 74 & Feminino \\
\hline 74 & 66 & Feminino \\
\hline 75 & 63 & Masculino \\
\hline 76 & 73 & Feminino \\
\hline 77 & 61 & Masculino \\
\hline 78 & 85 & Feminino \\
\hline 79 & 61 & Feminino \\
\hline 80 & 63 & Masculino \\
\hline 81 & 58 & Feminino \\
\hline 82 & 71 & Masculino \\
\hline 83 & 78 & Masculino \\
\hline 84 & 75 & Feminino \\
\hline 85 & 71 & Masculino \\
\hline 86 & 82 & Feminino \\
\hline 87 & 79 & Feminino \\
\hline 88 & 72 & Feminino \\
\hline 89 & 77 & Masculino \\
\hline 90 & 76 & Feminino \\
\hline
\end{tabular}




\begin{tabular}{|c|c|c|}
\hline 91 & 74 & Feminino \\
\hline 92 & 76 & Masculino \\
\hline 93 & 71 & Feminino \\
\hline 94 & 71 & Masculino \\
\hline 95 & 68 & Feminino \\
\hline 96 & 74 & Feminino \\
\hline 97 & 83 & Masculino \\
\hline 98 & 79 & Feminino \\
\hline 99 & 76 & Feminino \\
\hline \hline
\end{tabular}

$\overline{\mathrm{ID}}=$ identificação 
Quadro 2. Dados demográficos do grupo controle

\begin{tabular}{|c|c|c|}
\hline ID & $\begin{array}{l}\text { Idade } \\
\text { (anos) }\end{array}$ & Sexo \\
\hline 100 & 81 & Masculino \\
\hline 101 & 81 & Feminino \\
\hline 102 & 76 & Feminino \\
\hline 103 & 75 & Feminino \\
\hline 104 & 82 & Feminino \\
\hline 105 & 69 & Masculino \\
\hline 106 & 79 & Masculino \\
\hline 107 & 57 & Feminino \\
\hline 108 & 55 & Feminino \\
\hline 109 & 62 & Feminino \\
\hline 110 & 67 & Masculino \\
\hline 111 & 68 & Feminino \\
\hline 112 & 74 & Feminino \\
\hline 113 & 63 & Masculino \\
\hline 114 & 85 & Feminino \\
\hline 115 & 63 & Masculino \\
\hline 116 & 70 & Feminino \\
\hline 117 & 76 & Masculino \\
\hline 118 & 63 & Feminino \\
\hline 119 & 74 & Feminino \\
\hline 120 & 84 & Feminino \\
\hline 121 & 74 & Feminino \\
\hline 122 & 60 & Feminino \\
\hline 123 & 63 & Masculino \\
\hline 124 & 68 & Masculino \\
\hline 125 & 66 & Feminino \\
\hline 126 & 65 & Masculino \\
\hline 127 & 67 & Feminino \\
\hline 128 & 70 & Masculino \\
\hline 129 & 69 & Feminino \\
\hline 130 & 60 & Feminino \\
\hline 131 & 71 & Feminino \\
\hline 132 & 73 & Feminino \\
\hline 133 & 75 & Feminino \\
\hline 134 & 75 & Feminino \\
\hline 135 & 69 & Masculino \\
\hline 136 & 72 & Feminino \\
\hline 137 & 73 & Feminino \\
\hline 138 & 63 & Masculino \\
\hline 139 & 70 & Feminino \\
\hline 140 & 80 & Feminino \\
\hline 141 & 78 & Feminino \\
\hline 142 & 72 & Feminino \\
\hline 143 & 63 & Feminino \\
\hline 144 & 76 & Masculino \\
\hline 145 & 67 & Feminino \\
\hline
\end{tabular}




\begin{tabular}{|c|c|c|}
\hline 146 & 69 & Feminino \\
\hline 147 & 70 & Feminino \\
\hline 148 & 72 & Feminino \\
\hline 149 & 74 & Feminino \\
\hline 150 & 72 & Masculino \\
\hline 151 & 81 & Masculino \\
\hline 152 & 76 & Feminino \\
\hline 153 & 76 & Masculino \\
\hline 154 & 80 & Masculino \\
\hline 155 & 83 & Masculino \\
\hline 156 & 77 & Masculino \\
\hline 157 & 75 & Masculino \\
\hline 158 & 88 & Masculino \\
\hline 159 & 61 & Masculino \\
\hline 160 & 61 & Feminino \\
\hline 161 & 77 & Feminino \\
\hline 162 & 81 & Feminino \\
\hline 163 & 76 & Feminino \\
\hline 164 & 63 & Masculino \\
\hline 165 & 70 & Feminino \\
\hline 166 & 61 & Feminino \\
\hline 167 & 68 & Masculino \\
\hline 168 & 69 & Feminino \\
\hline 169 & 80 & Feminino \\
\hline 170 & 77 & Masculino \\
\hline 171 & 75 & Feminino \\
\hline 172 & 63 & Feminino \\
\hline 173 & 63 & Feminino \\
\hline 174 & 76 & Feminino \\
\hline 175 & 71 & Feminino \\
\hline 176 & 90 & Feminino \\
\hline 177 & 69 & Feminino \\
\hline 178 & 86 & Feminino \\
\hline 179 & 60 & Feminino \\
\hline 180 & 74 & Feminino \\
\hline 181 & 74 & Masculino \\
\hline 182 & 83 & Masculino \\
\hline 183 & 62 & Feminino \\
\hline 184 & 60 & Feminino \\
\hline 185 & 65 & Feminino \\
\hline 186 & 65 & Feminino \\
\hline 187 & 68 & Feminino \\
\hline 188 & 72 & Feminino \\
\hline 189 & 88 & Masculino \\
\hline 190 & 59 & Feminino \\
\hline 191 & 74 & Feminino \\
\hline 192 & 62 & Masculino \\
\hline 193 & 63 & Masculino \\
\hline 194 & 80 & Feminino \\
\hline 195 & 60 & Masculino \\
\hline 196 & 88 & Feminino \\
\hline
\end{tabular}




\begin{tabular}{|l|l|l|}
\hline 197 & 90 & Masculino \\
\hline 198 & 83 & Masculino \\
\hline 199 & 61 & Feminino \\
\hline 200 & 62 & Feminino \\
\hline 201 & 66 & Feminino \\
\hline 202 & 80 & Feminino \\
\hline 203 & 53 & Feminino \\
\hline 204 & 67 & Feminino \\
\hline 205 & 62 & Feminino \\
\hline 206 & 76 & Feminino \\
\hline 207 & 82 & Masculino \\
\hline 208 & 69 & Feminino \\
\hline 209 & 70 & Feminino \\
\hline 210 & 72 & Feminino \\
\hline
\end{tabular}

ID = identificação 
Quadro 3. Genótipos dos pacientes com DA

\begin{tabular}{|c|c|c|c|c|c|}
\hline ID & Códon 117 & Códon 129 & Octarrepetição & Códon 171 & apoE \\
\hline 1 & Normal & $\mathrm{M} / \mathrm{V}$ & Normal & $\mathrm{N} / \mathrm{N}$ & $\varepsilon 3 / \varepsilon 4$ \\
\hline 2 & Normal & $\mathrm{M} / \mathrm{M}$ & Normal & $\mathrm{N} / \mathrm{N}$ & $\varepsilon 3 / \varepsilon 3$ \\
\hline 3 & Normal & $\mathrm{M} / \mathrm{M}$ & Normal & $\mathrm{N} / \mathrm{N}$ & $\varepsilon 3 / \varepsilon 3$ \\
\hline 4 & Normal & $\mathrm{V} / \mathrm{V}$ & Normal & $\mathrm{N} / \mathrm{N}$ & $\varepsilon 3 / \varepsilon 3$ \\
\hline 5 & Normal & $\mathrm{M} / \mathrm{M}$ & Normal & $\mathrm{N} / \mathrm{N}$ & $\varepsilon 3 / \varepsilon 4$ \\
\hline 6 & Normal & $\mathrm{M} / \mathrm{V}$ & Normal & $\mathrm{N} / \mathrm{N}$ & $\varepsilon 3 / \varepsilon 4$ \\
\hline 7 & Normal & $\mathrm{M} / \mathrm{M}$ & Normal & $\mathrm{N} / \mathrm{N}$ & $\varepsilon 3 / \varepsilon 3$ \\
\hline 8 & Normal & $\mathrm{M} / \mathrm{M}$ & Normal & $\mathrm{N} / \mathrm{N}$ & $\varepsilon 3 / \varepsilon 4$ \\
\hline 9 & Normal & $\mathrm{M} / \mathrm{M}$ & Normal & $\mathrm{N} / \mathrm{N}$ & $\varepsilon 3 / \varepsilon 3$ \\
\hline 10 & Normal & $\mathrm{M} / \mathrm{V}$ & Normal & $\mathrm{N} / \mathrm{N}$ & $\varepsilon 3 / \varepsilon 3$ \\
\hline 11 & Normal & $\mathrm{M} / \mathrm{V}$ & Normal & $\mathrm{N} / \mathrm{N}$ & $\varepsilon 3 / \varepsilon 3$ \\
\hline 12 & Normal & $\mathrm{M} / \mathrm{V}$ & Normal & $\mathrm{N} / \mathrm{N}$ & $\varepsilon 3 / \varepsilon 3$ \\
\hline 13 & Normal & $\mathrm{V} / \mathrm{V}$ & Normal & $\mathrm{N} / \mathrm{N}$ & $\varepsilon 3 / \varepsilon 3$ \\
\hline 14 & Normal & $\mathrm{M} / \mathrm{M}$ & Normal & $\mathrm{N} / \mathrm{N}$ & $\varepsilon 3 / \varepsilon 3$ \\
\hline 15 & Normal & $\mathrm{M} / \mathrm{V}$ & Normal & $\mathrm{N} / \mathrm{N}$ & $\varepsilon 2 / \varepsilon 3$ \\
\hline 16 & Normal & $\mathrm{M} / \mathrm{V}$ & Normal & $\mathrm{N} / \mathrm{N}$ & $\varepsilon 3 / \varepsilon 3$ \\
\hline 17 & Normal & $\mathrm{M} / \mathrm{M}$ & Normal & $\mathrm{N} / \mathrm{N}$ & $\varepsilon 3 / \varepsilon 4$ \\
\hline 18 & Silente & $\mathrm{M} / \mathrm{V}$ & Normal & $\mathrm{N} / \mathrm{N}$ & $\varepsilon 3 / \varepsilon 4$ \\
\hline 19 & Normal & $\mathrm{M} / \mathrm{V}$ & Normal & $\mathrm{N} / \mathrm{N}$ & $\varepsilon 3 / \varepsilon 3$ \\
\hline 20 & Normal & $\mathrm{M} / \mathrm{M}$ & Normal & $\mathrm{N} / \mathrm{N}$ & $\varepsilon 3 / \varepsilon 3$ \\
\hline 21 & Normal & $\mathrm{M} / \mathrm{M}$ & Normal & $\mathrm{N} / \mathrm{N}$ & $\varepsilon 3 / \varepsilon 3$ \\
\hline 22 & Normal & $\mathrm{M} / \mathrm{V}$ & Normal & $\mathrm{N} / \mathrm{N}$ & $\varepsilon 3 / \varepsilon 4$ \\
\hline 23 & Normal & $\mathrm{M} / \mathrm{M}$ & Normal & $\mathrm{N} / \mathrm{N}$ & $\varepsilon 3 / \varepsilon 3$ \\
\hline 24 & Normal & $\mathrm{M} / \mathrm{M}$ & Normal & $\mathrm{N} / \mathrm{N}$ & $\varepsilon 3 / \varepsilon 4$ \\
\hline 25 & Normal & $\mathrm{M} / \mathrm{M}$ & Normal & $\mathrm{N} / \mathrm{N}$ & $\varepsilon 3 / \varepsilon 3$ \\
\hline 26 & Normal & $\mathrm{M} / \mathrm{M}$ & Normal & $\mathrm{N} / \mathrm{N}$ & $\varepsilon 3 / \varepsilon 3$ \\
\hline 27 & Normal & $\mathrm{M} / \mathrm{V}$ & Normal & $\mathrm{N} / \mathrm{N}$ & $\varepsilon 3 / \varepsilon 3$ \\
\hline 28 & Normal & $\mathrm{M} / \mathrm{V}$ & Normal & $\mathrm{N} / \mathrm{N}$ & $\varepsilon 3 / \varepsilon 3$ \\
\hline 29 & Normal & $\mathrm{M} / \mathrm{M}$ & Normal & $\mathrm{N} / \mathrm{N}$ & $\varepsilon 3 / \varepsilon 3$ \\
\hline 30 & Normal & $\mathrm{M} / \mathrm{V}$ & Normal & $\mathrm{N} / \mathrm{N}$ & $\varepsilon 3 / \varepsilon 4$ \\
\hline 31 & Normal & $\mathrm{M} / \mathrm{V}$ & Normal & $\mathrm{N} / \mathrm{N}$ & $\varepsilon 2 / \varepsilon 3$ \\
\hline 32 & Normal & $\mathrm{M} / \mathrm{M}$ & Deletado & $\mathrm{N} / \mathrm{N}$ & $\varepsilon 3 / \varepsilon 4$ \\
\hline 33 & Normal & $\mathrm{M} / \mathrm{V}$ & Normal & $\mathrm{N} / \mathrm{N}$ & $\varepsilon 3 / \varepsilon 3$ \\
\hline 34 & Normal & $\mathrm{V} / \mathrm{V}$ & Normal & $\mathrm{N} / \mathrm{N}$ & $\varepsilon 3 / \varepsilon 4$ \\
\hline 35 & Normal & $\mathrm{M} / \mathrm{V}$ & Normal & $\mathrm{N} / \mathrm{N}$ & $\varepsilon 3 / \varepsilon 3$ \\
\hline 36 & Normal & $\mathrm{V} / \mathrm{V}$ & Normal & $\mathrm{N} / \mathrm{N}$ & $\varepsilon 3 / \varepsilon 3$ \\
\hline 37 & Silente & $\mathrm{M} / \mathrm{V}$ & Normal & $\mathrm{N} / \mathrm{N}$ & $\varepsilon 3 / \varepsilon 4$ \\
\hline 38 & Normal & $\mathrm{M} / \mathrm{M}$ & Normal & $\mathrm{N} / \mathrm{N}$ & $\varepsilon 3 / \varepsilon 4$ \\
\hline 39 & Normal & $\mathrm{M} / \mathrm{M}$ & Deletado & $\mathrm{N} / \mathrm{N}$ & $\varepsilon 3 / \varepsilon 4$ \\
\hline 40 & Normal & $\mathrm{V} / \mathrm{V}$ & Deletado & $\mathrm{N} / \mathrm{N}$ & $\varepsilon 3 / \varepsilon 4$ \\
\hline 41 & Normal & $\mathrm{M} / \mathrm{V}$ & Normal & $\mathrm{N} / \mathrm{N}$ & $\varepsilon 3 / \varepsilon 4$ \\
\hline 42 & Normal & $\mathrm{M} / \mathrm{M}$ & Normal & $\mathrm{N} / \mathrm{N}$ & $\varepsilon 3 / \varepsilon 4$ \\
\hline 43 & Normal & $\mathrm{M} / \mathrm{M}$ & Normal & $\mathrm{N} / \mathrm{N}$ & $\varepsilon 3 / \varepsilon 4$ \\
\hline 44 & Normal & $\mathrm{M} / \mathrm{V}$ & Deletado & $\mathrm{N} / \mathrm{N}$ & $\varepsilon 3 / \varepsilon 4$ \\
\hline 45 & Normal & $\mathrm{M} / \mathrm{V}$ & Normal & $\mathrm{N} / \mathrm{N}$ & $\varepsilon 4 / \varepsilon 4$ \\
\hline 46 & Normal & $\mathrm{M} / \mathrm{M}$ & Normal & $\mathrm{N} / \mathrm{N}$ & $\varepsilon 4 / \varepsilon 4$ \\
\hline 47 & Normal & $\mathrm{M} / \mathrm{M}$ & Normal & $\mathrm{N} / \mathrm{N}$ & $\varepsilon 3 / \varepsilon 3$ \\
\hline
\end{tabular}




\begin{tabular}{|c|c|c|c|c|c|}
\hline 48 & Normal & $\mathrm{V} / \mathrm{V}$ & Normal & $\mathrm{N} / \mathrm{N}$ & $\varepsilon 2 / \varepsilon 3$ \\
\hline 49 & Normal & $\mathrm{M} / \mathrm{V}$ & Normal & $\mathrm{N} / \mathrm{N}$ & $\varepsilon 3 / \varepsilon 3$ \\
\hline 50 & Normal & $\mathrm{M} / \mathrm{M}$ & Normal & $\mathrm{N} / \mathrm{N}$ & $\varepsilon 3 / \varepsilon 3$ \\
\hline 51 & Silente & $\mathrm{M} / \mathrm{V}$ & Normal & $\mathrm{N} / \mathrm{N}$ & $\varepsilon 3 / \varepsilon 4$ \\
\hline 52 & Normal & $\mathrm{M} / \mathrm{M}$ & Normal & $\mathrm{N} / \mathrm{N}$ & $\varepsilon 3 / \varepsilon 4$ \\
\hline 53 & Normal & $\mathrm{M} / \mathrm{V}$ & Normal & $\mathrm{N} / \mathrm{N}$ & $\varepsilon 3 / \varepsilon 4$ \\
\hline 54 & Normal & $\mathrm{V} / \mathrm{V}$ & Normal & $\mathrm{N} / \mathrm{N}$ & $\varepsilon 3 / \varepsilon 4$ \\
\hline 55 & Normal & $\mathrm{M} / \mathrm{V}$ & Normal & $\mathrm{N} / \mathrm{N}$ & $\varepsilon 3 / \varepsilon 3$ \\
\hline 56 & Normal & $\mathrm{M} / \mathrm{V}$ & Normal & $\mathrm{N} / \mathrm{N}$ & $\varepsilon 3 / \varepsilon 4$ \\
\hline 57 & Normal & $\mathrm{M} / \mathrm{V}$ & Normal & $\mathrm{N} / \mathrm{N}$ & $\varepsilon 4 / \varepsilon 4$ \\
\hline 58 & Normal & $\mathrm{M} / \mathrm{M}$ & Normal & $\mathrm{N} / \mathrm{N}$ & $\varepsilon 3 / \varepsilon 3$ \\
\hline 59 & Normal & $\mathrm{M} / \mathrm{M}$ & Normal & $\mathrm{N} / \mathrm{N}$ & $\varepsilon 3 / \varepsilon 4$ \\
\hline 60 & Normal & $\mathrm{M} / \mathrm{M}$ & Normal & $\mathrm{N} / \mathrm{N}$ & $\varepsilon 3 / \varepsilon 4$ \\
\hline 61 & Normal & $\mathrm{M} / \mathrm{V}$ & Normal & $\mathrm{N} / \mathrm{N}$ & $\varepsilon 3 / \varepsilon 4$ \\
\hline 62 & Normal & $\mathrm{M} / \mathrm{M}$ & Normal & $\mathrm{N} / \mathrm{N}$ & $\varepsilon 4 / \varepsilon 4$ \\
\hline 63 & Normal & $\mathrm{M} / \mathrm{V}$ & Normal & $\mathrm{N} / \mathrm{N}$ & $\varepsilon 3 / \varepsilon 3$ \\
\hline 64 & Normal & $\mathrm{M} / \mathrm{M}$ & Normal & $\mathrm{N} / \mathrm{N}$ & $\varepsilon 3 / \varepsilon 4$ \\
\hline 65 & Normal & $\mathrm{M} / \mathrm{M}$ & Normal & $\mathrm{N} / \mathrm{N}$ & $\varepsilon 4 / \varepsilon 4$ \\
\hline 66 & Normal & $\mathrm{V} / \mathrm{V}$ & Normal & $\mathrm{N} / \mathrm{N}$ & $\varepsilon 3 / \varepsilon 3$ \\
\hline 67 & Silente & $\mathrm{V} / \mathrm{V}$ & Normal & $\mathrm{N} / \mathrm{N}$ & $\varepsilon 3 / \varepsilon 3$ \\
\hline 68 & Normal & $\mathrm{M} / \mathrm{M}$ & Normal & $\mathrm{N} / \mathrm{N}$ & $\varepsilon 2 / \varepsilon 4$ \\
\hline 69 & Normal & $\mathrm{M} / \mathrm{M}$ & Normal & $\mathrm{N} / \mathrm{N}$ & $\varepsilon 3 / \varepsilon 3$ \\
\hline 70 & Normal & $\mathrm{M} / \mathrm{V}$ & Normal & N/N & $\varepsilon 3 / \varepsilon 3$ \\
\hline 71 & Normal & $\mathrm{M} / \mathrm{V}$ & Normal & $\mathrm{N} / \mathrm{N}$ & $\varepsilon 3 / \varepsilon 3$ \\
\hline 72 & Normal & $\mathrm{M} / \mathrm{M}$ & Normal & $\mathrm{N} / \mathrm{N}$ & $\varepsilon 4 / \varepsilon 4$ \\
\hline 73 & Normal & $\mathrm{M} / \mathrm{V}$ & Normal & $\mathrm{N} / \mathrm{N}$ & $\varepsilon 3 / \varepsilon 4$ \\
\hline 74 & Normal & $\mathrm{M} / \mathrm{M}$ & Normal & $\mathrm{N} / \mathrm{N}$ & $\varepsilon 3 / \varepsilon 4$ \\
\hline 75 & Normal & $\mathrm{M} / \mathrm{V}$ & Normal & $\mathrm{N} / \mathrm{N}$ & $\varepsilon 3 / \varepsilon 4$ \\
\hline 76 & Silente & $\mathrm{M} / \mathrm{V}$ & Normal & $\mathrm{N} / \mathrm{N}$ & $\varepsilon 3 / \varepsilon 4$ \\
\hline 77 & Normal & $\mathrm{M} / \mathrm{V}$ & Normal & N/N & $\varepsilon 4 / \varepsilon 4$ \\
\hline 78 & Normal & $\mathrm{M} / \mathrm{V}$ & Normal & $\mathrm{N} / \mathrm{N}$ & $\varepsilon 3 / \varepsilon 3$ \\
\hline 79 & Normal & $\mathrm{M} / \mathrm{V}$ & Normal & $\mathrm{N} / \mathrm{N}$ & $\varepsilon 3 / \varepsilon 4$ \\
\hline 80 & Normal & $\mathrm{M} / \mathrm{M}$ & Normal & $\mathrm{N} / \mathrm{N}$ & $\varepsilon 3 / \varepsilon 3$ \\
\hline 81 & Normal & $\mathrm{M} / \mathrm{M}$ & Normal & $\mathrm{N} / \mathrm{N}$ & $\varepsilon 3 / \varepsilon 3$ \\
\hline 82 & Normal & $\mathrm{M} / \mathrm{M}$ & Normal & $\mathrm{N} / \mathrm{N}$ & NP \\
\hline 83 & Normal & $\mathrm{M} / \mathrm{M}$ & Normal & $\mathrm{N} / \mathrm{N}$ & NP \\
\hline 84 & Normal & $\mathrm{M} / \mathrm{V}$ & Normal & $\mathrm{N} / \mathrm{N}$ & NP \\
\hline 85 & Normal & $\mathrm{M} / \mathrm{V}$ & Normal & $\mathrm{N} / \mathrm{N}$ & $\mathrm{NP}$ \\
\hline 86 & Normal & $\mathrm{V} / \mathrm{V}$ & Normal & $\mathrm{N} / \mathrm{N}$ & NP \\
\hline 87 & Normal & $\mathrm{M} / \mathrm{V}$ & Normal & $\mathrm{N} / \mathrm{N}$ & NP \\
\hline 88 & Normal & $\mathrm{M} / \mathrm{M}$ & Normal & $\mathrm{N} / \mathrm{N}$ & NP \\
\hline 89 & Normal & $\mathrm{M} / \mathrm{M}$ & Normal & $\mathrm{N} / \mathrm{N}$ & NP \\
\hline 90 & Normal & $\mathrm{M} / \mathrm{V}$ & Deletado & $\mathrm{N} / \mathrm{N}$ & NP \\
\hline 91 & Normal & $\mathrm{V} / \mathrm{V}$ & Normal & $\mathrm{N} / \mathrm{N}$ & NP \\
\hline 92 & Normal & $\mathrm{M} / \mathrm{M}$ & Normal & $\mathrm{N} / \mathrm{N}$ & NP \\
\hline 93 & Normal & $\mathrm{V} / \mathrm{V}$ & Normal & $\mathrm{N} / \mathrm{N}$ & NP \\
\hline 94 & Normal & $\mathrm{M} / \mathrm{M}$ & Normal & $\mathrm{N} / \mathrm{N}$ & NP \\
\hline 95 & Normal & $\mathrm{M} / \mathrm{M}$ & Normal & $\mathrm{N} / \mathrm{N}$ & NP \\
\hline 96 & Normal & $\mathrm{M} / \mathrm{M}$ & Normal & $\mathrm{N} / \mathrm{N}$ & NP \\
\hline 97 & Normal & $\mathrm{M} / \mathrm{V}$ & Normal & $\mathrm{N} / \mathrm{N}$ & $\mathrm{NP}$ \\
\hline
\end{tabular}




\begin{tabular}{|c|c|c|c|c|c|}
\hline 98 & Normal & $\mathrm{M} / \mathrm{V}$ & Normal & $\mathrm{N} / \mathrm{N}$ & $\mathrm{NP}$ \\
\hline 99 & Normal & $\mathrm{M} / \mathrm{M}$ & Normal & $\mathrm{N} / \mathrm{N}$ & $\mathrm{NP}$ \\
\hline \hline
\end{tabular}

ID = identificação; $\mathrm{M}=$ metionina; $\mathrm{V}=$ valina; $\mathrm{N} / \mathrm{N}=$ aspargina em homozigose; $\mathrm{NP}=$ não pesquisado 
Quadro 4. Genótipos do grupo controle

\begin{tabular}{|c|c|c|c|c|c|}
\hline ID & Códon 117 & Códon 129 & Octarrepetição & Códon 171 & apoE \\
\hline 100 & Normal & $\mathrm{V} / \mathrm{V}$ & Normal & $\mathrm{N} / \mathrm{N}$ & $\varepsilon 3 / \varepsilon 3$ \\
\hline 101 & Normal & $\mathrm{V} / \mathrm{V}$ & Normal & $\mathrm{N} / \mathrm{N}$ & $\varepsilon 3 / \varepsilon 3$ \\
\hline 102 & Normal & $\mathrm{M} / \mathrm{V}$ & Normal & $\mathrm{N} / \mathrm{N}$ & $\varepsilon 4 / \varepsilon 4$ \\
\hline 103 & Normal & $\mathrm{M} / \mathrm{V}$ & Normal & $\mathrm{N} / \mathrm{N}$ & $\varepsilon 3 / \varepsilon 3$ \\
\hline 104 & Normal & $\mathrm{V} / \mathrm{V}$ & Normal & $\mathrm{N} / \mathrm{N}$ & $\varepsilon 2 / \varepsilon 3$ \\
\hline 105 & Normal & $\mathrm{M} / \mathrm{M}$ & Normal & $\mathrm{N} / \mathrm{N}$ & $\varepsilon 2 / \varepsilon 3$ \\
\hline 106 & Normal & $\mathrm{M} / \mathrm{M}$ & Normal & $\mathrm{N} / \mathrm{N}$ & $\varepsilon 3 / \varepsilon 3$ \\
\hline 107 & Normal & $\mathrm{M} / \mathrm{M}$ & Normal & $\mathrm{N} / \mathrm{N}$ & $\varepsilon 3 / \varepsilon 3$ \\
\hline 108 & Normal & $\mathrm{M} / \mathrm{M}$ & Normal & $\mathrm{N} / \mathrm{N}$ & $\varepsilon 3 / \varepsilon 3$ \\
\hline 109 & Normal & $\mathrm{M} / \mathrm{M}$ & Normal & $\mathrm{N} / \mathrm{N}$ & NP \\
\hline 110 & Normal & $\mathrm{M} / \mathrm{V}$ & Normal & $\mathrm{N} / \mathrm{N}$ & NP \\
\hline 111 & Normal & $\mathrm{M} / \mathrm{V}$ & Normal & $\mathrm{N} / \mathrm{N}$ & $\varepsilon 3 / \varepsilon 3$ \\
\hline 112 & Silente & $\mathrm{M} / \mathrm{V}$ & Normal & $\mathrm{N} / \mathrm{N}$ & $\varepsilon 3 / \varepsilon 4$ \\
\hline 113 & Normal & $\mathrm{M} / \mathrm{M}$ & Normal & $\mathrm{N} / \mathrm{N}$ & $\varepsilon 3 / \varepsilon 3$ \\
\hline 114 & Normal & $\mathrm{M} / \mathrm{V}$ & Normal & $\mathrm{N} / \mathrm{N}$ & $\varepsilon 2 / \varepsilon 3$ \\
\hline 115 & Normal & $\mathrm{M} / \mathrm{V}$ & Normal & $\mathrm{N} / \mathrm{N}$ & $\varepsilon 3 / \varepsilon 3$ \\
\hline 116 & Normal & $\mathrm{M} / \mathrm{V}$ & Deletado & $\mathrm{N} / \mathrm{N}$ & $\varepsilon 3 / \varepsilon 4$ \\
\hline 117 & Silente & $\mathrm{M} / \mathrm{V}$ & Normal & $\mathrm{N} / \mathrm{N}$ & $\varepsilon 3 / \varepsilon 3$ \\
\hline 118 & Normal & $\mathrm{M} / \mathrm{M}$ & Normal & $\mathrm{N} / \mathrm{N}$ & $\varepsilon 3 / \varepsilon 3$ \\
\hline 119 & Normal & $\mathrm{M} / \mathrm{M}$ & Normal & $\mathrm{N} / \mathrm{N}$ & $\varepsilon 3 / \varepsilon 3$ \\
\hline 120 & Normal & $\mathrm{M} / \mathrm{V}$ & Normal & $\mathrm{N} / \mathrm{N}$ & $\varepsilon 3 / \varepsilon 3$ \\
\hline 121 & Normal & $\mathrm{V} / \mathrm{V}$ & Normal & $\mathrm{N} / \mathrm{N}$ & NP \\
\hline 122 & Normal & $\mathrm{M} / \mathrm{V}$ & Normal & $\mathrm{N} / \mathrm{N}$ & $\varepsilon 3 / \varepsilon 4$ \\
\hline 123 & Normal & $\mathrm{M} / \mathrm{V}$ & Normal & $\mathrm{N} / \mathrm{N}$ & $\varepsilon 3 / \varepsilon 3$ \\
\hline 124 & Normal & $\mathrm{M} / \mathrm{M}$ & Normal & $\mathrm{N} / \mathrm{N}$ & $\varepsilon 3 / \varepsilon 3$ \\
\hline 125 & Normal & $\mathrm{M} / \mathrm{V}$ & Normal & $\mathrm{N} / \mathrm{N}$ & $\varepsilon 3 / \varepsilon 3$ \\
\hline 126 & Normal & $\mathrm{M} / \mathrm{M}$ & Normal & $\mathrm{N} / \mathrm{N}$ & NP \\
\hline 127 & Normal & $\mathrm{M} / \mathrm{V}$ & Normal & $\mathrm{N} / \mathrm{N}$ & $\varepsilon 2 / \varepsilon 3$ \\
\hline 128 & Normal & $\mathrm{M} / \mathrm{V}$ & Normal & $\mathrm{N} / \mathrm{N}$ & $\varepsilon 3 / \varepsilon 3$ \\
\hline 129 & Normal & $\mathrm{M} / \mathrm{V}$ & Normal & $\mathrm{N} / \mathrm{N}$ & $\varepsilon 3 / \varepsilon 3$ \\
\hline 130 & Normal & $\mathrm{V} / \mathrm{V}$ & Normal & $\mathrm{N} / \mathrm{N}$ & $\varepsilon 3 / \varepsilon 3$ \\
\hline 131 & Normal & $\mathrm{M} / \mathrm{M}$ & Normal & $\mathrm{N} / \mathrm{N}$ & $\varepsilon 3 / \varepsilon 3$ \\
\hline 132 & Normal & $\mathrm{V} / \mathrm{V}$ & Normal & $\mathrm{N} / \mathrm{N}$ & $\varepsilon 3 / \varepsilon 3$ \\
\hline 133 & Normal & $\mathrm{M} / \mathrm{M}$ & Normal & $\mathrm{N} / \mathrm{N}$ & $\varepsilon 3 / \varepsilon 4$ \\
\hline 134 & Normal & $\mathrm{M} / \mathrm{V}$ & Normal & $\mathrm{N} / \mathrm{N}$ & $\varepsilon 3 / \varepsilon 3$ \\
\hline 135 & Normal & $\mathrm{V} / \mathrm{V}$ & Normal & $\mathrm{N} / \mathrm{N}$ & $\varepsilon 3 / \varepsilon 3$ \\
\hline 136 & Normal & $\mathrm{M} / \mathrm{V}$ & Normal & $\mathrm{N} / \mathrm{N}$ & NP \\
\hline 137 & Normal & $\mathrm{M} / \mathrm{V}$ & Normal & $\mathrm{N} / \mathrm{N}$ & $\varepsilon 2 / \varepsilon 3$ \\
\hline 138 & Normal & $\mathrm{M} / \mathrm{V}$ & Deletado & $\mathrm{N} / \mathrm{N}$ & $\varepsilon 3 / \varepsilon 4$ \\
\hline 139 & Normal & $\mathrm{V} / \mathrm{V}$ & Normal & $\mathrm{N} / \mathrm{N}$ & NP \\
\hline 140 & Normal & $\mathrm{M} / \mathrm{V}$ & Normal & $\mathrm{N} / \mathrm{N}$ & NP \\
\hline 141 & Silente & $\mathrm{M} / \mathrm{V}$ & Normal & $\mathrm{N} / \mathrm{N}$ & $\varepsilon 3 / \varepsilon 3$ \\
\hline 142 & Normal & $\mathrm{M} / \mathrm{V}$ & Normal & $\mathrm{N} / \mathrm{N}$ & $\varepsilon 3 / \varepsilon 3$ \\
\hline 143 & Normal & $\mathrm{M} / \mathrm{V}$ & Deletado & $\mathrm{N} / \mathrm{N}$ & $\varepsilon 3 / \varepsilon 4$ \\
\hline 144 & Normal & $\mathrm{M} / \mathrm{V}$ & Normal & $\mathrm{N} / \mathrm{N}$ & NP \\
\hline 145 & Normal & $\mathrm{M} / \mathrm{M}$ & Normal & $\mathrm{N} / \mathrm{N}$ & $\varepsilon 3 / \varepsilon 3$ \\
\hline
\end{tabular}




\begin{tabular}{|c|c|c|c|c|c|}
\hline 146 & Normal & $\mathrm{M} / \mathrm{M}$ & Normal & $\mathrm{N} / \mathrm{N}$ & $\varepsilon 3 / \varepsilon 3$ \\
\hline 147 & Normal & $\mathrm{M} / \mathrm{M}$ & Normal & $\mathrm{N} / \mathrm{N}$ & NP \\
\hline 148 & Normal & $\mathrm{M} / \mathrm{V}$ & Normal & $\mathrm{N} / \mathrm{N}$ & $\varepsilon 3 / \varepsilon 3$ \\
\hline 149 & Normal & $\mathrm{V} / \mathrm{V}$ & Normal & $\mathrm{N} / \mathrm{N}$ & $\varepsilon 2 / \varepsilon 3$ \\
\hline 150 & Normal & $\mathrm{M} / \mathrm{V}$ & Normal & $\mathrm{N} / \mathrm{N}$ & $\varepsilon 2 / \varepsilon 3$ \\
\hline 151 & Normal & $\mathrm{M} / \mathrm{V}$ & Normal & $\mathrm{N} / \mathrm{N}$ & $\varepsilon 3 / \varepsilon 4$ \\
\hline 152 & Normal & $\mathrm{M} / \mathrm{M}$ & Normal & $\mathrm{N} / \mathrm{N}$ & $\varepsilon 3 / \varepsilon 3$ \\
\hline 153 & Normal & $\mathrm{M} / \mathrm{V}$ & Normal & $\mathrm{N} / \mathrm{N}$ & $\varepsilon 3 / \varepsilon 4$ \\
\hline 154 & Normal & $\mathrm{M} / \mathrm{M}$ & Normal & $\mathrm{N} / \mathrm{N}$ & $\varepsilon 3 / \varepsilon 3$ \\
\hline 155 & Normal & $\mathrm{M} / \mathrm{M}$ & Normal & $\mathrm{N} / \mathrm{N}$ & $\varepsilon 2 / \varepsilon 3$ \\
\hline 156 & Normal & $\mathrm{M} / \mathrm{V}$ & Normal & $\mathrm{N} / \mathrm{N}$ & $\varepsilon 3 / \varepsilon 3$ \\
\hline 157 & Normal & $\mathrm{M} / \mathrm{V}$ & Normal & $\mathrm{N} / \mathrm{N}$ & NP \\
\hline 158 & Normal & $\mathrm{M} / \mathrm{V}$ & Normal & $\mathrm{N} / \mathrm{N}$ & $\varepsilon 3 / \varepsilon 4$ \\
\hline 159 & Normal & $\mathrm{V} / \mathrm{V}$ & Normal & $\mathrm{N} / \mathrm{N}$ & $\varepsilon 3 / \varepsilon 3$ \\
\hline 160 & Normal & $\mathrm{M} / \mathrm{V}$ & Normal & $\mathrm{N} / \mathrm{N}$ & $\varepsilon 3 / \varepsilon 3$ \\
\hline 161 & Normal & $\mathrm{M} / \mathrm{M}$ & Normal & $\mathrm{N} / \mathrm{N}$ & $\varepsilon 3 / \varepsilon 3$ \\
\hline 162 & Normal & $\mathrm{M} / \mathrm{M}$ & Normal & $\mathrm{N} / \mathrm{N}$ & $\varepsilon 3 / \varepsilon 3$ \\
\hline 163 & Normal & $\mathrm{M} / \mathrm{M}$ & Normal & $\mathrm{N} / \mathrm{N}$ & $\varepsilon 3 / \varepsilon 4$ \\
\hline 164 & Normal & $\mathrm{M} / \mathrm{V}$ & Normal & $\mathrm{N} / \mathrm{N}$ & $\varepsilon 3 / \varepsilon 3$ \\
\hline 165 & Normal & $\mathrm{M} / \mathrm{V}$ & Normal & $\mathrm{N} / \mathrm{N}$ & $\varepsilon 3 / \varepsilon 3$ \\
\hline 166 & Normal & $\mathrm{M} / \mathrm{M}$ & Normal & $\mathrm{N} / \mathrm{N}$ & $\varepsilon 3 / \varepsilon 4$ \\
\hline 167 & Normal & $\mathrm{M} / \mathrm{V}$ & Deletado & $\mathrm{N} / \mathrm{N}$ & $\varepsilon 3 / \varepsilon 3$ \\
\hline 168 & Normal & $\mathrm{M} / \mathrm{M}$ & Normal & $\mathrm{N} / \mathrm{N}$ & NP \\
\hline 169 & Normal & $\mathrm{M} / \mathrm{M}$ & Normal & $\mathrm{N} / \mathrm{N}$ & $\varepsilon 3 / \varepsilon 3$ \\
\hline 170 & Normal & $\mathrm{M} / \mathrm{V}$ & Normal & $\mathrm{N} / \mathrm{N}$ & $\varepsilon 2 / \varepsilon 3$ \\
\hline 171 & Normal & $\mathrm{M} / \mathrm{M}$ & Normal & $\mathrm{N} / \mathrm{N}$ & NP \\
\hline 172 & Normal & $\mathrm{M} / \mathrm{M}$ & Normal & $\mathrm{N} / \mathrm{N}$ & $\mathrm{NP}$ \\
\hline 173 & Normal & $\mathrm{M} / \mathrm{M}$ & Normal & $\mathrm{N} / \mathrm{N}$ & NP \\
\hline 174 & Normal & $\mathrm{M} / \mathrm{V}$ & Normal & $\mathrm{N} / \mathrm{N}$ & $\varepsilon 2 / \varepsilon 3$ \\
\hline 175 & Normal & $\mathrm{M} / \mathrm{M}$ & Normal & $\mathrm{N} / \mathrm{N}$ & $\varepsilon 3 / \varepsilon 3$ \\
\hline 176 & Normal & $\mathrm{M} / \mathrm{V}$ & Normal & $\mathrm{N} / \mathrm{N}$ & $\varepsilon 3 / \varepsilon 3$ \\
\hline 177 & Normal & $\mathrm{M} / \mathrm{V}$ & Normal & $\mathrm{N} / \mathrm{N}$ & $\varepsilon 2 / \varepsilon 2$ \\
\hline 178 & Normal & $\mathrm{M} / \mathrm{V}$ & Normal & $\mathrm{N} / \mathrm{N}$ & $\varepsilon 3 / \varepsilon 4$ \\
\hline 179 & Normal & $\mathrm{M} / \mathrm{M}$ & Normal & $\mathrm{N} / \mathrm{N}$ & $\varepsilon 3 / \varepsilon 3$ \\
\hline 180 & Normal & $\mathrm{M} / \mathrm{M}$ & Normal & $\mathrm{N} / \mathrm{N}$ & $\varepsilon 4 / \varepsilon 4$ \\
\hline 181 & Normal & $\mathrm{M} / \mathrm{V}$ & Normal & $\mathrm{N} / \mathrm{N}$ & $\varepsilon 3 / \varepsilon 3$ \\
\hline 182 & Normal & $\mathrm{M} / \mathrm{V}$ & Normal & $\mathrm{N} / \mathrm{N}$ & $\varepsilon 3 / \varepsilon 3$ \\
\hline 183 & Normal & $\mathrm{M} / \mathrm{V}$ & Normal & $\mathrm{N} / \mathrm{N}$ & $\varepsilon 3 / \varepsilon 4$ \\
\hline 184 & Normal & $\mathrm{M} / \mathrm{M}$ & Normal & $\mathrm{N} / \mathrm{N}$ & $\varepsilon 3 / \varepsilon 3$ \\
\hline 185 & Normal & $\mathrm{M} / \mathrm{M}$ & Normal & $\mathrm{N} / \mathrm{N}$ & $\varepsilon 3 / \varepsilon 3$ \\
\hline 186 & Normal & $\mathrm{M} / \mathrm{M}$ & Normal & $\mathrm{N} / \mathrm{N}$ & $\varepsilon 3 / \varepsilon 3$ \\
\hline 187 & Normal & $\mathrm{M} / \mathrm{V}$ & Normal & $\mathrm{N} / \mathrm{N}$ & $\varepsilon 3 / \varepsilon 3$ \\
\hline 188 & Normal & $\mathrm{M} / \mathrm{V}$ & Normal & $\mathrm{N} / \mathrm{N}$ & $\varepsilon 3 / \varepsilon 3$ \\
\hline 189 & Normal & $\mathrm{M} / \mathrm{M}$ & Normal & $\mathrm{N} / \mathrm{N}$ & $\varepsilon 3 / \varepsilon 3$ \\
\hline 190 & Normal & $\mathrm{M} / \mathrm{M}$ & Normal & $\mathrm{N} / \mathrm{N}$ & $\varepsilon 3 / \varepsilon 3$ \\
\hline 191 & Normal & $\mathrm{M} / \mathrm{V}$ & Normal & $\mathrm{N} / \mathrm{N}$ & NP \\
\hline 192 & Normal & $\mathrm{M} / \mathrm{M}$ & Normal & $\mathrm{N} / \mathrm{N}$ & $\varepsilon 3 / \varepsilon 3$ \\
\hline 193 & Normal & $\mathrm{M} / \mathrm{V}$ & Normal & $\mathrm{N} / \mathrm{N}$ & $\varepsilon 3 / \varepsilon 4$ \\
\hline 194 & Normal & $\mathrm{M} / \mathrm{V}$ & Normal & $\mathrm{N} / \mathrm{N}$ & $\varepsilon 3 / \varepsilon 3$ \\
\hline 195 & Normal & $\mathrm{M} / \mathrm{V}$ & Normal & $\mathrm{N} / \mathrm{N}$ & $\varepsilon 3 / \varepsilon 3$ \\
\hline
\end{tabular}




\begin{tabular}{|c|l|l|l|l|c|}
\hline 196 & Normal & $\mathrm{M} / \mathrm{M}$ & Normal & $\mathrm{N} / \mathrm{N}$ & $\varepsilon 3 / \varepsilon 3$ \\
\hline 197 & Normal & $\mathrm{M} / \mathrm{V}$ & Normal & $\mathrm{N} / \mathrm{N}$ & $\varepsilon 3 / \varepsilon 3$ \\
\hline 198 & Normal & $\mathrm{M} / \mathrm{V}$ & Normal & $\mathrm{N} / \mathrm{N}$ & $\varepsilon 2 / \varepsilon 2$ \\
\hline 199 & Normal & $\mathrm{M} / \mathrm{V}$ & Normal & $\mathrm{N} / \mathrm{N}$ & $\varepsilon 3 / \varepsilon 3$ \\
\hline 200 & Normal & $\mathrm{M} / \mathrm{M}$ & Normal & $\mathrm{N} / \mathrm{N}$ & $\mathrm{NP}$ \\
\hline 201 & Normal & $\mathrm{M} / \mathrm{M}$ & Normal & $\mathrm{N} / \mathrm{N}$ & $\mathrm{NP}$ \\
\hline 202 & Normal & $\mathrm{M} / \mathrm{M}$ & Normal & $\mathrm{N} / \mathrm{N}$ & $\varepsilon 3 / \varepsilon 3$ \\
\hline 203 & Normal & $\mathrm{M} / \mathrm{V}$ & Normal & $\mathrm{N} / \mathrm{N}$ & $\varepsilon 3 / \varepsilon 3$ \\
\hline 204 & Normal & $\mathrm{M} / \mathrm{M}$ & Normal & $\mathrm{N} / \mathrm{N}$ & $\varepsilon 3 / \varepsilon 3$ \\
\hline 205 & Normal & $\mathrm{M} / \mathrm{M}$ & Normal & $\mathrm{N} / \mathrm{N}$ & $\varepsilon 3 / \varepsilon 3$ \\
\hline 206 & Normal & $\mathrm{M} / \mathrm{M}$ & Normal & $\mathrm{N} / \mathrm{N}$ & $\varepsilon 3 / \varepsilon 3$ \\
\hline 207 & Normal & $\mathrm{M} / \mathrm{V}$ & Normal & $\mathrm{N} / \mathrm{N}$ & $\varepsilon 2 / \varepsilon 2$ \\
\hline 208 & Normal & $\mathrm{V} / \mathrm{V}$ & Normal & $\mathrm{N} / \mathrm{N}$ & $\varepsilon 3 / \varepsilon 4$ \\
\hline 209 & Normal & $\mathrm{M} / \mathrm{V}$ & Normal & $\mathrm{N} / \mathrm{N}$ & $\varepsilon 3 / \varepsilon 3$ \\
\hline 210 & Normal & $\mathrm{M} / \mathrm{M}$ & Normal & $\mathrm{N} / \mathrm{N}$ & $\varepsilon 3 / \varepsilon 3$ \\
\hline \hline
\end{tabular}

ID = identificação; $M$ = metionina; $\mathrm{V}=$ valina; $\mathrm{N} / \mathrm{N}$ = aspargina em homozigose; $\mathrm{NP}=$ não pesquisado 
Quadro 5. Avaliação cognitiva grupo DA

\begin{tabular}{|c|c|c|c|c|c|c|c|}
\hline ID & $\begin{array}{c}\text { Idade } \\
\text { (anos) }\end{array}$ & Sexo & AA129 & $\begin{array}{l}\text { Escolaridade } \\
\quad(\text { anos })\end{array}$ & MEEM & FV & $\begin{array}{c}\text { Tempo de } \\
\text { doença } \\
\text { (meses) }\end{array}$ \\
\hline 1 & 59 & Masculino & $\mathrm{M} / \mathrm{V}$ & 11 & 17 & 6 & 24 \\
\hline 2 & 59 & Masculino & $\mathrm{M} / \mathrm{M}$ & 15 & 13 & 5 & 48 \\
\hline 3 & 53 & Masculino & $\mathrm{M} / \mathrm{M}$ & 16 & 18 & 12 & 36 \\
\hline 4 & 74 & Feminino & $\mathrm{V} / \mathrm{V}$ & 4 & 16 & 7 & 48 \\
\hline 5 & 75 & Masculino & $\mathrm{M} / \mathrm{M}$ & 7 & 10 & 4 & 36 \\
\hline 6 & 70 & Masculino & $\mathrm{M} / \mathrm{V}$ & 0 & 16 & SR & 12 \\
\hline 7 & 77 & Feminino & $\mathrm{M} / \mathrm{M}$ & 0 & 17 & 15 & 18 \\
\hline 8 & 76 & Feminino & $\mathrm{M} / \mathrm{M}$ & 0 & 9 & 11 & 72 \\
\hline 9 & 72 & Feminino & $\mathrm{M} / \mathrm{M}$ & 4 & 16 & 5 & 8 \\
\hline 10 & 81 & Feminino & $\mathrm{M} / \mathrm{V}$ & SR & 3 & SR & SR \\
\hline 11 & 80 & Feminino & $\mathrm{M} / \mathrm{V}$ & 1 & 11 & 5 & 18 \\
\hline 12 & 80 & Feminino & $\mathrm{M} / \mathrm{V}$ & 0 & 15 & 8 & 12 \\
\hline 13 & 88 & Masculino & $\mathrm{V} / \mathrm{V}$ & 4 & 19 & 6 & 48 \\
\hline 14 & 86 & Masculino & $\mathrm{M} / \mathrm{M}$ & 1 & 17 & 2 & 12 \\
\hline 15 & 81 & Masculino & $\mathrm{M} / \mathrm{V}$ & 11 & 20 & 0 & 12 \\
\hline 16 & 87 & Feminino & $\mathrm{M} / \mathrm{V}$ & 1 & 18 & 10 & 24 \\
\hline 17 & 73 & Feminino & $\mathrm{M} / \mathrm{M}$ & 3 & 21 & SR & 18 \\
\hline 18 & 66 & Feminino & $\mathrm{M} / \mathrm{V}$ & 0 & 14 & 7 & 6 \\
\hline 19 & 85 & Masculino & $\mathrm{M} / \mathrm{V}$ & 1 & 23 & SR & 6 \\
\hline 20 & 90 & Feminino & $\mathrm{M} / \mathrm{M}$ & 0 & 9 & SR & 30 \\
\hline 21 & 81 & Feminino & $\mathrm{M} / \mathrm{M}$ & 0 & 11 & 7 & 24 \\
\hline 22 & 84 & Feminino & $\mathrm{M} / \mathrm{V}$ & 0 & 14 & 5 & 60 \\
\hline 23 & 80 & Feminino & $\mathrm{M} / \mathrm{M}$ & 0 & 8 & SR & 36 \\
\hline 24 & 76 & Feminino & $\mathrm{M} / \mathrm{M}$ & 0 & 1 & 2 & 72 \\
\hline 25 & 81 & Feminino & $\mathrm{M} / \mathrm{M}$ & 1 & 16 & 2 & 36 \\
\hline 26 & 81 & Feminino & $\mathrm{M} / \mathrm{M}$ & 5 & 14 & 5 & 48 \\
\hline 27 & 81 & Feminino & $\mathrm{M} / \mathrm{V}$ & 0 & 10 & 8 & 24 \\
\hline 28 & 82 & Feminino & $\mathrm{M} / \mathrm{V}$ & 4 & 15 & SR & 24 \\
\hline 29 & 75 & Feminino & $\mathrm{M} / \mathrm{M}$ & 2 & 11 & 3 & 36 \\
\hline 31 & 74 & Masculino & $\mathrm{M} / \mathrm{V}$ & 0 & 17 & SR & 12 \\
\hline 32 & 75 & Feminino & $\mathrm{M} / \mathrm{M}$ & 3 & 22 & 7 & 18 \\
\hline 33 & 52 & Feminino & $\mathrm{M} / \mathrm{V}$ & 4 & 14 & SR & 6 \\
\hline 34 & 51 & Masculino & $\mathrm{V} / \mathrm{V}$ & 6 & 22 & 15 & 12 \\
\hline 35 & 79 & Feminino & $\mathrm{M} / \mathrm{V}$ & 4 & 20 & 7 & 12 \\
\hline 36 & 74 & Feminino & $\mathrm{V} / \mathrm{V}$ & 5 & 21 & 12 & 12 \\
\hline 37 & 59 & Masculino & $\mathrm{M} / \mathrm{V}$ & 7 & 19 & 12 & 36 \\
\hline 38 & 73 & Feminino & $\mathrm{M} / \mathrm{M}$ & 2 & 21 & 10 & 18 \\
\hline 39 & 71 & Masculino & $\mathrm{M} / \mathrm{M}$ & 15 & 15 & 9 & 30 \\
\hline 40 & 69 & Feminino & $\mathrm{V} / \mathrm{V}$ & 4 & 12 & 2 & 48 \\
\hline 41 & 77 & Feminino & $\mathrm{M} / \mathrm{V}$ & 4 & 19 & SR & 30 \\
\hline 42 & 78 & Masculino & $\mathrm{M} / \mathrm{M}$ & 1 & 16 & SR & 12 \\
\hline 43 & 60 & Feminino & $\mathrm{M} / \mathrm{M}$ & 4 & 9 & SR & 36 \\
\hline 46 & 63 & Masculino & $\mathrm{M} / \mathrm{M}$ & 16 & 0 & SR & 60 \\
\hline 47 & 55 & Masculino & $\mathrm{M} / \mathrm{M}$ & 9 & 3 & SR & 96 \\
\hline 48 & 72 & Feminino & $\mathrm{V} / \mathrm{V}$ & 4 & 21 & 12 & 12 \\
\hline 49 & 75 & Feminino & $\mathrm{M} / \mathrm{V}$ & 8 & 21 & 9 & 24 \\
\hline 50 & 54 & Feminino & $\mathrm{M} / \mathrm{M}$ & 17 & 13 & SR & 48 \\
\hline 51 & 78 & Feminino & $\mathrm{M} / \mathrm{V}$ & 11 & 24 & 12 & 12 \\
\hline 52 & 60 & Feminino & $\mathrm{M} / \mathrm{M}$ & 11 & 17 & 10 & 36 \\
\hline 54 & 73 & Feminino & $\mathrm{V} / \mathrm{V}$ & 15 & 26 & 11 & 12 \\
\hline
\end{tabular}




\begin{tabular}{|c|c|c|c|c|c|c|c|}
\hline 55 & 86 & Masculino & $\mathrm{M} / \mathrm{V}$ & 17 & 17 & 7 & 12 \\
\hline 56 & 73 & Masculino & $\mathrm{M} / \mathrm{V}$ & 17 & 21 & 5 & 24 \\
\hline 57 & 71 & Feminino & $\mathrm{M} / \mathrm{V}$ & 11 & 22 & 11 & 24 \\
\hline 58 & 82 & Feminino & $\mathrm{M} / \mathrm{M}$ & 3 & 11 & SR & 36 \\
\hline 59 & 74 & Feminino & $\mathrm{M} / \mathrm{M}$ & 5 & 20 & 6 & 6 \\
\hline 60 & 50 & Feminino & $\mathrm{M} / \mathrm{M}$ & 15 & 20 & 12 & 24 \\
\hline 61 & 70 & Masculino & $\mathrm{M} / \mathrm{V}$ & 11 & 24 & 18 & 72 \\
\hline 63 & 69 & Masculino & $\mathrm{M} / \mathrm{V}$ & 15 & 9 & SR & 72 \\
\hline 64 & 86 & Feminino & $\mathrm{M} / \mathrm{M}$ & 8 & 21 & 10 & 24 \\
\hline 65 & 76 & Masculino & $\mathrm{M} / \mathrm{M}$ & 4 & 7 & SR & 96 \\
\hline 66 & 71 & Feminino & $\mathrm{V} / \mathrm{V}$ & 2 & 6 & SR & 72 \\
\hline 67 & 77 & Feminino & $\mathrm{V} / \mathrm{V}$ & 4 & 25 & 14 & 12 \\
\hline 68 & 66 & Feminino & $\mathrm{M} / \mathrm{M}$ & 16 & 19 & 7 & 12 \\
\hline 69 & 60 & Feminino & $\mathrm{M} / \mathrm{M}$ & 15 & 19 & 9 & 48 \\
\hline 70 & 53 & Feminino & $\mathrm{M} / \mathrm{V}$ & 11 & 15 & 6 & 18 \\
\hline 71 & 64 & Masculino & $\mathrm{M} / \mathrm{V}$ & 10 & 21 & 12 & 18 \\
\hline 72 & 64 & Feminino & $\mathrm{M} / \mathrm{M}$ & 8 & 15 & 7 & 60 \\
\hline 74 & 66 & Feminino & $\mathrm{M} / \mathrm{M}$ & 3 & 11 & 2 & 36 \\
\hline 75 & 63 & Masculino & $\mathrm{M} / \mathrm{V}$ & 6 & 22 & SR & 48 \\
\hline 76 & 73 & Feminino & $\mathrm{M} / \mathrm{V}$ & 2 & 15 & 10 & 72 \\
\hline 78 & 85 & Feminino & $\mathrm{M} / \mathrm{V}$ & 3 & 22 & 8 & 36 \\
\hline 79 & 61 & Feminino & $\mathrm{M} / \mathrm{V}$ & 1 & 22 & 5 & 24 \\
\hline 80 & 63 & Masculino & $\mathrm{M} / \mathrm{M}$ & 15 & 18 & SR & 30 \\
\hline 81 & 58 & Feminino & $\mathrm{M} / \mathrm{M}$ & 4 & 2 & 0 & 24 \\
\hline 82 & 71 & Masculino & $\mathrm{M} / \mathrm{M}$ & 10 & 21 & 3 & 36 \\
\hline 83 & 78 & Masculino & $\mathrm{M} / \mathrm{M}$ & 17 & 24 & 9 & 24 \\
\hline 84 & 75 & Feminino & $\mathrm{M} / \mathrm{V}$ & 4 & 19 & 14 & 24 \\
\hline 85 & 71 & Masculino & $\mathrm{M} / \mathrm{V}$ & 10 & 25 & 12 & 24 \\
\hline 86 & 82 & Feminino & $\mathrm{V} / \mathrm{V}$ & 3 & 23 & SR & 24 \\
\hline 87 & 79 & Feminino & $\mathrm{M} / \mathrm{V}$ & 4 & 20 & 5 & 12 \\
\hline 88 & 72 & Feminino & $\mathrm{M} / \mathrm{M}$ & 4 & 18 & 7 & 24 \\
\hline 89 & 77 & Masculino & $\mathrm{M} / \mathrm{M}$ & 4 & 22 & 5 & 24 \\
\hline 90 & 76 & Feminino & $\mathrm{M} / \mathrm{V}$ & 10 & 19 & 6 & 36 \\
\hline 91 & 74 & Feminino & $\mathrm{V} / \mathrm{V}$ & 4 & 22 & 9 & 18 \\
\hline 92 & 76 & Masculino & $\mathrm{M} / \mathrm{M}$ & 4 & 21 & 6 & 36 \\
\hline 93 & 71 & Feminino & $\mathrm{V} / \mathrm{V}$ & 4 & 21 & 11 & 24 \\
\hline 94 & 71 & Masculino & $\mathrm{M} / \mathrm{M}$ & 4 & 19 & 14 & 48 \\
\hline 95 & 68 & Feminino & $\mathrm{M} / \mathrm{M}$ & 4 & 19 & 8 & 24 \\
\hline 96 & 74 & Feminino & $\mathrm{M} / \mathrm{M}$ & 8 & 21 & 7 & 24 \\
\hline 97 & 83 & Masculino & $\mathrm{M} / \mathrm{V}$ & 7 & 24 & 7 & 6 \\
\hline 98 & 79 & \multirow{2}{*}{$\begin{array}{l}\text { Feminino } \\
\text { Feminino }\end{array}$} & $\mathrm{M} / \mathrm{V}$ & 12 & 24 & 16 & 12 \\
\hline 99 & 76 & & $\mathrm{M} / \mathrm{M}$ & 9 & 18 & 10 & 24 \\
\hline
\end{tabular}

ID = identificação; $M$ = metionina; $V$ = valina; $S R=$ sem registro 
Quadro 6. Avaliação cognitiva do grupo controle

\begin{tabular}{|c|c|c|c|c|c|c|}
\hline ID & $\begin{array}{l}\text { Idade } \\
\text { (anos) }\end{array}$ & Sexo & AA129 & $\begin{array}{c}\text { Escolaridade } \\
\text { (anos) }\end{array}$ & MEEM & FV \\
\hline 107 & 57 & Feminino & $\mathrm{M} / \mathrm{M}$ & 4 & 25 & 12 \\
\hline 109 & 62 & Feminino & $\mathrm{M} / \mathrm{M}$ & 8 & 24 & 14 \\
\hline 110 & 67 & Masculino & $\mathrm{M} / \mathrm{V}$ & 11 & 30 & 20 \\
\hline 111 & 68 & Feminino & $\mathrm{M} / \mathrm{V}$ & 8 & 30 & 22 \\
\hline 112 & 74 & Feminino & $\mathrm{M} / \mathrm{V}$ & 8 & 28 & 17 \\
\hline 113 & 63 & Masculino & $\mathrm{M} / \mathrm{M}$ & 8 & 28 & 17 \\
\hline 115 & 63 & Masculino & $\mathrm{M} / \mathrm{V}$ & 8 & 30 & 17 \\
\hline 116 & 70 & Feminino & $\mathrm{M} / \mathrm{V}$ & 15 & 27 & 19 \\
\hline 117 & 76 & Masculino & $\mathrm{M} / \mathrm{V}$ & 0 & 23 & 19 \\
\hline 118 & 63 & Feminino & $\mathrm{M} / \mathrm{M}$ & 4 & 28 & 14 \\
\hline 121 & 74 & Feminino & $\mathrm{V} / \mathrm{V}$ & 4 & 28 & 15 \\
\hline 122 & 60 & Feminino & $\mathrm{M} / \mathrm{V}$ & 7 & 28 & 22 \\
\hline 123 & 63 & Masculino & $\mathrm{M} / \mathrm{V}$ & 4 & 27 & 21 \\
\hline 124 & 68 & Masculino & $\mathrm{M} / \mathrm{M}$ & 4 & 27 & 13 \\
\hline 125 & 66 & Feminino & $\mathrm{M} / \mathrm{V}$ & 4 & 29 & 13 \\
\hline 126 & 65 & Masculino & $\mathrm{M} / \mathrm{M}$ & 16 & 29 & 21 \\
\hline 128 & 70 & Masculino & $\mathrm{M} / \mathrm{V}$ & 10 & 28 & 12 \\
\hline 130 & 60 & Feminino & V/V & 11 & 30 & 20 \\
\hline 131 & 71 & Feminino & $\mathrm{M} / \mathrm{M}$ & 0 & 21 & 14 \\
\hline 132 & 73 & Feminino & $\mathrm{V} / \mathrm{V}$ & 11 & 29 & 18 \\
\hline 135 & 69 & Masculino & $\mathrm{V} / \mathrm{V}$ & 4 & 28 & 16 \\
\hline 136 & 72 & Feminino & $\mathrm{M} / \mathrm{V}$ & 16 & 29 & 19 \\
\hline 138 & 63 & Masculino & $\mathrm{M} / \mathrm{V}$ & 4 & 25 & 13 \\
\hline 139 & 70 & Feminino & $\mathrm{V} / \mathrm{V}$ & 5 & 26 & 17 \\
\hline 140 & 80 & Feminino & $\mathrm{M} / \mathrm{V}$ & 8 & 28 & 14 \\
\hline 143 & 63 & Feminino & $\mathrm{M} / \mathrm{V}$ & 11 & 28 & 22 \\
\hline 144 & 76 & Masculino & $\mathrm{M} / \mathrm{V}$ & 4 & 26 & 18 \\
\hline 147 & 70 & Feminino & $\mathrm{M} / \mathrm{M}$ & 4 & 27 & 23 \\
\hline 148 & 72 & Feminino & $\mathrm{M} / \mathrm{V}$ & 4 & 29 & 17 \\
\hline 149 & 74 & Feminino & $\mathrm{V} / \mathrm{V}$ & 0 & 20 & 15 \\
\hline 152 & 76 & Feminino & $\mathrm{M} / \mathrm{M}$ & 11 & 28 & 15 \\
\hline 153 & 76 & Masculino & $\mathrm{M} / \mathrm{V}$ & 6 & 28 & 19 \\
\hline 154 & 80 & Masculino & $\mathrm{M} / \mathrm{M}$ & 8 & 29 & 20 \\
\hline 156 & 77 & Masculino & $\mathrm{M} / \mathrm{V}$ & 4 & 25 & 16 \\
\hline 157 & 75 & Masculino & $\mathrm{M} / \mathrm{V}$ & 4 & 25 & 17 \\
\hline 160 & 61 & Feminino & $\mathrm{M} / \mathrm{V}$ & 8 & 30 & 17 \\
\hline 162 & 81 & Feminino & $\mathrm{M} / \mathrm{M}$ & 6 & 27 & 13 \\
\hline 164 & 63 & Masculino & $\mathrm{M} / \mathrm{V}$ & 8 & 27 & 13 \\
\hline 165 & 70 & Feminino & $\mathrm{M} / \mathrm{V}$ & 10 & 28 & 22 \\
\hline 166 & 61 & Feminino & $\mathrm{M} / \mathrm{M}$ & 8 & 27 & 21 \\
\hline 167 & 68 & Masculino & $\mathrm{M} / \mathrm{V}$ & 6 & 26 & 23 \\
\hline 168 & 69 & Feminino & $\mathrm{M} / \mathrm{M}$ & 8 & 29 & 15 \\
\hline 169 & 80 & Feminino & $\mathrm{M} / \mathrm{M}$ & 8 & 28 & 13 \\
\hline 170 & 77 & Masculino & $\mathrm{M} / \mathrm{V}$ & 4 & 24 & 13 \\
\hline 171 & 75 & Feminino & $\mathrm{M} / \mathrm{M}$ & 15 & 27 & 22 \\
\hline 172 & 63 & Feminino & $\mathrm{M} / \mathrm{M}$ & 10 & 29 & 22 \\
\hline 173 & 63 & Feminino & $\mathrm{M} / \mathrm{M}$ & 12 & 28 & 22 \\
\hline 176 & 90 & Feminino & $\mathrm{M} / \mathrm{V}$ & 11 & 28 & 12 \\
\hline 180 & 74 & Feminino & $\mathrm{M} / \mathrm{M}$ & 4 & 29 & 14 \\
\hline 183 & 62 & Feminino & $\mathrm{M} / \mathrm{V}$ & 3 & 29 & 17 \\
\hline 184 & 60 & Feminino & $\mathrm{M} / \mathrm{M}$ & 8 & 28 & 21 \\
\hline
\end{tabular}




\begin{tabular}{|l|l|l|l|c|c|c|}
\hline 185 & 65 & Feminino & $\mathrm{M} / \mathrm{M}$ & 4 & 26 & 19 \\
\hline 186 & 65 & Feminino & $\mathrm{M} / \mathrm{M}$ & 4 & 30 & 19 \\
\hline 188 & 72 & Feminino & $\mathrm{M} / \mathrm{V}$ & 7 & 28 & 15 \\
\hline 190 & 59 & Feminino & $\mathrm{M} / \mathrm{M}$ & 5 & 28 & 12 \\
\hline 191 & 74 & Feminino & $\mathrm{M} / \mathrm{V}$ & 16 & 29 & 24 \\
\hline 193 & 63 & Masculino & $\mathrm{M} / \mathrm{V}$ & 8 & 29 & 13 \\
\hline 194 & 80 & Feminino & $\mathrm{M} / \mathrm{V}$ & 1 & 24 & 14 \\
\hline 199 & 61 & Feminino & $\mathrm{M} / \mathrm{V}$ & 2 & 28 & 13 \\
\hline 200 & 62 & Feminino & $\mathrm{M} / \mathrm{M}$ & 16 & 28 & 25 \\
\hline 201 & 66 & Feminino & $\mathrm{M} / \mathrm{M}$ & 16 & 30 & 20 \\
\hline 202 & 80 & Feminino & $\mathrm{M} / \mathrm{M}$ & 4 & 24 & 14 \\
\hline 204 & 67 & Feminino & $\mathrm{M} / \mathrm{M}$ & 5 & 26 & 13 \\
\hline 206 & 76 & Feminino & $\mathrm{M} / \mathrm{M}$ & 4 & 26 & 12 \\
\hline 207 & 82 & Masculino & $\mathrm{M} / \mathrm{V}$ & 5 & 27 & 13 \\
\hline 209 & 70 & Feminino & $\mathrm{M} / \mathrm{V}$ & 4 & 26 & 16 \\
\hline \hline
\end{tabular}

ID = identificação; MEEM = miniexame do estado mental; $\mathrm{FV}=$ fluência verbal; $\mathrm{M}=$ metionina; $\mathrm{V}=$ valina 